Aus der Klinik für Kardiologie und Pneumologie

(Prof. Dr. med. G. Hasenfuß)

der Medizinischen Fakultät der Universität Göttingen

\title{
Gibt es einen Unterschied in der Prädiktion von Vorhofflimmern - diagnostiziert durch Holter-EKG vs. Usual Care? \\ Was sind die Prädiktionsfaktoren für die Detektion von inzidentem Vorhofflimmern mittels verlängerten und verbesserten Monitorings?
}

Eine Analyse der randomisierten multizentrischen Find-AF RANDOMISED-Studie

\author{
INAUGURAL - DISSERTATION \\ zur Erlangung des Doktorgrades \\ der Medizinischen Fakultät der \\ Georg-August-Universität zu Göttingen
}

vorgelegt von

Nico Behnke

aus

Burgwedel

Göttingen 2018 
Dekan:

Referent:

Ko-Referent/in:

Dritt-Referent/in:

Datum der mündlichen Prüfung
Prof. Dr. med. Wolfgang Brück

Prof. Dr. med. Rolf Wachter

Prof. Dr. med. Jan Liman

Prof. Dr. mult. Thomas Meyer

17. März 2020 
Hiermit erkläre ich, die Dissertation mit dem Titel

„Gibt es einen Unterschied in der Prädiktion von Vorhofflimmern - diagnostiziert durch Holter-EKG vs. Usual Care? Was sind die Prädiktionsfaktoren für die Detektion von inzidentem Vorhofflimmern mittels verlängerten und verbesserten Monitorings? Eine Analyse der randomisierten multizentrischen Find-AF RANDOMISED-Studie““

eigenständig angefertigt und keine anderen Hilfsmittel als die von mir angegebenen Quellen und Hilfsmittel verwendet zu haben.

Göttingen, den 10. März 2020

(Unterschrift) 


\section{Inhaltsverzeichnis}

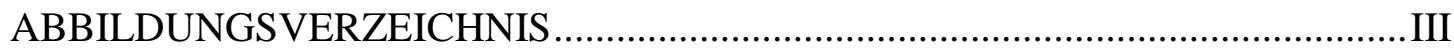

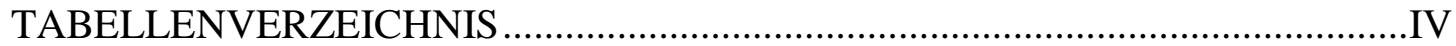

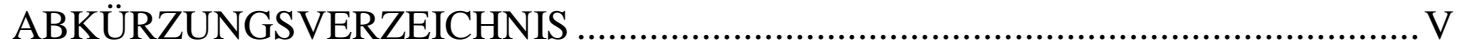

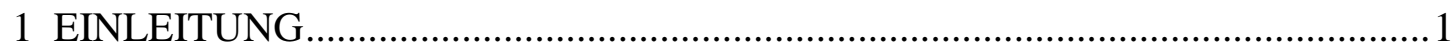

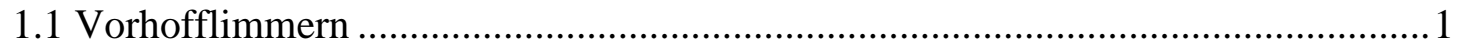

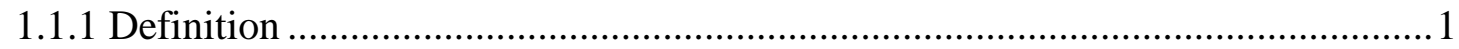

1.1.2 Ätiologie und Risikofaktoren des Vorhofflimmerns ...........................................

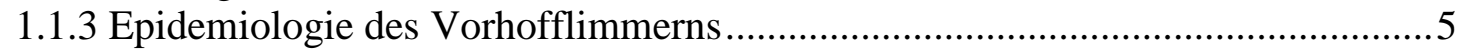

1.1.4 Pathophysiologie und Folgen des Vorhofflimmerns ..........................................5

1.1.5 Die Rolle von natriuretischen Peptiden bei Vorhofflimmern ...............................9

1.1.6 Diagnostik des Vorhofflimmerns....................................................................... 10

1.1.7 Therapie des Vorhofflimmerns und Konsequenz des $\mathrm{CHA}_{2} \mathrm{DS}_{2}$-VASc-Scores 10

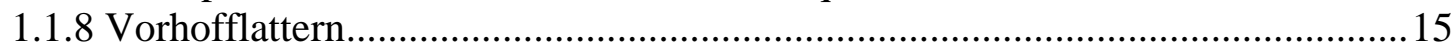

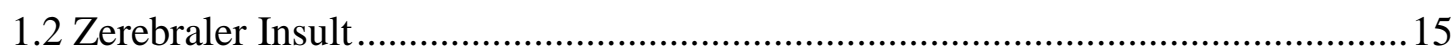

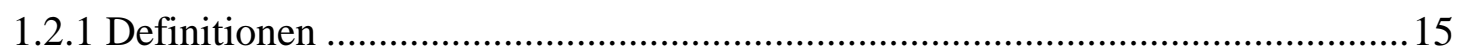

1.2.2 Weitere Formen und Einteilungen zerebraler Ischämien.................................16

1.2.3 Ätiologie und Risikofaktoren des zerebralen Insults ......................................17

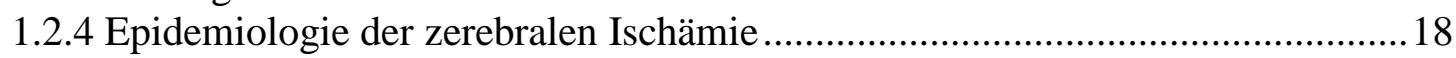

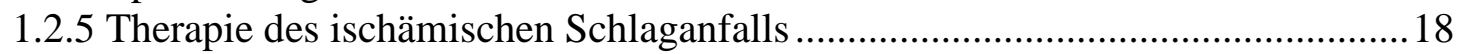

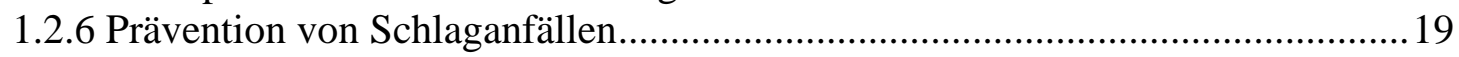

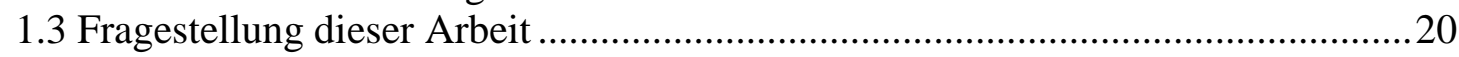

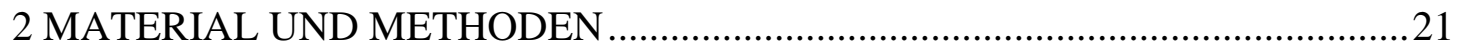

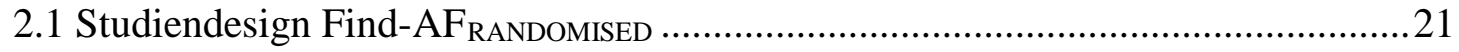

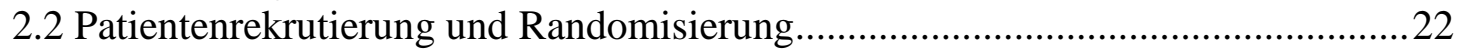

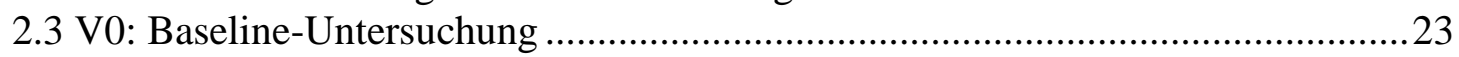

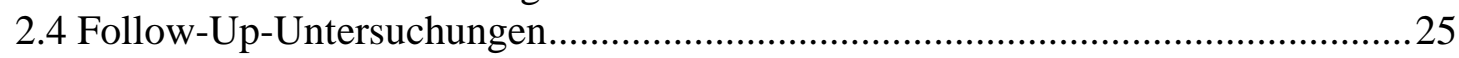

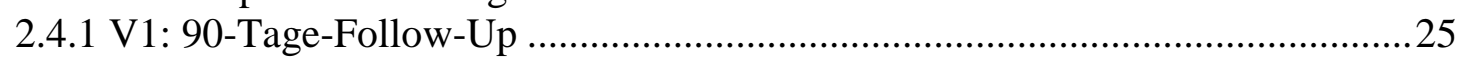

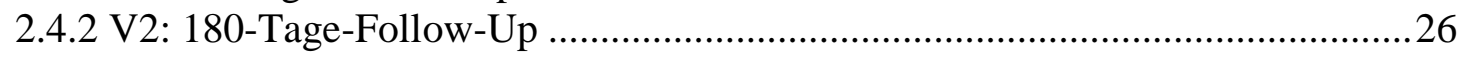

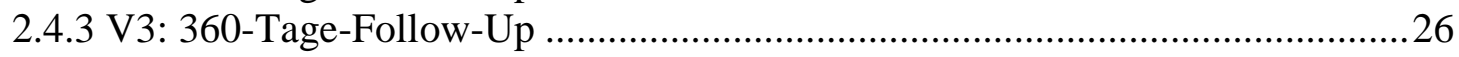

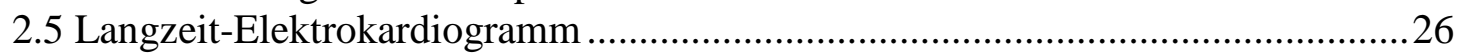

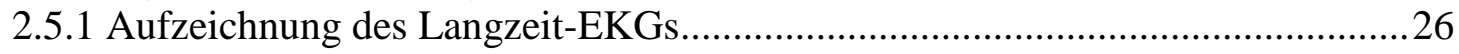

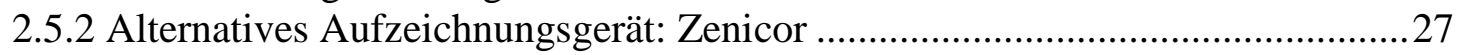

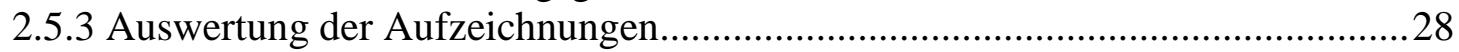

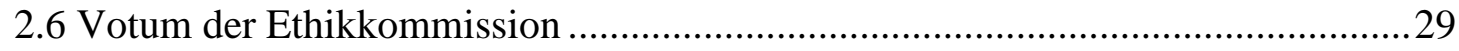

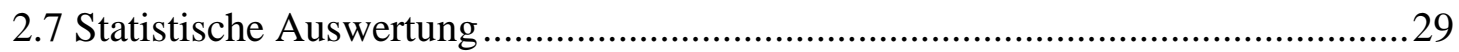

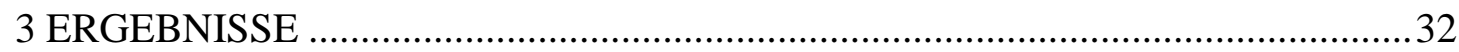

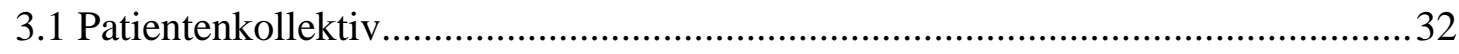

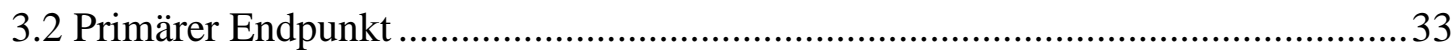

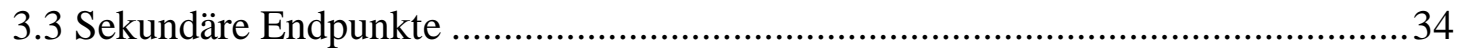

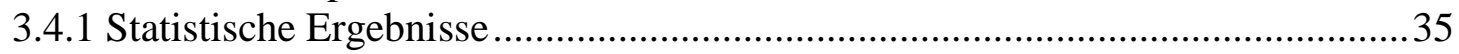

3.4.2 Separate Subgruppenanalyse - Interventionsgruppe ......................................47

3.4.3 Separate Subgruppenanalyse - Kontrollgruppe ..............................................50

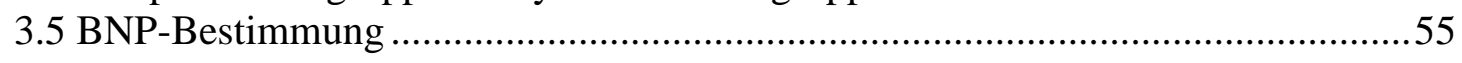




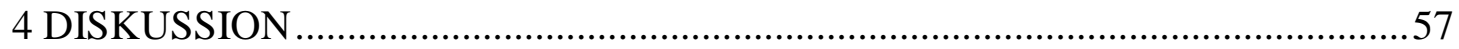

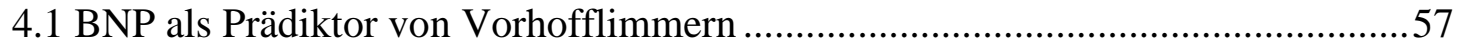

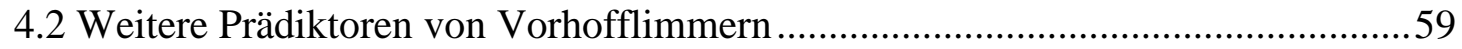

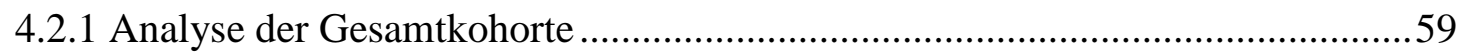

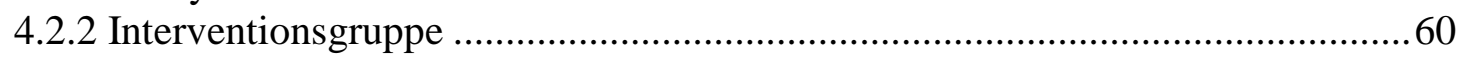

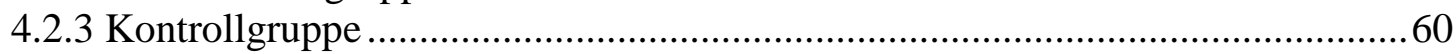

4.3 Stärken und Limitationen der Studie .................................................................62

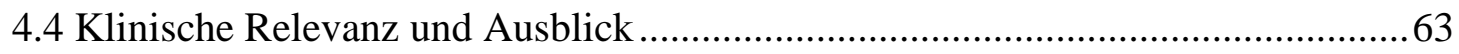

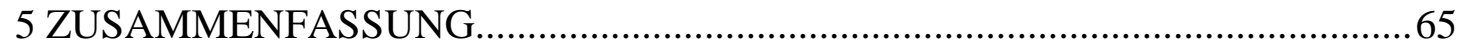

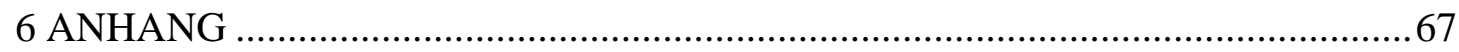

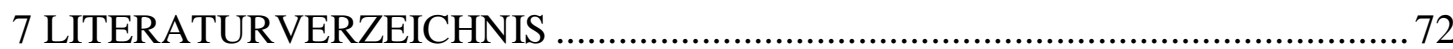




\section{ABBILDUNGSVERZEICHNIS}

Abb. 1: EKG eines Studienpatienten im Sinusrhythmus ...........................................................3

Abb. 2: EKG eines Studienpatienten mit Vorhofflimmern.................................................... 3

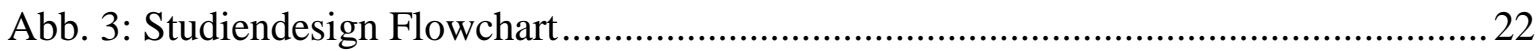

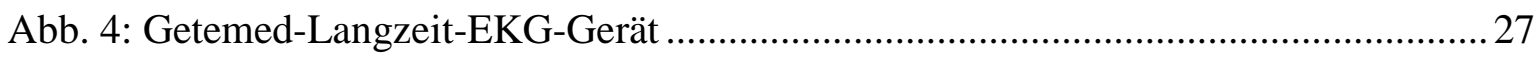

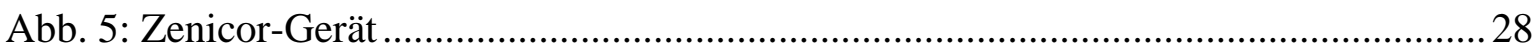

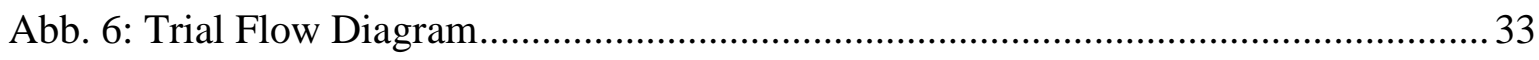

Abb. 7: ROC-Kurve nach sechs Monaten............................................................................... 43

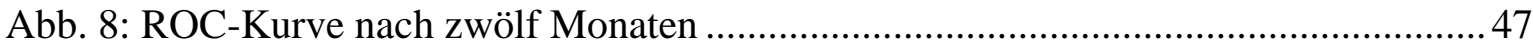

Abb. 9: Verteilung von BNP-Werten bei Baseline und 3-Monats-Visite............................. 56

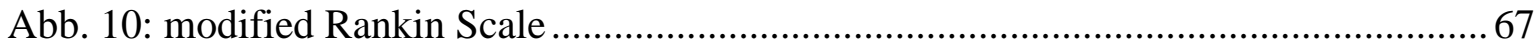

Abb. 11: National Institutes of Health Stroke Scale (NIHSS) ..........................................68

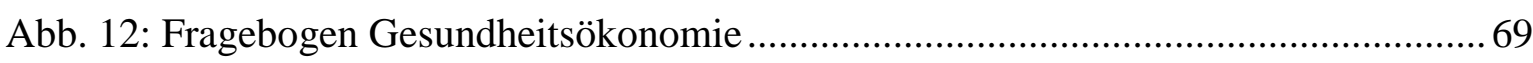

Abb. 13: Gründe für eine Nicht-Teilnahme der gescreenten Patienten ............................... 70

Abb. 14: Elektrodenpads-Anordnung .......................................................................... 71 


\section{TABELLENVERZEICHNIS}

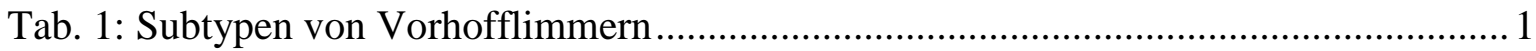

Tab. 2: Risiko ischämischer Schlaganfälle/100 Patientenjahre in Bezug auf den $\mathrm{CHA}_{2} \mathrm{DS}_{2}$ -

VASc-Score 7

Tab. 3: Thrombembolieprophylaxe bei Patienten mit Vorhofflimmern anhand des

$\mathrm{CHA}_{2} \mathrm{DS}_{2}$-VASc-Scores

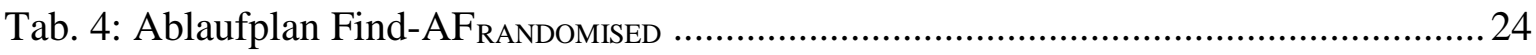

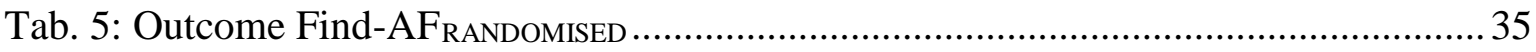

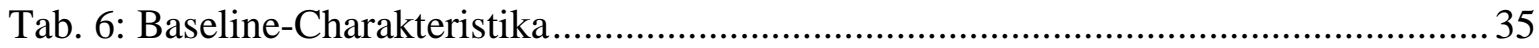

Tab. 7: Odds Ratio, Konfidenzintervall und p-Wert für nicht gleichverteilte Variablen (6-

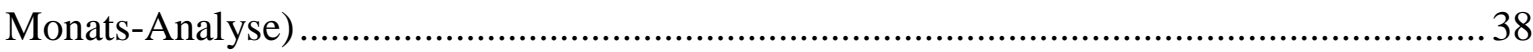

Tab. 8: Univariate Analyse der Gesamtkohorte nach sechs Monaten ................................. 39

Tab. 9: Odds Ratio, Konfidenzintervall und p-Wert der multivariablen Analyse nach sechs

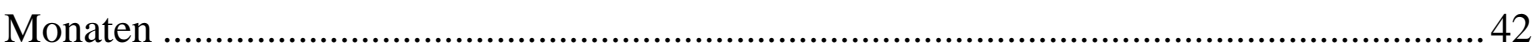

Tab. 10: Univariate Analyse der Gesamtkohorte nach zwölf Monaten ................................43

Tab. 11: Odds Ratio, Konfidenzintervall und p-Wert der multivariablen Analyse nach zwölf Monaten .46

Tab. 12: Univariate Subgruppenanalyse der Interventionsgruppe nach sechs Monaten ..... 47

Tab. 13: Univariate Subgruppenanalyse der Kontrollgruppe nach sechs Monaten .............. 50

Tab. 14: Univariate Subgruppenanalyse der Kontrollgruppe nach zwölf Monaten ............52

Tab. 15: BNP-Bestimmung aufgeteilt nach Randomisierungsgruppe ...............................55 


\section{ABKÜRZUNGSVERZEICHNIS}

ACB

AHA/ASA

AF

ANP

ASS

AUC

AV-Knoten

AVNRT

AVRT

BNP

$\mathrm{CHADS}_{2}$

$\mathrm{CHA}_{2} \mathrm{DS}_{2}$-VASc

CI

CRP

CT

DEGAM

DZHK

eCRF

EKG

EPM

ESC

FIM

GFR

GSM

GPRS

HADS

HAS-BLED

HbA1c

HDL

ICD

IFS

INR

IQR

KHK

LDL

mRS

MRT

MW

NASCET

NIHSS

NOAKs

NT-proBNP

OR

pAVK

PCI

ROC aortocoronarer Bypass

American Heart Association/American Stroke Association atrial fibrillation $=$ Vorhofflimmern

atriales natriuretisches Peptid

Acetylsalicylsäure

Area Under Curve

Atrioventrikularknoten

AV-Knoten-Reentrytachykardie

atrioventrikuläre Reentrytachykardie

brain natriuretic peptide / b-type natriuretic peptide

klinischer Score zur Abschätzung des Schlaganfallrisikos

klinischer Score zur Abschätzung des Schlaganfallrisikos

Konfidenzintervall

C-reaktives Protein

Computertomographie

Deutsche Gesellschaft für Allgemeinmedizin und Familienmedizin

Deutsches Zentrum für Herz-Kreislauf-Forschung

electronic Case Report Form

Elektrokardiogramm

enhanced and prolonged monitoring

European Society of Cardiology

Functional Independence Measure

glomeruläre Filtrationsrate

Global System for Mobile Communications

General Packet Radio Service

Hospital Anxiety and Depression Scale

klinischer Score zur Abschätzung des Blutungsrisikos

medizinischer Terminus des Blutzuckergedächtnisses

high density lipoprotein

implantable cardioverter-defibrillator

Institut für anwendungsorientierte Forschung und klinische

Studien

international normalized ratio

Interquartilsabstand

koronare Herzkrankheit

low density lipoprotein

modified Rankin Scale

Magnetresonanztomographie

Mittelwert

North American Symptomatic Carotid Endarterectomy Trial

National Institutes of Health Stroke Scale

neue orale Antikoagulantien

N-terminal pro b-type natriuretic peptide

Odds Ratio

periphere arterielle Verschlusskrankheit

perkutane Koronarintervention

Receiver-Operating-Characteristic 
RR

SD

SIS-16

SVES

TIA

VES

VHF

VVI

WHO

PROBE

ZNS
Riva-Rocci (med. Abkürzung für Blutdruck gemessen nach Riva-Rocci)

Standardabweichung (engl.: standard deviation)

Stroke Impact Scale-16

supraventrikuläre Extrasystole

transiente ischämische Attacke

ventrikuläre Extrasystolen

Vorhofflimmern

Kodierungsprinzip eines Schrittmachers

World Health Organization

prospective randomized open, blinded end-point

zentrales Nervensystem 


\section{EINLEITUNG}

\subsection{Vorhofflimmern}

\subsubsection{Definition}

Vorhofflimmern (VHF) ist die häufigste anhaltende Störung des kardialen Rhythmus (Lip und Hee 2001; Dang et al. 2002) und eine Form der supraventrikulären Tachyarrhythmie bei altersabhängig steigender Inzidenz (Campbell et al. 1974; Kannel et al. 1982; Benjamin et al. 1994; Jorgensen et al. 1996; Go et al. 2001; Dang et al. 2002). Sie wird vorrangig durch unkoordinierte atriale Erregung hervorgerufen und geht mit einer Verschlechterung der atrialen mechanischen Funktion einher (Lévy et al. 2003).

Es existieren verschiedene Einteilungen von VHF. Beispielsweise kann Vorhofflimmern in akutes und chronisches Vorhofflimmern eingeteilt werden (Lip und Watson 2008). Akutes VHF kann beispielsweise nach Myokardinfarkt oder Alkoholkonsum einsetzen und selbstlimitierend sein oder aber auch in chronisches VHF übergehen (Lip und Hee 2001; Lévy et al. 2003).

Auch eine andere Art der Klassifikation ist möglich: Tab. 1 zeigt Subtypen von Vorhofflimmern (Lévy et al. 2003).

Tabelle 1: Subtypen von Vorhofflimmern

\begin{tabular}{|l|l|}
\hline Bezeichnung & Definition \\
\hline - erstmals detektiertes Vorhofflimmern & \\
\hline - Paroxysmales (oder auch intermittieren- & $\begin{array}{l}\text { liegt vor, wenn mindestens zwei Episoden } \\
\text { existieren (und das VHF damit als rekurrie- } \\
\text { rend eingestuft wird), welche in der Regel } \\
\text { innerhalb von 48 Stunden spontan enden - } \\
\text { aber spätestens innerhalb von sieben Tagen }\end{array}$ \\
\hline - Persistierendes Vorhofflimmern & $\begin{array}{l}\text { liegt vor, wenn die Episode länger als sie- } \\
\text { ben Tage anhält. Die Zeitspanne von sieben } \\
\text { Tagen ist zufällig gewählt, wird aber weit- } \\
\text { hin als der Zeitpunkt angesehen, ab dem ein } \\
\text { dauerhaftes Vorhofflimmern nicht mehr } \\
\text { spontan in einen Sinusrhythmus konvertiert. }\end{array}$ \\
\hline
\end{tabular}




\begin{tabular}{|l|l|}
\hline - Permanentes Vorhofflimmern & $\begin{array}{l}\text { liegt vor, wenn eine Kardioversion nicht } \\
\text { erfolgreich ist oder der Rhythmus innerhalb } \\
\text { von } 24 \text { Stunden wieder spontan in Vorhof- } \\
\text { flimmern regrediert. Patienten, bei denen } \\
\text { eine Kardioversion kontraindiziert ist oder } \\
\text { vom Patienten abgelehnt wird, fallen eben- } \\
\text { falls in diese Kategorie und können als „ak- } \\
\text { zeptiertes permanentes Vorhofflimmern“ } \\
\text { angesehen werden. Per definitionem wird } \\
\text { hier keine Kardioversion angestrebt. }\end{array}$ \\
\hline
\end{tabular}

Diese Einteilung findet erst Verwendung, wenn die Episoden 30 Sekunden oder länger anhalten (Lévy et al. 2003).

In der Vergangenheit wurde Vorhofflimmern in valvuläres und nicht-valvuläres VHF eingeteilt, wobei bisher keine allgemein anerkannte, offizielle Abgrenzung dieser Beschreibungen existiert (Kirchhof et al. 2016). Häufig wird ein VHF aufgrund eines rheumatischen Ursprungs oder aufgrund einer künstlichen Herzklappe als valvulär angesehen (Kirchhof et al. 2016).

Die Erregung der Ventrikel ist von den jeweiligen gegebenen Umständen abhängig (i. e. elektrophysiologische Eigenschaften des AV-Knotens, Vorhandensein von akzessorischen Übertragungswegen und/oder Auswirkungen von Medikamenten) (Fuster et al. 2006).

Im Elektrokardiogramm (EKG) zeichnet sich Vorhofflimmern durch eine fehlende regelmäßige p-Welle und dadurch uneinheitliche Abstände der R-Zacken aus. Das EKG zeigt statt der p-Welle unregelmäßige hochfrequente Oszillationen um die Nulllinie, was in ungleichmäßige Übertragung der Erregung auf die Ventrikel resultiert. Bei Patienten mit Herzschrittmachern kann eine temporäre Deaktivierung notwendig sein, um Vorhofflimmern sichtbar zu machen (Lévy et al. 1998).

Abb. 1 zeigt einen Ausschnitt des EKG eines unserer Studienpatienten im Sinusrhythmus. Abb. 2 zeigt einen Ausschnitt des EKG eines unserer Studienpatienten mit Vorhofflimmern. 


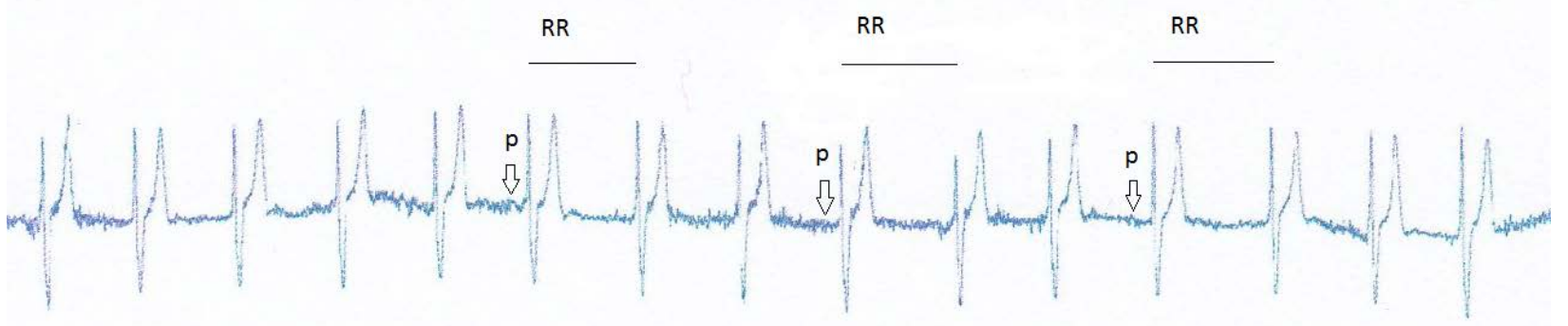

Abbildung 1: EKG eines Patienten im Sinusrhythmus

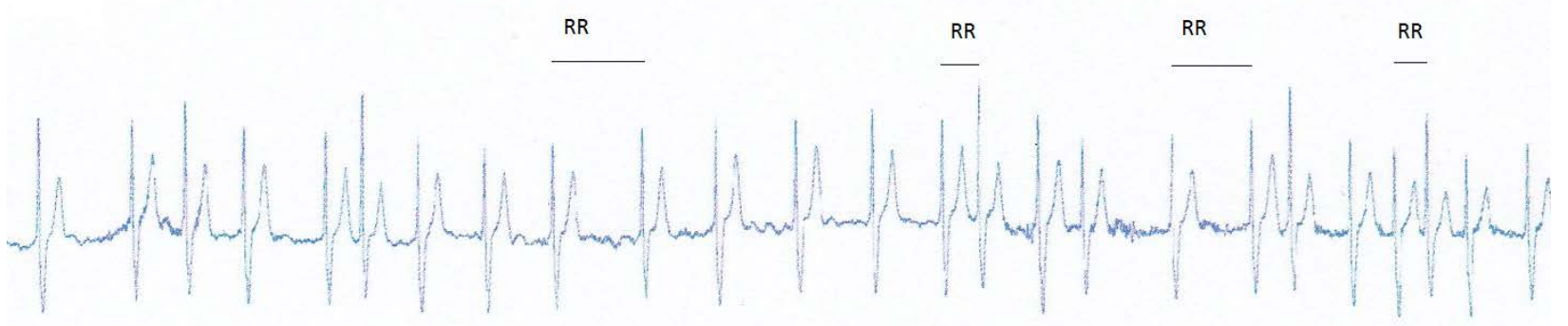

Abbildung 2: EKG eines Patienten mit Vorhofflimmern

\subsection{2 Ätiologie und Risikofaktoren des Vorhofflimmerns}

Die Ätiologie des Vorhofflimmerns kann primärer oder sekundärer Genese sein.

Primär kann es idiopathischen Ursprungs sein oder sich um ein sogenanntes lone atrial fibrillation handeln. Von einem Vorhofflimmern idiopathischen Ursprungs wird gesprochen bei Patienten mit einem Alter über 60, bei denen keine zugrunde liegende Erkrankung diagnostiziert werden kann (Potpara und Lip 2014). Von lone atrial fibrillation wird bei Patienten gesprochen, welche jünger als 60 Jahre sind ohne klinische oder echokardiographische Grunderkrankung einschließlich arterieller Hypertonie. Die genaue Prävalenz von lone atrial fibrillation ist unbekannt - sie wird in der Literatur zwischen 0,7\% und 30\% angegeben (Lévy et al. 1999; Lip und Hee 2001; Potpara und Lip 2014).

Ebenso spielen genetische Ursachen in der Ätiologie ein Rolle: Genetische Faktoren, die mit Vorhofflimmern assoziiert wurden, umfassen unter anderem Short-/Long-QTSyndrom, Brugada-Syndrom und hypertrophe Kardiomyopathie (Camm et al. 2010). 
Sekundär kann ein Vorhofflimmern kardial oder extrakardial bedingt sein.

Kardiale Faktoren können eine koronare Herzkrankheit, Herzklappenerkrankungen, ein Myokardinfarkt oder eine kongestive Herzinsuffizienz sein (Benjamin et al. 1994; Lip und Hee 2001).

Vorhofflimmern ist ebenfalls mit anderen atrialen Tachykardien wie atrioventrikulärer Reentrytachykardie (AVRT) und AV-Knoten-Reentrytachykardie (AVNRT) assoziiert und kann durch diese ausgelöst werden (Lévy et al. 2003).

Echokardiographische, voneinander unabhängige Prädiktoren für VHF sind ein vergrößerter linker Vorhof, eine verdickte linksventrikuläre Wand, linksventrikuläre Wandbewegungsstörungen, eine verminderte Herzohrflussgeschwindigkeit und eine reduzierte prozentuale systolische Verkürzungsfraktion (fractional shortening) (Henry et al. 1976; Takahashi et al. 1982; Keren et al. 1987; Vaziri et al. 1994; Lip und Hee 2001). Falls diese Faktoren simultan vorliegen, erhöht sich die Auftrittswahrscheinlichkeit für VHF deutlich (Vaziri et al. 1994).

Extrakardial kann ein Vorhofflimmern gefördert werden durch arterielle Hypertonie, Hyperthyreose, männliches Geschlecht, Diabetes mellitus, Rauchen, Alkohol, bestimmte Medikamente (z. B. Fluoxetin) und durch voranschreitendes Alter (Benjamin et al. 1994; Lip und Hee 2001; Go et al. 2001; Auer et al. 2001; Heeringa et al. 2008; Samokhvalov et al. 2010; Tamargo et al. 2012; Meinertz und Sydow 2014).

Nicht zuletzt wird Vorhofflimmern auch durch sich selbst gefördert, wie Wijffels et al. 1995 mit einem Experiment an Ziegen zeigen konnten. Vorhofflimmern bewirkt strukturelle und elektrophysiologische Veränderungen innerhalb des Atriums, die wiederum einer Kardioversion in den Sinusrhythmus entgegenwirken können.

Ergänzend existieren Studien, welche sich speziell mit paroxysmalem Vorhofflimmern befassen:

Clementy et al. 1992 (43\%) und Suttorp et al. 1993 (41\%) konnten jeweils in knapp der Hälfte der Fälle keine kardiale Ursache für paroxysmales Vorhofflimmern bzw. paroxysmales Vorhofflattern finden.

Des Weiteren beschrieben Studien, dass das autonome Nervensystem Auswirkungen auf paroxysmales Vorhofflimmern haben kann (Yamashita et al. 1997) und auch ein Autoimmunprozess wird bei einigen Patienten mit paroxysmalem VHF diskutiert (Maixent et al. 1998). 


\subsubsection{Epidemiologie des Vorhofflimmerns}

Die Prävalenz von Vorhofflimmern wird in der Literatur variabel beschrieben: Konsens besteht darüber, dass die Prävalenz mit zunehmendem Alter ansteigt (Campbell et al. 1974; Jorgensen et al. 1996; Benjamin et al. 1998; Go et al. 2001; Dang et al. 2002).

Hier ausgewählte Angaben zur Prävalenz aus der Literatur:

- Jorgensen et al. 1996 sahen die Prävalenz bei 2\% bei Unter-50-Jährigen, bei 15\% bei $70-80$-Jährigen, bei $28 \%$ bei $80-90$-Jährigen und bei bis zu $40 \%$ bei einem Alter von $90+$.

- Go et al. 2001 schätzten sie auf 1\% der adulten Bevölkerung.

- Dang et al. 2002 gaben die Prävalenz bei 5,9\% bei Über-65-Jährigen und bei 8,8\% bei Über-80-Jährigen an.

Der Anteil des paroxysmalen Typus an allen Patienten mit Vorhofflimmern beträgt ca. 25\% (Lévy et al. 1999; Hart et al. 2000) - allerdings liegen auch Studien vor, welche einen Prozentsatz bis zu 62\% postulieren (25-62\%, Lip und Hee 2001). Die unterschiedliche Prävalenz ist allerdings auch stark abhängig von den jeweiligen Definitionen von paroxysmalem VHF und den betrachteten Populationen in den Studien (Lip und Hee 2001).

Laut Hart et al. 2000 waren Patienten mit paroxysmalem im Vergleich zu Individuen mit konstantem Vorhofflimmern im Durchschnitt vier Jahre jünger, häufiger weiblich und hatten ein geringeres Vorkommen an Herzinsuffizienz und peripherer arterieller Verschlusskrankheit (pAVK). Hohnloser et al. 2007 konnten das geringere Alter ebenfalls nachweisen, sowie eine Assoziation mit einer kürzeren Anamnese von Vorhofflimmern, höherem Blutdruck und einer geringeren Rate von Herzklappenerkrankungen, Herzversagen und Diabetes mellitus. Hohnloser et al. 2007 postulierten, dass Patienten mit paroxysmalem VHF in einem früheren Stadium der Arrhythmie sind als Patienten mit konstantem Vorhofflimmern.

\subsubsection{Pathophysiologie und Folgen des Vorhofflimmerns}

Strukturelle Veränderungen im Vorhof führen zum sogenannten Remodelling - einem Prozess, bei dem Fibroblasten in Myofibroblasten modifiziert werden, und es zu einem Verlust von atrialer Muskelmasse (Fuster et al. 2006) und einem generellen Fibrosierungsprozess 
kommen kann. Diese Alterationen prädisponieren für elektrophysiologische Unregelmäßigkeiten und Vorhofflimmern (Camm et al. 2010).

Es existieren zwei Theorien für die Entstehung von Vorhofflimmern, welche einander allerdings nicht ausschließen müssen: Mikro-Reentry-Kreisläufe, die durch Refraktärzeit und Übertragungsgeschwindigkeit beeinflusst werden und zweitens eine gesteigerte Automatizität durch eine oder mehrere fokale Erregungen aus den Vorhöfen, den Pulmonalvenen oder dem Koronarsinusostium (Jais et al. 1997; Haïssaguerre et al. 1998; Lip und Hee 2001). Der Grund für die Anfälligkeit der Pulmonalvenenzellen zur Initiierung von atrialen Tachyarrhythmien liegt in einer kürzeren Refraktärzeit im Vergleich zu den Herzmuskelzellen und schlagartigen Veränderungen in der Orientierung der Myozytenfasern (Camm et al. 2010).

Die kreisenden Reentry-Erregungen im Vorhof beeinträchtigen die Vorhofkontraktion und deren Wegfall resultiert in Hämostase im Atrium, was wiederum zu einer Thrombose führen kann (Lip und Hee 2001; Veenhuyzen et al. 2004). Li-Saw-Hee et al. 2001 konnten zeigen, dass paroxysmales und permanentes VHF mit einem Zustand der Hyperkoagulabilität einhergeht, nicht jedoch persistierendes VHF oder ein Sinusrhythmus. Eine Studie von Sohara et al. 1997 zeigte, dass Vorhofflimmern an sich eine Hyperkoagulabilität fördert und diese von der Dauer der Arrhythmie positiv beeinflusst wird. Giansante et al. 2000 untersuchten den Einfluss von elektrischer und pharmakologischer Kardioversion auf Patienten mit paroxysmalem VHF und kamen zu dem Schluss, dass die bei diesen Patienten erhöhten Koagulationsparameter durch eine Kardioversion reduziert werden können: Eine elektrische Kardioversion aktiviert früh das fibrinolytische System, eine pharmakologische Kardioversion dagegen nicht (Giansante et al. 2000).

Schlaganfälle, welche aus VHF resultieren, sind schwerwiegender (Tu et al. 2015). Unbehandeltes chronisches Vorhofflimmern bringt ein jährliches Risiko an thrombembolischen Komplikationen von 3-6\% mit sich (Petersen 1990). Die Ein-Jahres-Mortalität liegt zwischen 0,2\% bei Patienten mit paroxysmalem VHF ohne zugrunde liegende Herzerkrankungen und 16,0\% bei älteren, hospitalisierten Patienten mit chronischem Vorhofflimmern (Petersen und Godtfredsen 1984).

Wolf et al. 1978 konnten zeigen, dass chronisches VHF ohne begleitende rheumatische Herzerkrankung die Inzidenz für Schlaganfälle fünffach erhöht - bei gleichzeitig vorliegender rheumatischer Herzerkrankung sogar um das Siebzehnfache. Friberg et al. 2010 ermittelten ein ungefähr identisches Schlaganfallrisiko bei paroxysmalem und permanentem Vorhofflimmern, wobei sie feststellten, dass Patienten mit paroxysmalem VHF zwar 
im Schnitt jünger waren, jedoch auch deutlich seltener eine Antikoagulation erhielten. Steinberg et al. 2015 stellten in der ROCKET-AF-Studie fest, dass unter Antikoagulation Patienten mit persistierendem Vorhofflimmern ein höheres Thrombembolie-Risiko und eine schlechtere Überlebensrate haben als Patienten mit paroxysmalem Vorhofflimmern. 2001 wurde der $\mathrm{CHADS}_{2}$-Score als Risikoklassifikation für Schlaganfälle bei Vorhofflimmerpatienten entwickelt (Gage et al. 2001). Der Score ist verhältnismäßig einfach zu berechnen und er kann die Mehrheit der Low-Risk-Patienten verlässlich von den Intermediate- und High-Risk-Patienten trennen (Karthikeyan und Eikelboom 2010). Im klinischen Alltag zeigten sich allerdings noch Verbesserungsmöglichkeiten, weshalb daraufhin der $\mathrm{CHA}_{2} \mathrm{DS}_{2}$-VASc-Score entwickelt wurde, der sieben Risikofaktoren berücksichtigt und eine bessere Auflösung im Niedrigrisikobereich zeigt (Lip et al. 2010; Chen et al. 2013):

- Herzinsuffizienz/ linksventrikuläre Dysfunktion (C für „congestive heart failure“, 1 Punkt)

- Hypertonie (H, 1 Punkt)

- Alter $\geq 75$ Jahre (A, 2 Punkte)

- Diabetes mellitus (D, 1 Punkt)

- TIA/Schlaganfall/Thrombembolie (S für „stroke“, 2 Punkte)

- Gefäßerkrankungen (V für „vascular disease“, 1 Punkt)

- $\quad$ Alter 65-74 Jahre (A, 1 Punkt)

- weibliches Geschlecht (Sc für „sex category“, 1 Punkt)

Eine schwedische Studie analysierte die Daten von 90.490 Patienten mit Vorhofflimmern, welche zu keinem Zeitpunkt Warfarin einnahmen, und errechnete das Risiko ischämischer Schlaganfälle anhand der Punktzahl des zugrunde gelegten $\mathrm{CHA}_{2} \mathrm{DS}_{2}$-VASc-Scores (Friberg et al. 2012).

Tab. 2 zeigt das zu erwartende jährliche Risiko ischämischer Schlaganfälle abhängig von der erhobenen Punktzahl im $\mathrm{CHA}_{2} \mathrm{DS}_{2}$-VASc-Score:

Tabelle 2: Risiko ischämischer Schlaganfälle/100 Patientenjahre in Bezug auf den $\mathrm{CHA}_{2} \mathrm{DS}_{2}$-VASc-Score

(nach Friberg et al. 2012)

\begin{tabular}{|l|l|}
\hline Punktzahl $\mathrm{CHA}_{2} \mathrm{DS}_{2}$-VASc & Risiko ischämischer Schlaganfälle/100 Patientenjahre in \% \\
\hline 0 & 0,2 \\
\hline 1 & 0,6 \\
\hline
\end{tabular}




\begin{tabular}{|l|l|}
\hline Punktzahl $\mathrm{CHA}_{2} \mathrm{DS}_{2}$-VASc & Risiko ischämischer Schlaganfälle/100 Patientenjahre in \% \\
\hline 2 & 2,5 \\
\hline 3 & 3,7 \\
\hline 4 & 5,5 \\
\hline 5 & 8,4 \\
\hline 6 & 11,4 \\
\hline 7 & 13,1 \\
\hline 8 & 12,6 \\
\hline 9 & 14,4 \\
\hline
\end{tabular}

Zu der klinischen Relevanz dieses Scores siehe 1.1.7.

Vorhofflimmern kann symptomatisch oder auch asymptomatisch sein. In der Auswertung der Canadian Registry of Atrial Fibrillation zeigten sich 142 (21\%) von 674 Patienten mit Vorhofflimmern asymptomatisch (Kerr et al. 1996). Ein Bericht der Framingham-Studie zeigte 18,3\% (21 von 115 Patienten) Neudiagnosen von Vorhofflimmern bei Patienten, welche mit Vorhofflimmern-assoziiertem Schlaganfall ins Krankenhaus eingeliefert wurden. In den folgenden 14 Tagen wurde hier bei weiteren 4,3\% (5 von 115 Patienten) paroxysmales VHF diagnostiziert (Lin et al. 1995). Es wurde zwar in dieser Veröffentlichung keine Aussage über die Beschwerdesymptomatik der Patienten getroffen, jedoch ist es ein Anhalt dafür, dass die Symptomatik zuvor als nicht derart störend empfunden wurde, medizinische Hilfe in Anspruch zu nehmen.

Symptome reichen von Palpitationen über Angina, Dyspnoe, Tachyarrhythmie, Schwindelgefühl bis hin zu Synkopen oder psychologischen Symptomen wie ein auftretendes Angstgefühl (Lip und Hee 2001; Fuster et al. 2006). Klinisch auffällig werden kann ein Vorhofflimmern durch einen unregelmäßigen Puls oder auch einen unregelmäßigen Jugularvenenpuls (Fuster et al. 2006).

Weiterhin kommt es - bedingt wahrscheinlich durch den hämodynamischen Effekt der Arrhythmie - zu einer erhöhten Sekretion des atrialen natriuretischen Peptids (ANP) aus den atrialen Myozyten (Wozakowska-Kaplon und Opolski 2002), was zu einer Polyurie führen kann (Fuster et al. 2006). 
Vorhofflimmern ist assoziiert mit einer erhöhten Morbidität und Mortalität in Bezug auf vorbestehende kardiovaskuläre Erkrankungen (Kannel et al. 1982; Britton und Gustafsson 1985).

Die durch das Vorhofflimmern mit einer unregelmäßigen Vorhofkontraktion und dadurch unregelmäßiger Kammerkontraktion entstehende Herzrhythmusstörung wird auch als „arrhythmia absoluta“ bezeichnet (Kirchhof 2009). Die unregelmäßige Erregung der Kammern kann zu einer Ventrikeldilatation und damit zu einer eingeschränkten systolischen Funktion führen, was als „Tachykardie-induzierte Kardiomyopathie“ bezeichnet wird (Lip und Hee 2001).

\subsubsection{Die Rolle von natriuretischen Peptiden bei Vorhofflimmern}

Wie in 1.1.4 bereits erwähnt, resultiert die Vorhofdehnung bei Vorhofflimmern in einer erhöhten Produktion des atrialen natriuretischen Peptids. Neben ANP existieren noch die natriuretischen Peptide vom B-Typ: brain natriuretic peptide (BNP) und NT-proBNP, welche vorrangig in den Ventrikeln produziert werden (Fuster et al. 2006), wobei jedoch auch eine atriale Sekretion diskutiert wird (Wozakowska-Kapłon 2004). Alle drei natriuretischen Peptide sind assoziiert mit Vorhofflimmern (Wozakowska-Kaplon und Opolski 2002; Knudsen et al. 2005; Jug et al. 2009).

Tsuchida und Tanabe 2004 konnten zeigen, dass der BNP-Spiegel bei akuten Anfällen von VHF ansteigt und anschließend auf den Wert vor dem Anfall abfällt. Ebenso postulierten sie, dass eine BNP-Erhöhung unbekannter Genese aus asymptomatischem VHF resultieren könnte.

Therkelsen et al. 2008 zeigten, dass sowohl ANP- als auch BNP-Spiegel nach Kardioversion abfallen.

Wachter et al. 2012 zeigten, dass BNP ein unabhängiger Prädiktor bei Patienten mit zerebraler Ischämie mit durch Holter-EKG entdecktem paroxysmalem Vorhofflimmern ist. Gould et al. 2010 und Seegers et al. 2015 zeigten ebenfalls die positive Korrelation zwischen paroxysmalen VHF und BNP-Wert. 


\subsubsection{Diagnostik des Vorhofflimmerns}

Wie in 1.1.1 beschrieben, liegt dem VHF eine inadäquate Kontraktion der Vorhöfe zugrunde, welche in einem unregelmäßigen Radialis- oder Jugularvenenpuls resultiert. Eine klinische Untersuchung mit Pulsbestimmung kann daher bereits Hinweise auf ein Vorhofflimmern liefern (Fuster et al. 2006).

Vor allem kann Vorhofflimmern durch eine Aufzeichnung des Herzrhythmus detektiert werden. Prinzipiell stehen hierfür verschiedene Methoden zur Verfügung:

- 12-Kanal-Oberflächen-EKG: Standard-EKG

- Langzeit-EKG (auch Holter-EKG genannt): wie in dieser Studie genutzt, siehe 2.5.1

- Event-Recorder (auch Loop-Recorder genannt): Hierbei handelt es sich um kleine Geräte, die den Herzrhythmus aufzeichnen und speichern können. Event-Recorder können implantiert werden und zeichnen EKG-Episoden über einen Zeitraum von bis zu mehreren Jahren auf (Brignole et al. 2009).

- Handheld-Geräte wie z. B. Zenicor: wie in dieser Studie genutzt, siehe 2.5.2

Da, wie in 1.1.4 dargelegt, ein Vorhofflimmern Ursache von Schlaganfällen sein kann, wird bei Patienten, welche einen Schlaganfall erlitten haben, mit einer EKG-Überwachung nach Herzrhythmusstörungen gescreent. Während bis vor Kurzem nur bei Patienten mit kryptogenem Schlaganfall ein verlängertes Monitoring gebräuchlich war, empfiehlt die ESC-Leitlinie von 2016 (Kirchhof et al. 2016) ein verlängertes Monitoring von 72 Stunden bei allen Schlaganfallpatienten, bei denen noch kein Vorhofflimmern diagnostiziert wurde.

Definitionsgemäß wurde bei einem kryptogenen Schlaganfall trotz intensiver Diagnostik keine Ursache detektiert (Bang et al. 2003). Dies ist in ca. 17-40\% der zerebralen Ischämien der Fall (Grau et al. 2001; Kolominsky-Rabas et al. 2001; Bang et al. 2003).

\subsubsection{Therapie des Vorhofflimmerns und Konsequenz des $\mathrm{CHA}_{2} \mathrm{DS}_{2}-\mathrm{VASc}$-Scores}

Die Therapie des Vorhofflimmerns zielt auf eine Minimierung der Symptome und der Komplikationen in Zahl und Ausmaß ab. Weiterhin umfasst sie eine möglichst risikofreie und nebenwirkungsarme Rezidivprophylaxe (Kirchhof et al. 2016). 
Es stehen zwei Therapieoptionen zur Auswahl:

- Frequenzkontrolle und Rhythmuskontrolle

Frequenzkontrolle beschreibt eine Regulierung der Erregungsübertragung auf die Kammern, Rhythmuskontrolle dagegen eine Kardioversion in den physiologischen Sinusrhythmus.

Das Therapieregime eines neu diagnostizierten bzw. neu aufgetretenen akuten Vorhofflimmerns kann von der längerfristig angestrebten Strategie abweichen (Kirchhof et al. 2016).

Es existieren einige Studien, die Frequenz- und Rhythmuskontrolle vergleichen: In keiner dieser Studien konnte ein Vorteil der Rhythmuskontrolle gegenüber der Frequenzkontrolle hinsichtlich kardiovaskulärer Mortalität festgestellt werden (Wyse et al. 2002; Van Gelder et al. 2002; Roy et al. 2008). Im Gegenteil, es wurde sogar der potentielle Vorteil von geringeren Medikamentennebenwirkungen in der Frequenzstrategiegruppe aufgezeigt (Wyse et al. 2002). Ebenso scheint die Wahl zwischen Frequenz- und Rhythmuskontrolle keinen eindeutigen Effekt auf die Lebensqualität zu haben (Hohnloser et al. 2000; Wyse et al. 2002; Carlsson et al. 2003; Camm et al. 2010).

Aktuell ist die Rhythmuskontrolle indiziert bei Patienten, die unter Frequenzkontrolle weiterhin Symptome zeigen (Kirchhof et al. 2016).

Die Therapie des Vorhofflimmerns kann in akut und langfristig eingeteilt werden:

Im Akutfall werden bei Patienten mit einer zu schnellen Leitungsübertragung auf die Ventrikel Medikamente wie Beta-Blocker, Diltiazem/Verapamil oder ggf. auch Digitalis und Amiodaron eingesetzt, wobei die Wahl des jeweiligen Medikamentes hier von den vorliegenden Umständen abhängig ist (Kirchhof et al. 2016).

Einige Patienten mit einer durch Vorhofflimmern ausgelösten Bradykardie profitieren von einer Katheterablation, wodurch eine antiarrhythmische Medikation oder eine eventuelle Schrittmacherimplantation nicht vonnöten ist (Kirchhof et al. 2016).

Bei instabilen Patienten sollte eine Kardioversion in Erwägung gezogen werden (Kirchhof et al. 2016).

Falls im akuten Fall eine Rhythmuskontrolle angestrebt wird, stehen eine elektrische oder eine pharmakologische Kardioversion zur Wahl. Je länger Vorhofflimmern bei einem Pati- 
enten besteht, desto schwerer fällt eine (anhaltende) Konversion in den Sinusrhythmus, da Umbauprozesse im atrialen Gewebe eine Kardioversion erschweren (Kirchhof 2009).

Eine pharmakologische Kardioversion besitzt zwar eine geringere Erfolgsquote, hat jedoch den Vorteil, dass sie ohne Sedierung bzw. Anästhesie durchgeführt werden kann. Beispiele für verfügbare Medikamente sind Flecainid, Propafenon, Amiodaron, Ibutilid und Vernalakant (Kirchhof et al. 2016).

Eine elektrische Kardioversion wird über die Applikation von Energie (zwischen 50-360 J) auf den Thorax mittels zweier Elektroden durchgeführt. Der exakte Funktionsmechanismus ist unbekannt, jedoch wurden folgende Thesen formuliert: Zum einen könnte die Ursache in einer Refraktärzeit-Verlängerung der myokardialen Zellen liegen, zum anderen in der Überschreitung der Depolarisation einer kritischen Masse, welche zur Aufrechterhaltung der Arrhythmie notwendig ist. Es ist ebenso unbekannt, ob der zugrunde liegende Mechanismus zur Terminierung von ventrikulären Tachykardien und Vorhofflimmern identisch ist (Sucu et al. 2009).

Eine Frequenzkontrolle in der Langzeittherapie dient dem Zweck der Symptomverringerung. Beta-Blocker, Verapamil und Diltiazem, Digoxin und Digitoxin und ggf. Amiodaron sind hier potentielle Präparate. Falls eine medikamentöse Frequenzkontrolle frustran verläuft, kann eine Ablation des AV-Knotens, des His-Bündels oder auch die Implantation eines VVI-Schrittmachers in Erwägung gezogen werden (Kirchhof et al. 2016).

Eine Rhythmuskontrolle sollte in der Langzeittherapie bei unter Frequenzkontrolle symptomatischen Patienten durchgeführt werden. Beispiele für Medikamente, die für diesen Zweck verwendet werden, sind: Flecainid, Propafenon, Amiodaron, Sotalol und Dronedaron (Kirchhof et al. 2016).

Patienten mit Vorhofflimmern sollten des Weiteren eine Thromboseprophylaxe erhalten (Hart et al. 2007):

Hart et al. 2007 konnten zeigen, dass eine Antikoagulation bei nicht-valvulärem VHF eine relative Risikoreduktion von Schlaganfällen um 64\% bewirkt und somit eine absolute jährliche Schlaganfallverringerung um 2,7\% (Hart et al. 2007; Camm et al. 2010). Laut dieser Meta-Analyse bewirkt eine Plättchenhemmung eine relative Reduktion von Schlaganfällen um $22 \%$. 
Ein direkter Vergleich von Antikoagulation mit Warfarin (Ziel-INR 2-3) vs. Plättchenhemmung mit 75 mg Aspirin bei Über-75-Jährigen demonstrierte eine 52\%ige relative Reduktion von schweren Schlaganfällen, intrakraniellen Blutungen und arteriellen Embolien bei Antikoagulation und konnte keinen Unterschied beim Blutungsrisiko feststellen (Mant et al. 2007; Camm et al. 2010).

Ähnliches konnte eine Studie bestätigen, die eine Antikoagulation mit Warfarin verglich mit einer Plättchenhemmung aus einer Kombination aus Aspirin und Clopidogrel und eine absolute Risikoreduktion von 1,2\% bei bedeutenden vaskulären Ereignissen im WarfarinArm feststellen konnte - ebenfalls ohne Unterschied im Blutungsrisiko (Connolly et al. 2006; Camm et al. 2010).

Die Rolle von Aspirin in der Schlaganfallprophylaxe nimmt stetig weiter ab und scheint in einigen Studien keinen bzw. sogar einen negativen Effekt zu haben (Sato et al. 2006; Ogilvie et al. 2011; Olesen et al. 2011; Lip 2011). Bzgl. einer Aspirintherapie sind die Leitlinien angepasst worden. Während in den Leitlinien von 2012 eine Aspirintherapie (auch in Kombination mit Clopidogrel) unter bestimmten Umständen noch in Erwägung gezogen werden konnte (Camm et al. 2012), findet diese Aspirintherapie bei Vorhofflimmern in der neuesten Auflage von 2016 keine Erwähnung mehr (Kirchhof et al. 2016).

Zur Indikationsstellung einer Antikoagulation sollte auch das Blutungsrisiko einkalkuliert werden. Ein aktuell häufig genutzter Score ist HAS-BLED (Pisters et al. 2010) und beinhaltet die Risikofaktoren Bluthochdruck, eingeschränkte Leber- und Nierenfunktionen, vorangegangene Schlaganfälle, Blutungen in der Anamnese, schwer kontrollierbare INREinstellung, Alter ab 65 und Medikamenteneinnahme bzw. Alkoholkonsum.

Die sogenannten NOAKs (neue orale Antikoagulantien: Dabigatran, Rivaroxaban, Apixaban, Edoxaban) wurden erst kürzlich für Vorhofflimmern zugelassen. Entsprechend bestehen keine Langzeiterfahrungen mit dieser Medikamentengruppe. Erste Studien, welche die NOAKs mit Vitamin-K-Antagonisten verglichen, berichteten jedoch inzwischen ihre Ergebnisse:

Laut Connolly et al. 2009 ist Dabigatran dosisabhängig entweder vergleichbar effektiv in der Prävention von Thrombembolien mit einer geringeren Rate von Blutungen oder effektiver in der Prävention mit einer vergleichbaren Rate an Blutungen.

Patel et al. 2011 berichteten, dass Rivaroxaban ähnlich effektiv wie Warfarin in der Prävention von Schlaganfällen oder systemischen Embolien ist und es keinen signifikanten 
Unterschied in der Rate schwerer Blutungen gibt, wobei intrakranielle und tödliche Blutungen in der Rivaroxaban-Gruppe seltener auftraten. In den Studien zum Einsatz von NOAKs bei Vorhofflimmern zeigte Rivaroxaban das höchste Schlaganfallrisiko (Camm et al. 2012).

Granger et al. 2011 konnten bei Apixaban ein signifikant geringeres Schlaganfallrisiko sowie Blutungsrisiko gegenüber Warfarin zeigen und ging mit einer geringeren Mortalität einher.

Connolly et al. 2011 verglichen Apixaban mit einer Aspirinmonotherapie. Diese Studie wurde aufgrund der eindeutigen Überlegenheit von Apixaban vorzeitig gestoppt: es traten signifikant weniger Schlaganfälle und systemische Embolien auf bei vergleichbarem Blutungsrisiko.

Ruff et al. 2014 analysierten randomisierte Studien im Zeitraum von 2009 bis 2013 (RELY, ROCKET AF, ARISTOTLE, ENGAGE-AF TIMI 48), welche Patienten mit Vorhofflimmern einschlossen, die randomisiert entweder Warfarin oder eins der neuen oralen Antikoagulantien (je nach Studie Dabigatran, Rivaroxaban, Apixaban, Edoxaban) erhielten. Diese Meta-Analyse zeigte eine signifikante Reduktion an Schlaganfällen, intrakraniellen Blutungen und Mortalität bei vergleichbarer Rate an schweren Blutungen, aber einer erhöhten Rate an gastrointestinalen Blutungen bei den NOAKs im Vergleich zu Warfarin.

Die Entscheidung, ab wann ein Patient antikoaguliert wird, sollte immer eine individuelle Entscheidung sein - allerdings kann der in 1.1.4 erwähnte $\mathrm{CHA}_{2} \mathrm{DS}_{2}$-VASc-Score zur Entscheidungsfindung beitragen (Kirchhof et al. 2016).

Nach der aktuellen Leitlinie von 2016 wird bei Diagnose von Vorhofflimmern zur Thrombembolieprophylaxe nach folgendem Schema vorgegangen (Tab. 3):

Im Falle einer mechanischen Herzklappe oder bei Vorliegen einer moderaten oder schweren Mitralstenose ist eine Antikoagulation mit Vitamin-K-Antagonisten indiziert. Sollte dies nicht der Fall sein, wird abhängig vom $\mathrm{CHA}_{2} \mathrm{DS}_{2}$-VASc -Score entschieden.

Tabelle 3: Thrombembolieprophylaxe bei Patienten mit Vorhofflimmern anhand des $\mathrm{CHA}_{2} \mathrm{DS}_{2}$-VAScScores

(nach ESC 2016)

\begin{tabular}{|l|l|}
\hline CHA $_{2} \mathbf{D S}_{2}$-VASc-Score & Therapieempfehlung \\
\hline 0 & $\begin{array}{l}\text { keine Antikoagulation (ebenso bei Frauen } \\
\text { ohne weitere Risikofaktoren) }\end{array}$ \\
\hline
\end{tabular}




\begin{tabular}{|l|l|}
\hline CHA $_{2}$ DS $_{2}$-VASc-Score & Therapieempfehlung \\
\hline 1 & $\begin{array}{l}\text { eine orale Antikoagulation sollte in Erwä- } \\
\text { gung gezogen werden (ebenso bei Frauen } \\
\text { mit nur einem weiteren Risikofaktor) }\end{array}$ \\
\hline$\geq 2$ & eine orale Antikoagulation ist indiziert \\
\hline
\end{tabular}

Als nicht-medikamentöse Behandlungsmöglichkeiten stehen ein Verschluss des linken Herzohrs (Holmes et al. 2009) und eine Radiofrequenz- oder Kryoablation der Pulmonalvenen zur Verfügung (Calkins et al. 2009; Kirchhof et al. 2016).

\subsubsection{Vorhofflattern}

Vorhofflattern ist ebenfalls eine Arrhythmie des Atriums und verwandt mit dem Vorhofflimmern. Die im EKG charakteristischen „sägezahnartigen“ Flatterwellen sind vor allem prägnant in den Ableitungen II, III und aVF und gehen unbehandelt gewöhnlich mit einer Frequenz von 250-350 Schlägen pro Minute einher (Lévy et al. 2003). Vorhofflimmern kann in Vorhofflattern übergehen und umgekehrt (Lévy et al. 2003).

\subsection{Zerebraler Insult}

\subsubsection{Definitionen}

Im Jahre 1980 wurde der zerebrale Insult von der WHO definiert als „sich rasch entwickelnde Zeichen einer fokalen (oder globalen) Störung der zerebralen Funktion, welche länger als 24 Stunden anhalten oder zum Tod führen, ohne Anhalt für Gründe abgesehen von vaskulärer Genese“ (Aho et al. 1980). 2013 brachten die AHA/ASA (American Heart Association/American Stroke Association) in Kollaboration ein Update zu dieser Definition heraus:

„Ein ZNS-Infarkt ist Zelluntergang des Hirns, Rückenmarks oder Retina aufgrund von Ischämie, basierend auf

1. Pathologie, Bildgebung oder anderem objektiven Nachweis von fokaler ischämischer Schädigung des Hirns, Rückenmarks oder Retina, in einem definierten vaskulären Bereich; oder ein 
2. klinischer Nachweis fokaler ischämischer Schädigung des Hirns, Rückenmark oder Retina basierend auf Symptomen, welche länger als 24 Stunden anhalten oder zum Tod führen, unter Ausschluss anderer Ätiologien.“ (Sacco et al. 2013)

Diese oben beschriebene Ischämie kann ischämischer (ca. 90\%) oder hämorrhagischer (ca. 10\%) Genese sein (Andersen et al. 2009). Der hämorrhagische Schlaganfall beruht auf einer fokalen Ansammlung von Blut im Hirnparenchym, welches nicht auf ein Trauma zurückgeführt werden kann (Sacco et al. 2013).

Da sich die Find-AF RANDOMISED-Studie, auf der die Daten dieser Doktorarbeit basieren, vor allem mit der durch Vorhofflimmern ausgelösten ischämischen Form befasst, wird im Weiteren nur auf diese eingegangen.

\subsubsection{Weitere Formen und Einteilungen zerebraler Ischämien}

Eine weitere Einteilung kann anhand der zeitlichen Ausdehnung und dem Verlauf der Symptomatik vorgenommen werden:

Die Definition der transienten ischämischen Attacke (TIA) hat sich in den letzten Jahren leicht verändert. Bis 2009 wurde die TIA noch definiert als ein fokales, zerebrales ischämisches Event, dessen Symptome nicht länger als 24 Stunden anhalten (Easton et al. 2009). Jedoch war diese Schwelle willkürlich gewählt und bei 30\% - 50\% der TIAs nach der alten Definition konnten bereits Parenchymläsionen nachgewiesen werden. Seit 2009 wird die TIA neu definiert als „eine vorübergehende Episode neurologischer Dysfunktion aufgrund von fokaler Schädigung des Hirns oder der Retina, welche ohne Nachweis eines akuten Infarkts einhergeht“ (Easton et al. 2009)

Ein Schlaganfall kann weiterhin noch unterteilt werden in completed stroke und progressive stroke:

Ein Schlaganfall wird als completed stroke bezeichnet, sobald die Symptomatik länger als 24 Stunden anhält. Der Begriff progressive stroke wird genutzt, wenn die Symptomatik des Schlaganfalls im Verlauf zunimmt (DEGAM 2012).

Letztlich definiert die AHA/ASA noch den sogenannten silent stroke. Hier liegt der neuropathologische oder radiologische Nachweis eines Hirninfarkts vor ohne eine begleitende klinische Dysfunktion, welche in Zusammenhang mit der Läsion steht (Sacco et al. 2013). 


\subsection{3 Ätiologie und Risikofaktoren des zerebralen Insults}

Vorhofflimmern gehört zu den wichtigsten Ursachen des ischämischen Schlaganfalls. Eine deutsche Studie aus dem Jahr 2001 konnte kardiale Embolien als häufigste Ursache (25,6\%) nachweisen. Makroangiopathie (20,9\%) und Mikroangiopathie (20,5\%) folgten auf den weiteren Plätzen. In 22,7\% der Fälle blieb die genaue Ursache ungeklärt und in 6,9\% der Fälle konnte mehr als eine potentielle Ursache gefunden werden. Die restlichen Fälle verteilten sich auf seltenere Ursache wie bspw. Dissektion der A. cervicalis (Grau et al. 2001).

Kardiale Emboliequellen können nach Pepi et al. 2010 in drei Kategorien eingeteilt werden:

1. Kardiale Herde, die zu einer Thrombusbildung neigen (z. B. das linke Herzohr) bei Patienten mit Vorhofflimmern,

2. Kardiale Raumforderungen (z. B. kardiale Tumoren, Thromben, Vegetationen, Plaques) und

3. Intrakardiale Verbindungen, welche paradoxe Embolien ermöglichen (z. B. offenes Foramen ovale).

Eine weitere, jedoch seltene Ursache eines ischämischen Schlaganfalls ist der M. Fabry, der aufgrund einer Genmutation zu einer systemischen Vaskulopathie führt (Schiffmann 2015).

Die Risikofaktoren für ischämische Schlaganfälle sind zahlreich. Zu ihnen zählen unter anderem: Bluthochdruck, familiäre Prädisposition, Vorhofflimmern, Endokarditis, Mitralklappenstenose, Sichelzellanämie, vorangegangene zerebrale Ischämie, Zigarettenrauchen, asymptomatische Karotisstenose, Diabetes mellitus, Hyperhomozysteinämie, Hypertrophie des linken Ventrikels und Alter (Sacco et al. 1997; Francis et al. 2007; Grecu et al. 2014; Arboix 2015).

Friberg et al. 2012 ermittelten als Risikofaktoren für Schlaganfälle/TIAs/systemische Embolien vorangegangene Myokardinfarkte, vorangegangene Embolien und ischämische Schlaganfälle, Bluthochdruck, Diabetes mellitus, Nierenversagen, pAVK und Gefäßerkrankungen und fanden zusätzlich intrakranielle Blutungen in der Anamnese als Prädisposition. Des Weiteren konnten sie zeigen, dass das Risiko bei einem Alter von 65-74 ca. dreifach und ab 75 Jahren ca. fünffach erhöht ist im Vergleich zu Unter-65-Jährigen.

Als unabhängiger Risikofaktor für Schlaganfälle wird in der transthorakalen Echokardiographie eine mittlere bis schwere Einschränkung der linksventrikulären systolischen Funk- 
tion gesehen. In der transösophagealen Echokardiographie konnten zusätzlich zum Thrombus im linken Vorhof der Nachweis eines komplexen Plaques in der Aorta, spontaner Echokontrast und niedrige Flussgeschwindigkeiten im linken Herzohr als Risikofaktor nachgewiesen werden (Camm et al. 2010).

\subsubsection{Epidemiologie der zerebralen Ischämie}

Aufgrund mangelnder Schlaganfallstatistik in Deutschland wurde 1994 das Erlanger Schlaganfallregister eingerichtet, in welches alle Bürger von Erlangen eingeschlossen wurden. Laut dem Gesundheitsbericht des Bundes aus dem Jahre 2006, welcher sich auf genanntes Schlaganfallregister bezieht, nimmt die Häufigkeit von Schlaganfällen mit dem Alter zu und beinahe 85\% aller Schlaganfälle treten nach dem 60. Lebensjahr auf. Die jährliche altersstandardisierte Schlaganfall-Inzidenz liegt bei 182 pro 100.000 Einwohner (Männer 200/100.000; Frauen 170/100.000). Ebenfalls erfasst wurde die Letalität über bestimmte Zeiträume. Die Auswertung des Erlanger Schlaganfallregisters ergab, dass nach 28 Tagen 19,4\% der Patienten mit dem Erstereignis Schlaganfall gestorben waren. Nach drei Monaten hatte sich diese Zahl auf 28,5\% erhöht und nach einem Jahr auf 37,3\% (Kolominsky-Rabas und Heuschmann 2002).

In den westlich ausgerichteten Industrienationen ist die altersstandardisierte Schlaganfallrate über die vergangenen 30 Jahre kontinuierlich gesunken, jedoch könnte die alternde Bevölkerung zu einer steigenden absoluten Schlaganfallinzidenz führen (Kinlay 2011). Der Schlaganfall ist eine Krankheit des alternden Menschen, wobei 10-15\% aller Schlaganfälle bei jungen Menschen (unter 45 bzw. 49 Jahren) auftreten (Smajlović 2015).

\subsubsection{Therapie des ischämischen Schlaganfalls}

Präklinisch kommen vor allem supportive Maßnahmen zum Einsatz (DEGAM 2012): Atemwege freihalten, Oberkörperhochlagerung um 30 Grad, Sauerstoffgabe 2-4 1/min, peripher-venöser Zugang und isotonische Volumengabe, Blutzuckerkontrolle, Blutdruckkontrolle und evtl. Senkung bei Werten systolisch $>220 \mathrm{mmHg}$ und/oder diastolisch $>120$ mmHg. Hypotonie und ein eventueller Volumenverlust sollten behandelt werden. Kontraindiziert sind eine Gabe von ASS oder Clopidogrel, Heparin, Steroiden oder i.m.Injektionen, da durch diese Medikamente das Blutungsrisiko steigt und eine Lyse im Fol- 
genden nicht mehr möglich ist bzw. im Falle von Steroiden keine positiven Effekte nachgewiesen werden konnten bei steigendem Hyperglykämierisiko.

Im Verlauf sollten zum Ausschluss einer Hirnblutung und weiterer Anomalien eine Bildgebung vom Kopf angefertigt werden und die extrakraniellen Gefäße auf Stenosen untersucht werden (DEGAM 2012).

Grundsatz jeder Behandlung eines Schlaganfalls bzw. des Verdachts auf einen Schlaganfall sollte die schnellstmögliche Einweisung in ein geeignetes Krankenhaus sein, da eine schnelle Behandlung mit einem besseren Outcome korreliert (time is brain) (Hacke et al. 2004; Saver 2006).

Optimal ist die Durchführung einer Lysetherapie in den ersten 90 Minuten, kann aber auch noch bis zu drei Stunden durchgeführt werden resp. sogar bis zu sechs Stunden (Hacke et al. 2004; Wardlaw et al. 2014). Die Lyse ist eine kausale Therapieoption eines ischämischen Schlaganfalls - hat allerdings auch Risiken, weshalb sie nicht uneingeschränkt zu empfehlen ist. So erhöhen sich das Auftreten intrakranieller Blutung und die Todesrate innerhalb von 7-10 Tagen nach Lyse im Vergleich zu Patienten, die nicht lysiert werden (Wardlaw et al. 2014).

Das Risiko-Nutzen-Verhältnis sollte hier intensiv mit den Patienten besprochen werden (DEGAM 2012).

Immer mehr an Bedeutung gewonnen hat in den letzten Jahren auch die mechanische Thrombektomie im Anschluss an eine Lysetherapie. In der deutschen Leitlinie von 2012 wird sie noch nicht empfohlen, jedoch berichteten kürzlich einige Studien über ihre Effektivität (Berkhemer et al. 2015; Goyal et al. 2015; Campbell et al. 2015; Saver et al. 2015; Jovin et al. 2015; Muir et al. 2017).

Da auch das Vorhofflimmern ein unabhängiger Risikofaktor für Schlaganfälle ist (siehe 1.2.3), sollte sich eine kardiale Untersuchung anschließen (DEGAM 2012).

\subsubsection{Prävention von Schlaganfällen}

Wie in 1.2.3 dargelegt, erhöht eine Reihe von Faktoren das Risiko für Schlaganfälle. Die Prävention gliedert sich in zwei Säulen: die primäre und die sekundäre Säule. Von primä- 
rer Prävention wird gesprochen, solange noch kein Schlaganfall aufgetreten ist; von sekundärer Prävention, sobald die Person bereits einen Insult bzw. eine TIA erlitten hat.

Generell können Risikofaktoren in vier Obergruppen eingeteilt werden: Herz und Gefäße (z. B. Vorhofflimmern), Lebensstil (z. B. Rauchen), Stoffwechsel (z. B. Diabetes mellitus) und allgemeine Risikofaktoren wie z. B. Alter (DEGAM 2012).

Der Einfluss von Alkohol auf das Schlaganfallrisiko hängt von der Menge des Konsums ab: Reynolds et al. 2003 konnten in einer Meta-Analyse zeigen, dass ein hoher Alkoholkonsum (> 60 g/d) das relative Schlaganfallrisiko erhöht, wohingegen moderater bzw. leichter Genuss möglicherweise sogar präventiv wirkt (Reynolds et al. 2003; Knuiman und Vu 1996).

Für diese Studie besonders relevant ist das mögliche Vorliegen des Risikofaktors Vorhofflimmern, was kausal oder auch symptomatisch therapiert werden kann und somit präventiv eine entscheidende Rolle spielt.

\subsection{Fragestellung dieser Arbeit}

Basierend auf der Find-AFRANDOMISED-Studie, die ein verlängertes Monitoring mit Standardmonitoring vergleicht, sollte in dieser Arbeit folgenden Fragen nachgegangen werden:

1. Gibt es einen Unterschied in der Prädiktion von Vorhofflimmern - diagnostiziert durch Holter-EKG vs. Usual Care? Sind die Prädiktoren von VHF diagnostiziert mit Holter-EKG dieselben wie für VHF im Kontrollarm?

2. Was sind die Prädiktionsfaktoren für die Detektion von inzidentem Vorhofflimmern mittels verlängerten und verbesserten Monitorings? 


\section{MATERIAL UND METHODEN}

\subsection{Studiendesign Find-AF}

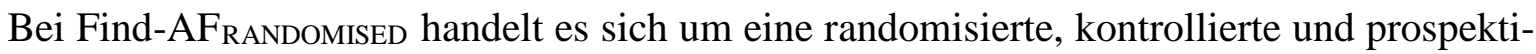
ve multizentrische Studie, die 402 Patienten mit akuten (Symptome $\leq 7$ Tage) und manifesten Schlaganfallsymptomen (entsprechende akute Läsion in der CT-/MRT-Bildgebung) an vier zertifizierten Stroke-Zentren in Deutschland (Göttingen, Mainz, Sande, Wiesbaden) einschloss. Das Studiendesign wurde 2014 publiziert (Weber-Krüger et al. 2014).

Es wurden nur diejenigen Patienten in die Studie aufgenommen, bei denen eine Detektion von Vorhofflimmern eine potentielle therapeutische Konsequenz hatte.

Patienten wurden 1:1 randomisiert in die Gruppen „verlängerte EKG-Überwachung“ (je zehn Tage Langzeit-EKG zur Baseline-Untersuchung und erneut nach 90 und 180 Tagen) und „momentaner Klinikstandard mit mindestens 24-Stunden-EKG-Überwachung“. Die Nachverfolgung aller Patienten wurde für ein Jahr angesetzt.

Da eine doppelte Verblindung aufgrund des Studiendesigns nicht möglich war, wurde das PROBE-Design (prospective randomized open, blinded end-point, Hansson et al. 1992) gewählt. Endpunkte werden hier durch ein verblindetes Adjudikationskomitee evaluiert. Primärer Endpunkt war die Detektion von Vorhofflimmern >30s nach sechs Monaten, welches von dem unabhängigen Adjudikationskomitee (PROBE-Design) bestätigt wurde. Sekundäre Endpunkte wurden in zwei Kategorien unterteilt: Sekundäre Hauptendpunkte waren die Detektion von Vorhofflimmern/-flattern innerhalb von zwölf Monaten, die Detektion von Vorhofflimmern während der Follow-Up-Untersuchungen, Re-Infarkte innerhalb von zwölf Monaten und Todesfälle innerhalb von zwölf Monaten. Sekundäre Nebenendpunkte waren Todesfälle aufgrund zerebrovaskulärer oder kardiovaskulärer Ursachen, transitorische ischämische Attacken, Myokardinfarkte, Blutungskomplikationen, Schlaganfallabhängige Behinderungen, ischämische oder hämorrhagische zerebrale Insulte, Lebensqualität und die quantitative und qualitative Inanspruchnahme des Gesundheitssystems.

Abb. 3 zeigt das Studiendesign nach Weber-Krüger et al. 2014.

Weiterhin wurden alle Schlaganfälle (Index- und Folgeevents) von einem unabhängigen Komitee nach Anonymisierung sämtlicher klinischer Daten auf ihre wahrscheinlichste Ätiologie hin überprüft. Voraussetzungskriterium für alle Studienzentren war eine von der Deutschen Schlaganfall-Gesellschaft zertifizierte Stroke Unit mit über 500 Insult-Patienten jährlich. 
Die diagnostischen Geräte wurden speziell für die Studie erworben. Finanziert wurde die Studie durch Boehringer Ingelheim. Das Unternehmen hatte keinen Einfluss auf das Studiendesign, Durchführung der Studie, Datenanalyse und -interpretation, Veröffentlichung oder Autorenschaft.

\section{Studiendesign Flowchart}

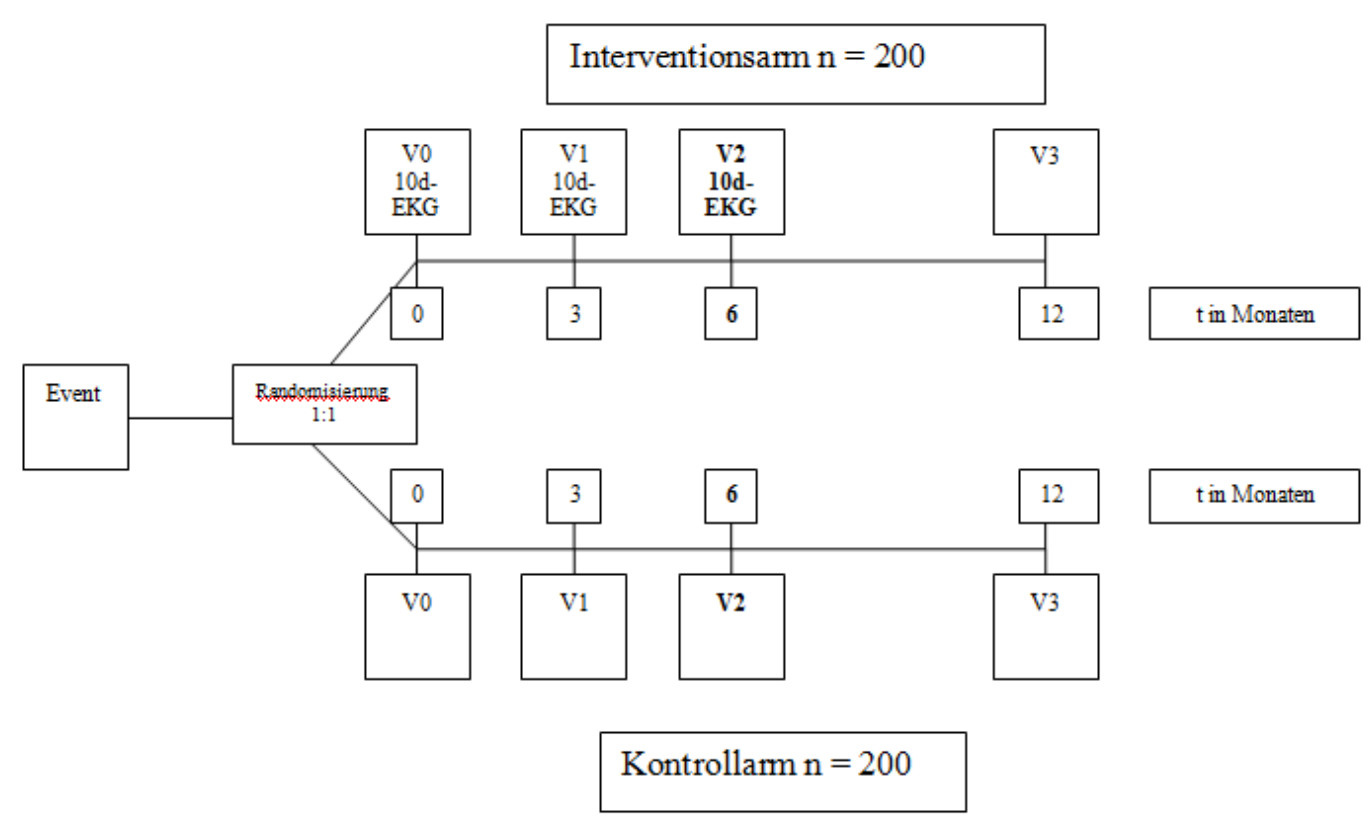

angelehnt an Weber-Krüger et al. 2014

primärer Endpunkt: neu diagnostiziertes Vorhofflimmem innerhalb von 6 Monaten

Abbildung 3: Studiendesign Flowchart (mit freundlicher Genehmigung von M. Weber-Krüger)

\subsection{Patientenrekrutierung und Randomisierung}

Die Patientenrekrutierung erfolgte von Mai 2013 bis August 2014. Studienteilnehmer wurden aus den Patientenpopulationen rekrutiert, die in den jeweiligen Zentren wegen eines Insultes stationär aufgenommenen wurden.

Einschlusskriterien waren hierbei:

- Diagnose eines akuten ischämischen Schlaganfalls

\section{UND/ODER}

- entsprechende Läsion in der Bildgebung

weitere:

- Schlaganfall-assoziierte Symptome seit $\leq 7$ Tagen 
- Alter $\geq 60$ Jahre

- modified Rankin Scale (mRS) $\leq 2$ (vor dem Indexereignis; zur näheren Erklärung des Scores siehe Anhang)

Ausschlusskriterien waren:

- Bekanntes Vorhofflimmern/Vorhofflattern

- Indikation zur oralen Antikoagulation vor Randomisierung

- Absolute Kontraindikation gegen orale Antikoagulation

- Intrazerebrale Blutung in der Vorgeschichte

- Langzeit-EKG/Event-Recorder > 48h (studienunabhängig) vorgesehen

- Signifikante Gefäßstenose (NASCET) > 50\% oder Dissektion in einer das Infarktgebiet versorgenden Arterie

- Implantierter Herzschrittmacher/ICD

- Lebenserwartung $<1$ Jahr

- Teilnahme an einer anderen randomisierten kontrollierten Studie

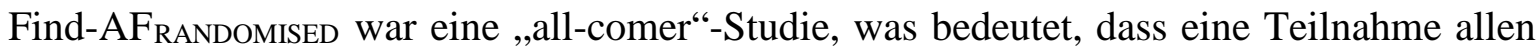
Patienten angeboten wurde, welche die Ein- und Ausschlusskriterien erfüllten.

Nach Einschluss in die Studie und Unterzeichnung ihres Einverständnisses wurden die Patienten in die Interventions- (Holter-Monitoring) bzw. Kontrollgruppe randomisiert. Beide Adjudikationskomitees wurden verblindet, wohingegen das bei den Teilnehmern der Studie und dem Studienpersonal aufgrund des Studiendesigns nicht möglich war.

\subsection{V0: Baseline-Untersuchung}

Nach Randomisierung wurde bei jedem Patient eine Baseline-Untersuchung durchgeführt, zu der eine ausführliche körperliche Untersuchung, die Erfassung aktueller Medikamente und neurologischer und physischer Defizite im Rahmen des NIHSS-Scores (National Institutes of Health Stroke Scale) und der modified Rankin Scale (mRS) gehörten. Weiterhin wurden zerebrale Bildgebungsuntersuchungen (kranielle Magnetresonanztomographie oder kranielle Computertomographie), Gefäßbildgebungen (Doppler-/Duplex-Untersuchungen, computertomographische Angiographie/Magnetresonanztomographie), eine transthorakale oder transösophageale Echokardiografie und eine Standard-Labor-Untersuchung durchgeführt. Mittels standardisierter Fragebögen wurden zusätzlich die Lebensqualität (EuroQoL 
5 Dimensions (EQ5D)), die durch den Schlaganfall aufgetretenen physischen Limitierungen (Stroke Impact Scale-16 (SIS-16)) und depressive Tendenzen und Angstsymptome (Hospital Anxiety and Depression Scale (HADS)) erfasst sowie die Inanspruchnahme des Gesundheitssystems mittels eines eigens konzipierten Fragebogens zur Gesundheitsökonomie.

Im Anschluss wurde bei den Patienten in der Interventionsgruppe ein 10-Tage-LangzeitEKG (2-Kanäle, 5 Ableitungen) (siehe Abb. 6 und Kap. 2.5.1) abgeleitet. Bei der Anlage wurden die Elektrodenpads BlueSensor VL der Firma Ambu verwendet (Elektrodenanordnung siehe Anhang Abb. 5). Zusätzlich erhielten die Patienten eine Trageschlaufe inkl. Tragetasche für Fixierung und Schutz. Die Patienten konnten das Gerät mit dieser Schlaufe um den Hals tragen oder am Gürtel befestigen. Des Weiteren erhielten sie eine Einweisung in den Umgang mit den Geräten und zusätzliche Informationsbögen. Eine Versorgung mit ausreichend Ersatz-Elektrodenpads wurde sichergestellt.

Die Patienten in der Kontrollgruppe erhielten lediglich das leitliniengerechte 24-StundenEKG (DEGAM 2012).

Alle erhobenen Daten wurden im Anschluss in eine durch das Institut für anwendungsorientierte Forschung und klinische Studien (IFS) supervisierte elektronische eCRFDatenbank übertragen.

Tab. 4 gibt eine Übersicht, zu welchem Zeitpunkt welche Untersuchungen durchgeführt und welche Fragebögen komplettiert wurden (nach Weber-Krüger et al. 2014):

Tabelle 4: Ablaufplan Find-AFRANDOMISED

\begin{tabular}{|c|c|c|c|c|}
\hline Visite & V0 & V1 & V2 & V3 \\
\hline Zeit (in Tagen) & 0 & $90( \pm 14)$ & $180( \pm 14)$ & $360( \pm 30)$ \\
\hline Endpunkte & $\mathrm{x}$ & $\mathrm{x}$ & $\mathrm{x}$ & $\mathrm{x}$ \\
\hline Medikamentenanamnese & $\mathrm{x}$ & $\mathrm{x}$ & $\mathrm{x}$ & $\mathrm{x}$ \\
\hline NIHSS & $\mathrm{x}$ & $\mathrm{x}$ & $\mathrm{x}$ & $\mathrm{x}$ \\
\hline $\mathrm{mRS}$ & $\mathrm{x}$ & $\mathrm{x}$ & $\mathrm{x}$ & $\mathrm{x}$ \\
\hline $\begin{array}{l}\text { 10-Tage-Langzeit- } \\
\text { EKG* }\end{array}$ & $\mathrm{x}$ & $\mathrm{x}$ & $\mathrm{x}$ & \\
\hline 12-Kanal-EKG & $\mathrm{x}$ & & & $\mathrm{x}$ \\
\hline SIS-16 & $\mathrm{x}$ & $\mathrm{x}$ & & $\mathrm{x}$ \\
\hline
\end{tabular}




\begin{tabular}{|l|l|l|l|l|}
\hline Visite & V0 & V1 & V2 & V3 \\
\hline HADS & $\mathrm{x}$ & $\mathrm{x}$ & & $\mathrm{x}$ \\
\hline EQ5D & $\mathrm{x}$ & $\mathrm{x}$ & $\mathrm{x}$ & $\mathrm{x}$ \\
\hline Gesundheitsökonomie & $\mathrm{x}$ & & $\mathrm{x}$ & $\mathrm{x}$ \\
\hline
\end{tabular}

*nur Patienten in der Interventionsgruppe

\subsection{Follow-Up-Untersuchungen}

Für Patienten beider Randomisierungsgruppen fanden drei Folge-Untersuchungen statt (Follow-Ups): Nach 90, 180 und 360 Tagen.

Alle erhobenen Daten wurden im Anschluss ebenfalls in die elektronische Datenbank übertragen.

\subsubsection{V1: 90-Tage-Follow-Up}

Nach 90 Tagen ( \pm 14 Tage) fand bei beiden Randomisierungsgruppen die erste Follow-UpUntersuchung statt. Bei Patienten der Holter-Monitoring-Gruppe wurde ein 10-TageLangzeit-EKG abgeleitet, welches die Patienten der Usual-Care-Gruppe nicht erhielten.

Weiterhin wurden folgende Untersuchungen durchgeführt:

Von jedem Patienten wurde erfragt, ob seit der letzten Visite im Rahmen der Studie Vorhofflimmern bzw. -flattern neu diagnostiziert wurde und/oder einer der folgenden Endpunkte auftrat:

- Zerebrale Ischämie

- Systemische Embolie

- Myokardinfarkt

- Schwere Blutung

- Revaskularisation (ACB, PCI, peripher, cerebrovaskulär)

Des Weiteren wurden der BNP-Wert bestimmt, der mRS-Score, der NIHSS-Score und die Fragebögen SIS-16, EQ5D erhoben und die momentan eingenommenen Medikamente dokumentiert, um Hinweise auf ein vom Hausarzt diagnostiziertes Vorhofflimmern zu erhalten. 


\subsubsection{V2: 180-Tage-Follow-Up}

Nach 180 Tagen ( \pm 14 Tage) fand bei beiden Randomisierungsgruppen die zweite FollowUp-Untersuchung statt. Bei Patienten der Holter-Monitoring-Gruppe wurde erneut ein 10Tage-Langzeit-EKG abgeleitet. Auch hier wurden Endpunkte (siehe 2.4.1), Medikamente, modified Rankin Scale, NIHSS-Score, der Fragebogen EQ5D und die Inanspruchnahme des Gesundheitssystems (Fragebogen Gesundheitsökonomie, siehe Anhang Abb. 12) erfasst.

\subsubsection{V3: 360-Tage-Follow-Up}

Nach 360 Tagen ( \pm 30 Tage) fand bei beiden Randomisierungsgruppen die zweite FollowUp-Untersuchung statt. Abschließend wurden auch hier die Endpunkte aus 2.4.1 erhoben, wobei kein Langzeit-EKG mehr abgeleitet wurde. Stattdessen erfolgte ein 12-Kanal-EKG. Es wurden die Fragebögen zur Lebensqualität (HADS, SIS-16, EQ5D) und die Inanspruchnahme des Gesundheitssystems (Fragebogen Gesundheitsökonomie) erfasst.

\subsection{Langzeit-Elektrokardiogramm}

\subsubsection{Aufzeichnung des Langzeit-EKGs}

Für die Aufzeichnung wurde routinemäßig das 2-Kanal-Holter EKG-Gerät CardioMem $3000 \circledast$ der Firma Getemed, Teltow, Germany verwendet (siehe Abb. 4). 


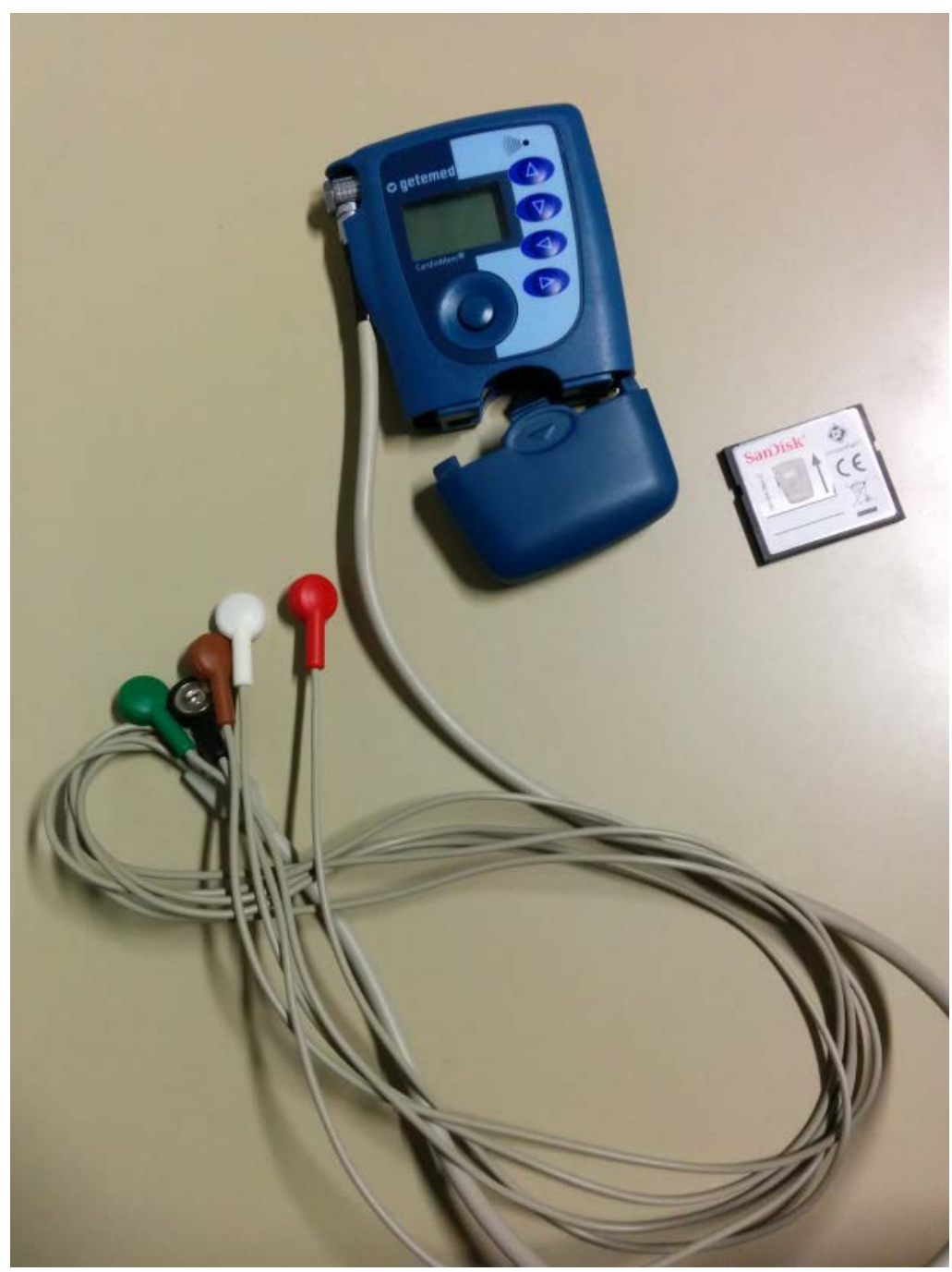

Abbildung 4: Getemed-Langzeit-EKG-Gerät

\subsubsection{Alternatives Aufzeichnungsgerät: Zenicor}

Patienten, die das Tragen eines Langzeit-EKGs ablehnten, wurde ein alternatives Aufzeichnungsgerät (Zenicor-EKG® ${ }^{\circledR}$ Zenicor, Stockholm, Schweden) angeboten (siehe Abb. 6). Dies besitzt ein integriertes GSM/GPRS-Modem, welches für die Datenübertragung genutzt wird. Die Stromversorgung erfolgt über drei 1,5V AA Batterien. Die Patienten wurden angewiesen, das Gerät mehrfach täglich - allerdings mindestens zwei Aufzeichnungen von Episoden täglich - für eine Dauer von zehn Tagen und vor allem bei kardialen Symptomen wie beispielsweise Palpationen einzusetzen. Das Aufzeichnen einer Episode erfolgte über das Auflegen beider Daumen für jeweils 30 Sekunden auf die Kontakte des Geräts. 
Abb. 5 zeigt das Zenicor-Gerät.

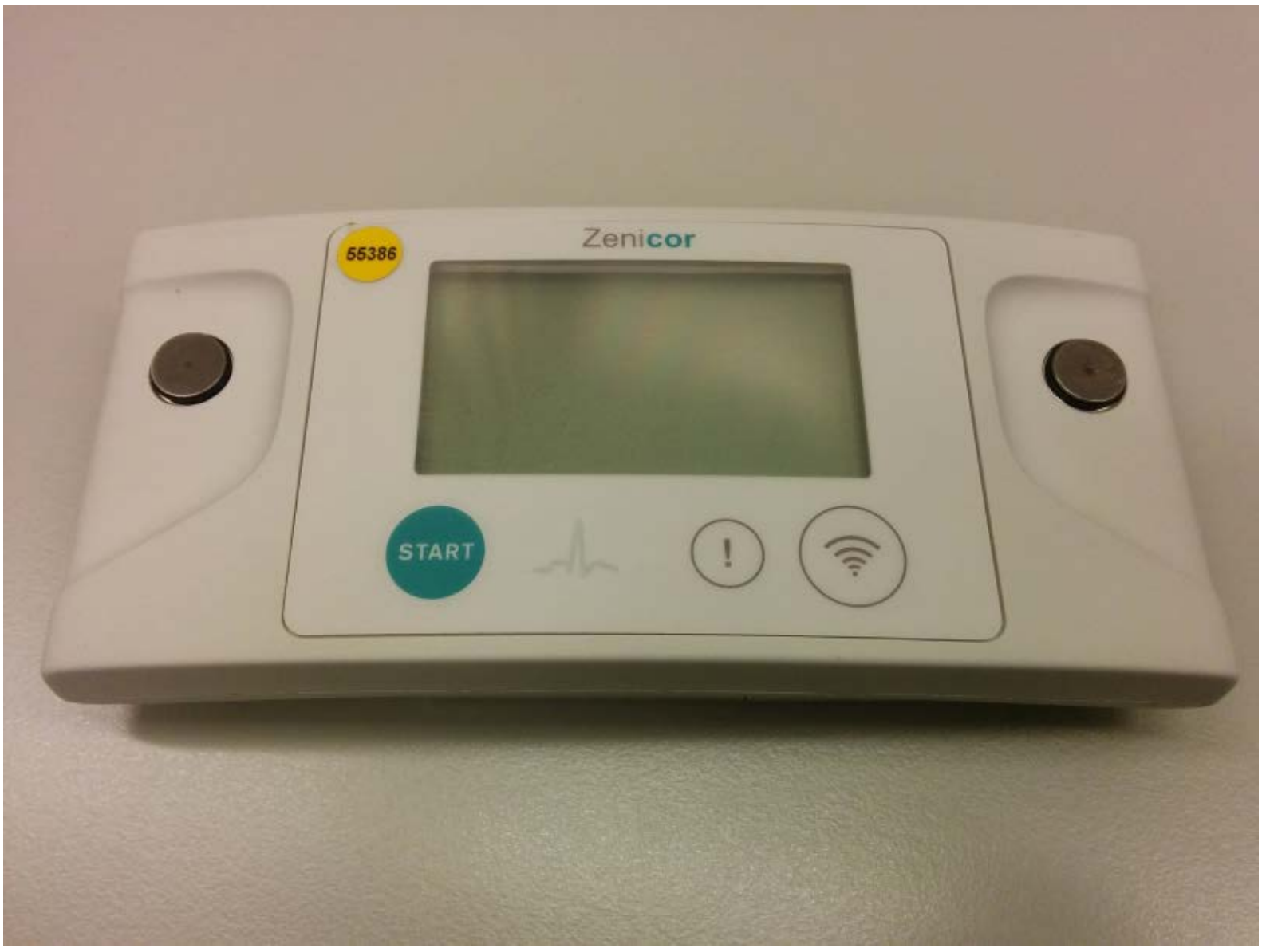

Abbildung 5: Die Benutzung des Zenicor-Gerätes erfolgt über das Auflegen beider Daumen für jeweils 30 Sekunden auf die runden Kontaktstellen an beiden Seiten.

\subsubsection{Auswertung der Aufzeichnungen}

Zur Auswertung der Langzeit-EKG-Aufzeichnungen der Getemed-Geräte wurde die CardioDay-Software (Version 2.4, Getemed) verwendet. Die Analyse folgte einem standardisierten Protokoll: Zunächst wurden jeweils 24-Stunden-Intervalle durch die Software analysiert, anschließend wurde nach einem halbautomatischen Algorithmus vorgegangen:

Alle durch die Software erkannten supraventrikulären Extrasystolen (SVES), Arrhythmien, supraventrikuläre Tachykardien und sonstige ventrikuläre Events wie z. B. ventrikuläre Extrasystolen (VES) wurden durch speziell geschulte Study Nurses ausgewertet. Die Erfassung durch die Software ermöglichte zusätzlich eine quantitative Bestimmung. Intervalle, in denen eine erhöhte Artefakt-Rate oder vermehrt SVES auftraten, wurden manuell ausgewertet, um eine sichere Detektion von Vorhofflimmern/-flattern zu gewährleisten.

Zur Auswertung der Zenicor-Aufzeichnungen wurden die Patientendaten über das ZenicorGerät direkt an die firmeneigene Software geschickt, woraufhin die Aufzeichnungen durch unsere Study Nurses ausgewertet wurden. Auch hier wurden wie in der CardioDay- 
Software SVES, VES, Salven und Arrhythmien bzw. evtl. Vorhofflimmern ausgewertet. Aufgrund der Kürze der Aufzeichnungen waren hier jedoch weitere Auswertungen und Einteilungen hinsichtlich Extrasystolen, Arrhythmien oder Tachykardie-Episoden wie in der CardioDay-Auswertung nicht sinnvoll resp. möglich.

Aufzeichnungen mit Verdacht auf vorliegendes Vorhofflimmern wurden zur Adjudikation an die Zentrale für Klinische Studien in Würzburg gegeben.

\subsection{Votum der Ethikkommission}

Find-AFrandomised ist vor Beginn von der Ethikkommission der Medizinischen Fakultät der Universität Göttingen (Antragsnummer: 15/2/13) genehmigt worden.

\subsection{Statistische Auswertung}

Allen Analysen wurde das Intention-to-treat-Prinzip zugrunde gelegt, welches besagt, dass alle randomisierten Patienten in der Gruppe analysiert werden, zu der sie randomisiert wurden.

Die Evaluation der Patientencharakteristika in den beiden Randomisierungsgruppen diente zur Überprüfung einer gleichmäßigen Verteilung der Variablen in den beiden Gruppen. Eine Überprüfung der Randomisierung erfolgte mittels univariater Analyse als Vergleich zwischen beiden Randomisierungsgruppen.

Anschließend erfolgten multivariable Analysen. Zielparameter für die binär logistischen Regressionsmodelle war die Detektion von Vorhofflimmern. Hierzu wurde die binäre Variable für die Gruppenzuteilung eingeschlossen sowie alle Variablen, für welche die univariate Analyse zuvor einen statistisch signifikanten Unterschied zwischen beiden Randomisierungsarmen gezeigt hatte.

Ziel dieses Teils der statistischen Datenevaluation war der Vergleich beider Randomisierungsarme in Bezug auf die Detektion von Vorhofflimmern. Für beide Randomisierungsgruppen resultieren Odds, die als Odds Ratio mit Konfidenzintervall und p-Wert verglichen werden können. Der Verständlichkeit halber wird der englische Begriff „Odds“ im Folgenden mit dem Begriff „Wahrscheinlichkeit“ gleichgesetzt. 
Im zweiten Teil der statistischen Datenauswertung erfolgte eine Analyse von Prädiktoren für das Auftreten von Vorhofflimmern zunächst unabhängig und anschließend abhängig von der Gruppenzuteilung.

Zunächst erfolgte eine univariate Analyse zur Detektion statistisch signifikanter Prädiktoren. Expositionsvariablen waren hierbei alle Randomisierungsvariablen sowie die Gruppenzuteilung. Zielparameter war eine binäre Variable für die Detektion von Vorhofflimmern.

Kategoriale Variablen wurden mittels Chi²$^{2}$-Test verglichen. Für kontinuierliche Variablen erfolgte ein Test auf Normalverteilung mittels Shapiro-Wilk-Test und abhängig davon entweder ein Wilcoxon-rank-sum-Test (=Mann-Whitney-U-Test) oder der t-Test.

Es folgte eine multivariable Analyse als binäres logistisches Regressionsmodell mit dem Zielparameter Vorhofflimmern. Eingeschlossen wurde zunächst der Faktor Gruppenzuteilung. Weiterhin wurden für die Analyse der Gesamtkohorte univariat signifikante Variablen sowie für die Subgruppenanalyse Variablen mit $\mathrm{p}<0,1$ in Betracht gezogen und nach aufsteigendem p-Wert in das Modell integriert, sodass zunächst die Variable mit dem kleinsten p-Wert eingeschlossen wurde.

Im Anschluss wurden multiplikative Interaktionen zwischen den statistisch signifikanten Prädiktoren überprüft.

Diskriminierung und Kalibrierung des multivariablen Modells wurden mittels ReceiverOperating-Characteristic-Kurve (ROC) und Hosmer-Lemeshow-goodness-of-fit-Test evaluiert.

Die Fläche unter der ROC-Kurve ist ein Maß für die diagnostische Leistungsfähigkeit eines Tests und kann Werte zwischen 0 und 1 annehmen. Einen Wert von 0,5 hätte ein Test, der rein zufällig Patienten mit und ohne Vorhofflimmern richtig analysiert. Einen Wert von 1 hätte ein Test, der die VHF-Patienten von denen ohne die Herzrhythmusstörung perfekt unterscheiden kann. Je höher der Wert ist, den die Fläche unter der ROC-Kurve annimmt, desto akkurater misst der Test (Park et al. 2004)

In der gesamten Arbeit wurden kontinuierliche Werte als Mittelwert \pm Standardabweichung (SD) angegeben bzw. abweichend davon wurden Scores (mRS, NIHSS, CHADS) an ihrem jeweiligen Median dichotomisiert. Eine Ausnahme bildet die Baseline-Tabelle: Hier wurde nur der NIHSS-Score dichotomisiert angegeben. Kategoriale Variablen wurden als absolute Anzahl (n) und Prozent angegeben. 
Für die multivariable Analyse wurden die univariat signifikanten Variablen in Betracht gezogen und nach aufsteigendem p-Wert in das Modell integriert, sodass zunächst die Variable mit dem kleinsten p-Wert eingeschlossen wurde.

Patienten, bei denen Werte einer Subgruppenvariable nicht zur Verfügung standen, wurden von der jeweiligen Analyse ausgeschlossen. Die entsprechende Anzahl von fehlenden Werten wurde bei jeder Analyse gesondert aufgeführt.

Es wurde angenommen, dass $\mathrm{p}<0,05$ ein statistisch signifikantes Niveau anzeigt. Alle aufgeführten Werte sind zweiseitig.

Alle statistischen Analysen wurden durchgeführt mit R (Version 3.3.2, R Core Development Team, Vienna, Austria) und RStudio (Version 1.0.136, RStudio, Inc., Boston, MA, USA). 


\section{ERGEBNISSE}

\subsection{Patientenkollektiv}

Es wurden 2848 Patienten gescreent (Zeitraum 08. Mai 2013 bis 31. August 2014), die mit einem ischämischen Schlaganfall und einem Alter >60 Jahren hospitalisiert wurden. Davon erfüllten 402 Patienten die Einschlusskriterien und gaben ihre Zustimmung zur Studienteilnahme. Abb. 13 im Anhang zeigt die Gründe für eine Nicht-Teilnahme der gescreenten Patienten für die beiden größten Rekrutierungszentren der Studie, welche zusammen 251 Patienten einschlossen.

Der erste Patient wurde am 08. Mai 2013 und der letzte Patient am 27. August 2014 randomisiert. Vier Patienten wurden fälschlicherweise randomisiert und mussten nachträglich aufgrund nicht erfüllter Einschlusskriterien bzw. bestehender Ausschlusskriterien aus der Studie ausgeschlossen werden. Von den verbleibenden 398 Patienten waren 200 der Interventionsgruppe zugeteilt worden und 198 der Kontrollgruppe (siehe Abb. 6, Wachter et al. 2017). 200 erhielten dementsprechend ein Langzeit-EKG, während 198 ein 24Stunden-EKG erhielten.

357 Patienten (89,7\%) nahmen die zweite Follow-Up-Untersuchung nach sechs Monaten (primärer Endpunkt nach sechs Monaten) wahr.

Aus der Interventionsgruppe konnten 177 Patienten (88,5\%) über sechs Monate nachverfolgt werden, 23 (11,5\%) schieden aus unterschiedlichen Gründen aus: Fünf Patienten (2,5\%) starben, 17 (8,5\%) entzogen ihr Einverständnis, und ein Patient (0,5\%) konnte nicht nachverfolgt werden, da kein Kontakt mehr hergestellt werden konnte („Lost to FollowUp“).

Aus der Kontrollgruppe konnten 180 Patienten (90,9\%) über sechs Monate nachverfolgt werden, 18 (9,1\%) schieden aus unterschiedlichen Gründen aus: sechs Patienten (3,0\%) starben, 12 (12,1\%) entzogen ihr Einverständnis.

318 Patienten (79,9\%) nahmen die dritte Follow-Up-Untersuchung nach zwölf Monaten wahr. Die letzte 12-Monats-Follow-Up-Untersuchung des letzten Patienten fand am 16. September 2015 statt.

Die Studie endete regelrecht.

Das mediane Alter der Studienpopulation ( \pm Standardabweichung) betrug $73 \pm 7$ Jahre (Streuungsbreite 60-96 Jahre). 60\% $(\mathrm{n}=238)$ der Patienten waren männlich. Die mediane Zeit zwischen Beginn der Symptome und Randomisierung betrug drei Tage (IQR 2;5). 
Die Diagnose der zerebralen Insulte wurde von den für die Station des zertifizierten Stroke Units zuständigen Ärzten gestellt.

197 der Schlaganfälle vor Aufnahme in die Studie wurden als „kryptogen“ eingestuft und 201 als „nicht kryptogen“. Hier waren die häufigsten Einteilungen „Okklusion kleiner Gefäße“ (n=118) und „kardioembolischer Schlaganfall“ (n=75).

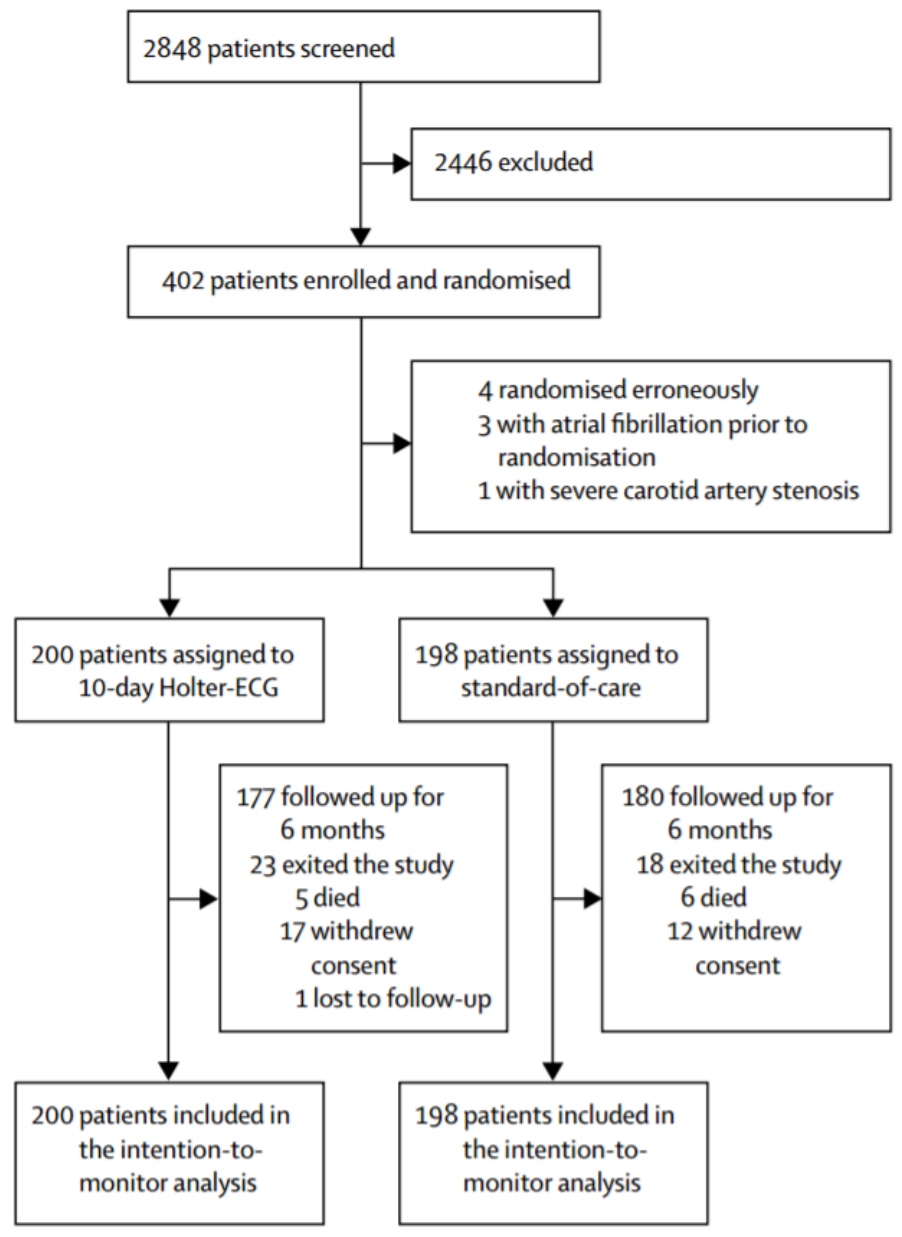

Abbildung 6: Trial Flow Diagram (mit freundlicher Genehmigung von R. Wachter)

\subsection{Primärer Endpunkt}

Innerhalb der ersten sechs Monate nach Randomisierung wurde bei 36 der 398 (9,1\%) Patienten Vorhofflimmern detektiert, davon bei 27 (13,5\%) in der Interventionsgruppe und bei 9 (4,5\%) in der Kontrollgruppe. Daraus ergibt sich eine absolute Differenz von 9,0\% (95\% Konfidenzintervall: 3,5\% - 14,6\%, p=0,002, number needed to screen 11, Wachter et al. 2017).

Keiner der Patienten, bei denen VHF neu entdeckt wurde, hatte einen erneuten Schlaganfall vor der VHF-Diagnose. Die mediane Dauer der längsten VHF-Episode betrug fünf 
Stunden (IQR: 2 Minuten; 46 Stunden), und die Zahl der detektierten VHF-Episoden lag zwischen 1 und 12 (Median: 1 Episode (IQR: 1; 2)).

In der Interventionsgruppe lag bei 1 der 27 Patienten ein Vorhofflattern vor. Bei 25 der 27 Patienten wurde das Vorhofflimmern mittels des Studien-Langzeit-EKGs festgestellt. Davon bei 18 während der ersten Langzeit-Untersuchung, bei 6 während der zweiten und bei 1 Patienten während der dritten. Bei den restlichen 2 der 27 Patienten wurde das VHF durch klinische Routineuntersuchungen zwischen der Baseline-Visite und der 3-MonatsVisite diagnostiziert.

Die Bereitschaft zum Tragen eines Langzeit-EKG-Gerätes nahm über den Verlauf der Studie kontinuierlich ab. Nach drei Monaten wurde bei 116 von 170 (68,2\%) ein 10-TageLangzeit-EKG abgeleitet und nach sechs Monaten bei 100 von 153 (65,4\%) Patienten.

Anstatt eines Langzeit-EKG-Gerätes benutzten 12 Patienten der Interventionsgruppe das alternative Zenicor-Gerät zur Visite nach drei Monaten und 16 Patienten zur Visite nach sechs Monaten. Hier wurden keine VHF-Fälle diagnostiziert.

Innerhalb der Kontrollgruppe wurden bei 7 der 9 Patienten innerhalb des ersten Monats nach dem Baseline-Schlaganfall Vorhofflimmern diagnostiziert und jeweils bei einem Patienten im dritten und sechsten Monat.

\subsection{Sekundäre Endpunkte}

Von den sekundären Studienendpunkten ist lediglich die Diagnose von Vorhofflimmern nach zwölf Monaten für diese Arbeit relevant.

Innerhalb der ersten zwölf Monate nach Randomisierung wurde bei insgesamt 39 der 398 (9,80\%) Patienten Vorhofflimmern detektiert. In der Kontrollgruppe wurden weitere 3 Patienten mit VHF diagnostiziert, während in der Interventionsgruppe keine weiteren Fälle hinzukamen. Daraus ergibt sich nach zwölf Monaten eine absolute Differenz von 7,4\% (95\% Konfidenzintervall (CI): 1,6\% - 13,2\%, p=0,02, number needed to screen 13, Wachter et al. 2017)

Bei 359 Patienten wurde während der Studienlaufzeit kein Vorhofflimmern detektiert. 


\subsubsection{Statistische Ergebnisse}

Tab. 5 zeigt die Detektion von Vorhofflimmern nach sechs und zwölf Monaten abhängig von der Randomisierungsgruppe:

Tabelle 5: Outcome Find-AFRANDOMISED

\begin{tabular}{|c|c|c|c|c|}
\hline \multicolumn{4}{|c|}{ Outcome Find-AF RANDOMISED } & \multirow[b]{2}{*}{ p-Wert } \\
\hline & \begin{tabular}{|l|} 
Total \\
$n=398$
\end{tabular} & $\begin{array}{l}\text { EKG } \\
n=198\end{array}$ & $\begin{array}{l}\text { Langzeit-EKG } \\
\mathrm{n}=\mathbf{2 0 0}\end{array}$ & \\
\hline \multicolumn{4}{|c|}{ Vorhofflimmern nach 6 Monaten } & 0,002 \\
\hline kein VHF & $362(91 \%)$ & 189 (95\%) & $173(86 \%)$ & \\
\hline VHF & $36(9 \%)$ & $9(5 \%)$ & $27(14 \%)$ & \\
\hline \multicolumn{4}{|c|}{ Vorhofflimmern nach 12 Monaten } & 0,02 \\
\hline kein VHF & $359(90 \%)$ & $186(94 \%)$ & $173(86 \%)$ & \\
\hline VHF & $39(10 \%)$ & $12(6 \%)$ & $27(14 \%)$ & \\
\hline
\end{tabular}

Zur Ermittlung der p-Werte wurde der Chi-Quadrat-Test (Chi²-Test) genutzt. Der Übersichtlichkeit halber wurde auf ganze Prozente gerundet.

Tabelle 6 stellt die Charakteristika der beiden Interventionsgruppen dar:

Tabelle 6: Baseline-Charakteristika

\begin{tabular}{|c|c|c|c|c|}
\hline & $\begin{array}{l}\text { Total } \\
n=398\end{array}$ & $\begin{array}{l}\text { Kontrollarm } \\
n=198\end{array}$ & $\begin{array}{l}\text { Interventionsarm } \\
\mathrm{n}=\mathbf{2 0 0}\end{array}$ & p-Wert \\
\hline Geschlecht & & & & 0,36 \\
\hline männlich & 238 (60\%) & $123(62 \%)$ & 115 (57\%) & \\
\hline weiblich & 160 (40\%) & 75 (38\%) & 85 (42\%) & \\
\hline Alter & $73( \pm 7)$ & $73( \pm 8)$ & $72( \pm 7)$ & 0,17 \\
\hline RR systolisch & & & & 0,41 \\
\hline MW (SD) & $160( \pm 25)$ & $158( \pm 23)$ & $161( \pm 27)$ & \\
\hline fehlend & $6(2 \%)$ & $3(2 \%)$ & $3(2 \%)$ & \\
\hline RR diastolisch & & & & 0,89 \\
\hline MW (SD) & $83( \pm 16)$ & $83( \pm 15)$ & $83( \pm 16)$ & \\
\hline fehlend & $7(2 \%)$ & $4(2 \%)$ & $3(2 \%)$ & \\
\hline Puls & & & & 0,15 \\
\hline MW (SD) & $74( \pm 14)$ & $73( \pm 14)$ & $75( \pm 13)$ & \\
\hline fehlend & $10(3 \%)$ & $4(2 \%)$ & $6(3 \%)$ & \\
\hline Hypertension & & & & 1,0 \\
\hline nein & 72 (18\%) & 36 (18\%) & $36(18 \%)$ & \\
\hline ja & 316 (79\%) & 159 (80\%) & 157 (78\%) & \\
\hline fehlend & $10(3 \%)$ & $3(2 \%)$ & $7(4 \%)$ & \\
\hline BMI & & & & 0,26 \\
\hline
\end{tabular}




\begin{tabular}{|c|c|c|c|c|}
\hline & $\begin{array}{l}\text { Total } \\
n=398\end{array}$ & $\begin{array}{l}\text { Kontrollarm } \\
n=198\end{array}$ & $\begin{array}{l}\text { Interventionsarm } \\
\mathrm{n}=\mathbf{2 0 0}\end{array}$ & p-Wert \\
\hline MW (SD) & $27( \pm 4)$ & $27( \pm 4)$ & $28( \pm 4)$ & \\
\hline fehlend & $20(5 \%)$ & $8(4 \%)$ & $12(6 \%)$ & \\
\hline \multicolumn{4}{|c|}{ Herzinsuffizienz } & 0,82 \\
\hline nein & 372 (93\%) & $186(94 \%)$ & $186(93 \%)$ & \\
\hline ja & $20(5 \%)$ & $9(5 \%)$ & $11(6 \%)$ & \\
\hline fehlend & $6(2 \%)$ & $3(2 \%)$ & $3(2 \%)$ & \\
\hline \multicolumn{4}{|c|}{ Diabetes mellitus Tyр 2} & 0,74 \\
\hline nein & 284 (71\%) & 143 (72\%) & 141 (70\%) & \\
\hline ja & 108 (27\%) & $52(26 \%)$ & $56(28 \%)$ & \\
\hline fehlend & $6(2 \%)$ & $3(2 \%)$ & $3(2 \%)$ & \\
\hline \multicolumn{4}{|c|}{ Hyperlipidämie } & 0,15 \\
\hline nein & 210 (53\%) & $95(48 \%)$ & 115 (57\%) & \\
\hline ja & $164(41 \%)$ & 87 (44\%) & 77 (38\%) & \\
\hline fehlend & $24(6 \%)$ & $16(8 \%)$ & $8(4 \%)$ & \\
\hline \multicolumn{4}{|c|}{ Koronare Herzkrankheit } & 0,27 \\
\hline nein & 325 (82\%) & 155 (78\%) & 170 (85\%) & \\
\hline ja & $61(15 \%)$ & $34(17 \%)$ & $27(14 \%)$ & \\
\hline fehlend & $12(3 \%)$ & $9(5 \%)$ & $3(2 \%)$ & \\
\hline \multicolumn{4}{|l|}{ mRS-Score } & 0,13 \\
\hline 0 & 35 (9\%) & 23 (12\%) & $12(6 \%)$ & \\
\hline 1 & $101(25 \%)$ & $53(27 \%)$ & 48 (24\%) & \\
\hline 2 & 115 (29\%) & 54 (27\%) & $61(30 \%)$ & \\
\hline 3 & $62(16 \%)$ & 33 (17\%) & 29 (14\%) & \\
\hline 4 & $62(16 \%)$ & 28 (14\%) & 34 (17\%) & \\
\hline 5 & $23(6 \%)$ & 7 (4\%) & $16(8 \%)$ & \\
\hline \multicolumn{4}{|c|}{ NIHSS Score } & 0,028 \\
\hline MW (SD) & $4( \pm 4)$ & $3( \pm 3)$ & $4( \pm 5)$ & \\
\hline fehlend & $1(0 \%)$ & $1(1 \%)$ & $0(0 \%)$ & \\
\hline \multicolumn{4}{|c|}{ CHADS Score } & 0,063 \\
\hline 2 & $54(14 \%)$ & $20(10 \%)$ & 34 (17\%) & \\
\hline 3 & 145 (36\%) & 82 (41\%) & 63 (32\%) & \\
\hline 4 & 146 (37\%) & 69 (35\%) & 77 (38\%) & \\
\hline 5 & 51 (13\%) & 27 (14\%) & 24 (12\%) & \\
\hline 6 & $2(1 \%)$ & $0(0 \%)$ & $2(1 \%)$ & \\
\hline \multicolumn{4}{|l|}{ 12cECG PQ } & 0,81 \\
\hline MW (SD) & $171( \pm 35)$ & $171( \pm 37)$ & $171( \pm 32)$ & \\
\hline fehlend & $5(1 \%)$ & $2(1 \%)$ & $3(2 \%)$ & \\
\hline \multicolumn{4}{|l|}{ BNP } & 0,36 \\
\hline MW (SD) & $68( \pm 151)$ & $62( \pm 102)$ & $74( \pm 188)$ & \\
\hline fehlend & $25(6 \%)$ & $11(6 \%)$ & $14(7 \%)$ & \\
\hline \multicolumn{4}{|l|}{ Cholesterin } & 0,20 \\
\hline MW (SD) & $199( \pm 46)$ & $197( \pm 51)$ & $201( \pm 41)$ & \\
\hline fehlend & 7 (2\%) & $1(1 \%)$ & $6(3 \%)$ & \\
\hline
\end{tabular}




\section{Total \\ $\mathrm{n}=398$ \\ Kontrollarm \\ $\mathrm{n}=198$}

LDL

MW (SD)

$124( \pm 40)$

9 (2\%)

HDL

MW (SD)

fehlend

Triglyzeride

MW (SD)

fehlend

HbA1c

MW (SD)

fehlend

CRP

MW (SD)

fehlend

Kreatinin

MW (SD)

fehlend

GFR

MW (SD)

fehlend

Zerebrale Ischämie

nie

Insult

TIA

$49( \pm 16)$

9 (2\%)

$123( \pm 44)$

2 (1\%)

$50( \pm 16)$

2 (1\%)

$142( \pm 73)$

10 (3\%)

135 ( \pm 69)

3 (2\%)

$7( \pm 7)$

20 (5\%)

7 ( \pm 7$)$

8 (4\%)

$6( \pm 16)$

3 (1\%)

$5( \pm 11)$

$0(0 \%)$

$1( \pm 1)$

4 (1\%)

$1( \pm 1)$

1 (1\%)

$71( \pm 21)$

5 (1\%)

$71( \pm 21)$

1 (1\%)

299 (75\%)

147 (74\%)

43 (22\%)

8 (4\%)

Rauchen

nein

ja

77 (19\%)

22 (6\%)

206 (52\%)

186 (47\%)

6 (2\%)

fehlend

100 (51\%)

95 (48\%)

3 (2\%)
Interventionsarm

$\mathbf{n}=\mathbf{2 0 0}$

p-Wert

0,27

$125( \pm 35)$

7 (4\%)

0,25

$49( \pm 15)$

7 (4\%)

0,047

$149( \pm 77)$

7 (4\%)

0,045

$7( \pm 7)$

12 (6\%)

0,91

$6( \pm 20)$

3 (2\%)

0,71

$1( \pm 0)$

3 (2\%)

0,84

$70( \pm 22)$

4 (2\%)

0,26

152 (76\%)

34 (17\%)

14 (7\%)

0,69

106 (53\%)

91 (46\%)

3 (2\%)

Alter in Jahren, RR in mmHg, Puls in 1/Min, 12cECG PQ in Sekunden, BNP in pg/ml, Cholesterin in mg/dl, LDL in mg/dl, HDL in mg/dl, Triglyzeride in mg/dl, HbA1c in \%, CRP in mg/dl, Kreatinin in mg/dl, GFR in $\mathrm{ml} / \mathrm{min}$

Ein statistisch signifikanter Unterschied zwischen den beiden Studienarmen zeigte sich nach Randomisierung für Triglyzeride $(p=0,047)$ und den HbA1c-Wert $(p=0,045)$. Diese beiden Werte waren demnach über Interventions- und Kontrollgruppe nicht gleich verteilt. Sie wurden später in der multivariablen Analyse erneut aufgegriffen, und es erfolgte eine statistische Adjustierung.

Der nicht dichotomisierte NIHSS-Score, für den auch die Randomisierung stattgefunden hatte, ist zwischen den Randomisierungsgruppen nicht statistisch signifikant unterschiedlich ( $p=0,3323)$ und wird daher nicht eingeschlossen. In der Baseline-Tabelle (Tab. 5) ist 
der signifikante $\mathrm{p}$-Wert gezeigt $(\mathrm{p}=0,028)$, da hier aus Gründen der Übersichtlichkeit dichotomisiert wurde.

In die multivariable Analyse wurde die Zielvariable „Vorhofflimmern nach sechs Monaten” eingeschlossen und zudem die Variablen, für die sich nach Randomisierung statistisch signifikante Unterschiede zwischen beiden Interventionsgruppen ergeben hatten: SerumTriglyzeride und Serum-HbA1c.

Tab. 7 zeigt die Odds Ratios, Konfidenzintervalle und p-Werte für die nichtgleichverteilten Variablen (6-Monats-Analyse).

Tabelle 7: Odds Ratio, Konfidenzintervall und p-Wert für nicht gleichverteilte Variablen (6-Monats-Analyse)

Odds Ratio $\quad 95 \% \quad$ Konfidenzinter- $\quad$ p-Wert vall

\begin{tabular}{lllll}
\hline Gruppenzuteilung & 24-h-EKG & 1 (Referenz) & & \\
& Langzeit & 3,368 & 1,581 bis 7,832 & 0,003 \\
\hline Triglyzeride & 0,999 & 0,993 bis 1,004 & 0,660 \\
\hline HbA1c & 0,933 & 0,658 bis 1,019 & 0,487 \\
\hline
\end{tabular}

Nach Adjustierung für die beiden nicht adäquat randomisierten Variablen zeigt sich in der multivariablen Analyse eine statistisch signifikant höhere Odds Ratio für die Detektion von VHF im Interventionsarm im Vergleich zum Kontrollarm (Vorhofflimmern nach sechs Monaten, OR=3,368 (95\% CI: 1,581-7,832; p=0,003)).

Die Wahrscheinlichkeit für die Detektion von Vorhofflimmern ist in der Langzeit-EKGGruppe 3,3fach höher als in der Standard-EKG-Gruppe. Die Detektionsrate von neu diagnostiziertem Vorhofflimmern betrug nach 6 Monaten 13,5\% (27 von 200) in der Interventionsgruppe vs. 4,5\% (9 von 198) im Kontrollarm. Das ergibt eine absolute Differenz von 9\% (95\% CI 3,5\%-14,6\%; $\mathrm{p}=0,002)$. 
Im zweiten Teil der statistischen Datenauswertung erfolgte eine Analyse von Prädiktoren für die Detektion von Vorhofflimmern unabhängig sowie abhängig von der Gruppenzuteilung.

Es wurden separate Analysen für sechs und zwölf Monate durchgeführt.

Analyse der Gesamtkohorte nach sechs Monaten:

Tab. 8 zeigt die univariate Analyse nach sechs Monaten:

Tabelle 8: Univariate Analyse der Gesamtkohorte nach sechs Monaten

\begin{tabular}{|c|c|c|c|c|}
\hline & $\begin{array}{l}\text { Total } \\
\mathrm{n}=398\end{array}$ & $\begin{array}{l}\text { keinVHF } \\
\mathrm{n}=362\end{array}$ & $\begin{array}{l}\text { VHF } \\
n=36\end{array}$ & p-Wert \\
\hline Gruppenzuteilung & & & & 0,003 \\
\hline EKG & 198 (50\%) & 189 (52\%) & $9(25 \%)$ & \\
\hline Langzeit-EKG & 200 (50\%) & 173 (48\%) & 27 (75\%) & \\
\hline Geschlecht & & & & 0,11 \\
\hline männlich & 238 (60\%) & $221(61 \%)$ & 17 (47\%) & \\
\hline weiblich & $160(40 \%)$ & 141 (39\%) & 19 (53\%) & \\
\hline Alter & $73( \pm 7)$ & $72( \pm 7)$ & $75( \pm 9)$ & 0,15 \\
\hline RR systolisch & & & & 0,23 \\
\hline MW (SD) & $160( \pm 25)$ & $159( \pm 25)$ & $166( \pm 28)$ & \\
\hline fehlend & $6(2 \%)$ & $6(2 \%)$ & $0(0 \%)$ & \\
\hline RR diastolisch & & & & 0,60 \\
\hline MW (SD) & $83( \pm 16)$ & $83( \pm 15)$ & $83( \pm 20)$ & \\
\hline fehlend & $7(2 \%)$ & $7(2 \%)$ & $0(0 \%)$ & \\
\hline Puls & & & & 0,63 \\
\hline MW (SD) & $74( \pm 14)$ & $74( \pm 14)$ & $72( \pm 10)$ & \\
\hline fehlend & $10(3 \%)$ & $10(3 \%)$ & $0(0 \%)$ & \\
\hline Hypertension & & & & 0,36 \\
\hline nein & 72 (18\%) & 68 (19\%) & $4(11 \%)$ & \\
\hline ja & 316 (79\%) & 285 (79\%) & 31 (86\%) & \\
\hline fehlend & $10(3 \%)$ & $9(2 \%)$ & $1(3 \%)$ & \\
\hline BMI & & & & 0,33 \\
\hline MW (SD) & $27( \pm 4)$ & $27( \pm 4)$ & $28( \pm 4)$ & \\
\hline fehlend & $20(5 \%)$ & $18(5 \%)$ & $2(6 \%)$ & \\
\hline Herzinsuffizienz & & & & 0,41 \\
\hline nein & 372 (93\%) & 340 (94\%) & 32 (89\%) & \\
\hline ja & $20(5 \%)$ & $17(5 \%)$ & $3(8 \%)$ & \\
\hline fehlend & $6(2 \%)$ & $5(1 \%)$ & $1(3 \%)$ & \\
\hline Diabetes mellitus Typ 2 & & & & 1,0 \\
\hline nein & 284 (71\%) & 258 (71\%) & 26 (72\%) & \\
\hline
\end{tabular}




\begin{tabular}{|c|c|c|c|c|}
\hline & $\begin{array}{l}\text { Total } \\
n=398\end{array}$ & $\begin{array}{l}\text { keinVHF } \\
\mathrm{n}=362\end{array}$ & $\begin{array}{l}\text { VHF } \\
n=36\end{array}$ & p-Wert \\
\hline ja & 108 (27\%) & 99 (27\%) & $9(25 \%)$ & \\
\hline fehlend & $6(2 \%)$ & $5(1 \%)$ & $1(3 \%)$ & \\
\hline Hyperlipidämie & & & & 0,14 \\
\hline nein & 210 (53\%) & 187 (52\%) & $23(64 \%)$ & \\
\hline ja & $164(41 \%)$ & $154(43 \%)$ & $10(28 \%)$ & \\
\hline fehlend & $24(6 \%)$ & $21(6 \%)$ & $3(8 \%)$ & \\
\hline Koronare Herzkrankheit & & & & 0,14 \\
\hline nein & 325 (82\%) & 293 (81\%) & 32 (89\%) & \\
\hline ja & 61 (15\%) & 59 (16\%) & $2(6 \%)$ & \\
\hline fehlend & $12(3 \%)$ & $10(3 \%)$ & $2(6 \%)$ & \\
\hline mRS-Score & & & & 0,007 \\
\hline hoch $(>2)$ & 147 (37\%) & 126 (35\%) & 21 (58\%) & \\
\hline niedrig $(\leq 2)$ & 251 (63\%) & $236(65 \%)$ & 15 (42\%) & \\
\hline NIHSS-Score & & & & 0,018 \\
\hline $\operatorname{hoch}(>3)$ & 145 (36\%) & 125 (35\%) & $20(56 \%)$ & \\
\hline niedrig $(\leq 3)$ & 252 (63\%) & 236 (65\%) & $16(44 \%)$ & \\
\hline fehlend & $1(0 \%)$ & $1(0 \%)$ & $0(0 \%)$ & \\
\hline CHADS-Score & & & & 0,60 \\
\hline hoch & 199 (50\%) & 179 (49\%) & $20(56 \%)$ & \\
\hline niedrig & 199 (50\%) & $183(51 \%)$ & $16(44 \%)$ & \\
\hline 12cECG PQ & & & & 0,52 \\
\hline MW (SD) & $171( \pm 35)$ & $170( \pm 34)$ & $174( \pm 41)$ & \\
\hline fehlend & $5(1 \%)$ & $4(1 \%)$ & $1(3 \%)$ & \\
\hline $\mathrm{BNP}$ & & & & 0,0002 \\
\hline MW (SD) & $68( \pm 151)$ & $57( \pm 93)$ & $178( \pm 392)$ & \\
\hline fehlend & $25(6 \%)$ & $23(6 \%)$ & $2(6 \%)$ & \\
\hline Cholesterin & & & & 0,83 \\
\hline MW (SD) & $199( \pm 46)$ & $200( \pm 47)$ & $196( \pm 35)$ & \\
\hline fehlend & $7(2 \%)$ & $6(2 \%)$ & $1(3 \%)$ & \\
\hline LDL & & & & 0,84 \\
\hline MW (SD) & $124( \pm 40)$ & $124( \pm 41)$ & $124( \pm 31)$ & \\
\hline fehlend & $9(2 \%)$ & $8(2 \%)$ & $1(3 \%)$ & \\
\hline HDL & & & & 0,79 \\
\hline MW (SD) & $49( \pm 16)$ & $49( \pm 16)$ & $48( \pm 12)$ & \\
\hline fehlend & $9(2 \%)$ & $8(2 \%)$ & $1(3 \%)$ & \\
\hline Triglyzeride & & & & 0,75 \\
\hline MW (SD) & $142( \pm 73)$ & $142( \pm 74)$ & $138( \pm 66)$ & \\
\hline fehlend & $10(3 \%)$ & $9(2 \%)$ & $1(3 \%)$ & \\
\hline HbA1c & & & & 0,60 \\
\hline MW (SD) & $7( \pm 7)$ & $7( \pm 8)$ & $6( \pm 1)$ & \\
\hline fehlend & $20(5 \%)$ & $19(5 \%)$ & $1(3 \%)$ & \\
\hline CRP & & & & 0,19 \\
\hline MW (SD) & $6( \pm 16)$ & $5( \pm 14)$ & $13( \pm 32)$ & \\
\hline
\end{tabular}




\begin{tabular}{|c|c|c|c|c|}
\hline & $\begin{array}{l}\text { Total } \\
n=398\end{array}$ & $\begin{array}{l}\text { keinVHF } \\
n=362\end{array}$ & $\begin{array}{l}\text { VHF } \\
n=36\end{array}$ & p-Wert \\
\hline fehlend & $3(1 \%)$ & $3(1 \%)$ & $0(0 \%)$ & \\
\hline Kreatinin & & & & 0,89 \\
\hline MW (SD) & $1( \pm 1)$ & $1( \pm 1)$ & $1( \pm 0)$ & \\
\hline fehlend & $4(1 \%)$ & $4(1 \%)$ & $0(0 \%)$ & \\
\hline GFR & & & & 0,47 \\
\hline MW (SD) & $71( \pm 21)$ & $71( \pm 22)$ & $68( \pm 18)$ & \\
\hline fehlend & $5(1 \%)$ & $5(1 \%)$ & $0(0 \%)$ & \\
\hline Zerebrale Ischämie & & & & 0,81 \\
\hline nie & 299 (75\%) & 270 (75\%) & 29 (81\%) & \\
\hline Insult & 77 (19\%) & 71 (20\%) & $6(17 \%)$ & \\
\hline TIA & $22(6 \%)$ & $21(6 \%)$ & $1(3 \%)$ & \\
\hline Rauchen & & & & 0,38 \\
\hline nein & 206 (52\%) & 190 (52\%) & $16(44 \%)$ & \\
\hline ja & 186 (47\%) & 166 (46\%) & 20 (56\%) & \\
\hline fehlend & $6(2 \%)$ & $6(2 \%)$ & $0(0 \%)$ & \\
\hline
\end{tabular}

Alter in Jahren, RR in mmHg, Puls in 1/Min, 12cECG PQ in Sekunden, BNP in pg/ml, Cholesterin in $\mathrm{mg} / \mathrm{dl}$, LDL in mg/dl, HDL in mg/dl, Triglyzeride in mg/dl, HbA1c in \%, CRP in mg/dl, Kreatinin in mg/dl, GFR in $\mathrm{ml} / \mathrm{min}$

Bei der univariaten Analyse nach sechs Monaten ergab sich ein statistisch signifikanter Unterschied zwischen beiden Interventionsgruppen für den BNP-Wert $(p<0,001)$, den mRS-Score $(p=0,007)$ und den dichotomisierten NIHSS $(p=0,018)$ als Prädiktoren für die Detektion von Vorhofflimmern.

Patienten mit einem erhöhten BNP-Spiegel oder einem höheren mRS-Score oder einem höheren NIHSS-Score haben in der univariaten Analyse eine höhere Wahrscheinlichkeit für die Detektion von Vorhofflimmern verglichen mit Patienten mit niedrigem BNPSpiegel, mRS-Score oder NIHSS-Score.

Im Folgenden sind die Odds Ratios sowie 95\% Konfidenzintervalle und p-Werte für die multivariable Analyse nach sechs Monaten für die Detektion von Vorhofflimmern dargestellt von Patienten mit einem erhöhten BNP-Spiegel oder einem höheren mRS-Score verglichen mit Patienten mit einem niedrigem BNP-Spiegel oder einem niedrigen mRS-Score. Da für die multivariable Analyse die Variablen nach der Reihenfolge der statistischen Signifikanz eingeschlossen wurden und die Odds Ratio für den mRS-Score bereits keinen signifikanten p-Wert mehr aufwies, wurde auf einen Einschluss des NIHSS verzichtet. 
Tab. 9 zeigt die Odds Ratios, Konfidenzintervalle und p-Werte der multivariablen Analyse nach sechs Monaten.

Tabelle 9: Odds Ratio, Konfidenzintervall und p-Wert der multivariablen Analyse nach sechs Monaten

$$
\begin{array}{ll}
\text { Odds Ratio } & \begin{array}{c}
95 \% \\
\text { vall }
\end{array}
\end{array}
$$

\begin{tabular}{|c|c|c|c|c|}
\hline \multirow[t]{2}{*}{ Gruppenzuteilung } & Kontrolle & 1 (Referenz) & & \\
\hline & Intervention & 3,547 & 1,588 bis 8,825 & 0,003 \\
\hline BNP (niedrig) & & 1 (Referenz) & & \\
\hline BNP (hoch) & & $\begin{array}{l}1,003 \\
\text { (pro Einheit) }\end{array}$ & 1,001 bis 1,006 & 0,024 \\
\hline mRS (niedrig) & & 1 (Referenz) & & \\
\hline mRS (hoch) & & 2,090 & 0,978 bis 4,527 & 0,057 \\
\hline
\end{tabular}

Pro Einheit des BNP-Werts erhöht sich die Wahrscheinlichkeit einer Detektion von Vorhofflimmern um das 1,003-fache.

Ebenso zeigt sich ein statistischer Trend ( $p=0,057)$, dass sich mit einem Anstieg des mRSScores um eine Einheit die Wahrscheinlichkeit einer Vorhofflimmerdetektion um das 2,09fache erhöht.

Es wurde keine statistische Interaktion zwischen mRS und BNP festgestellt ( $p=0,90801)$.

Die Diskriminierung des multivariablen Modells wurde mittels Receiver-OperatingCharacteristic-Kurve (ROC) evaluiert und ist als adäquat einzustufen: Es ergab sich eine ROC-Kurve mit einer AUC (Area Under Curve) von 0,749 (Abb. 7). 


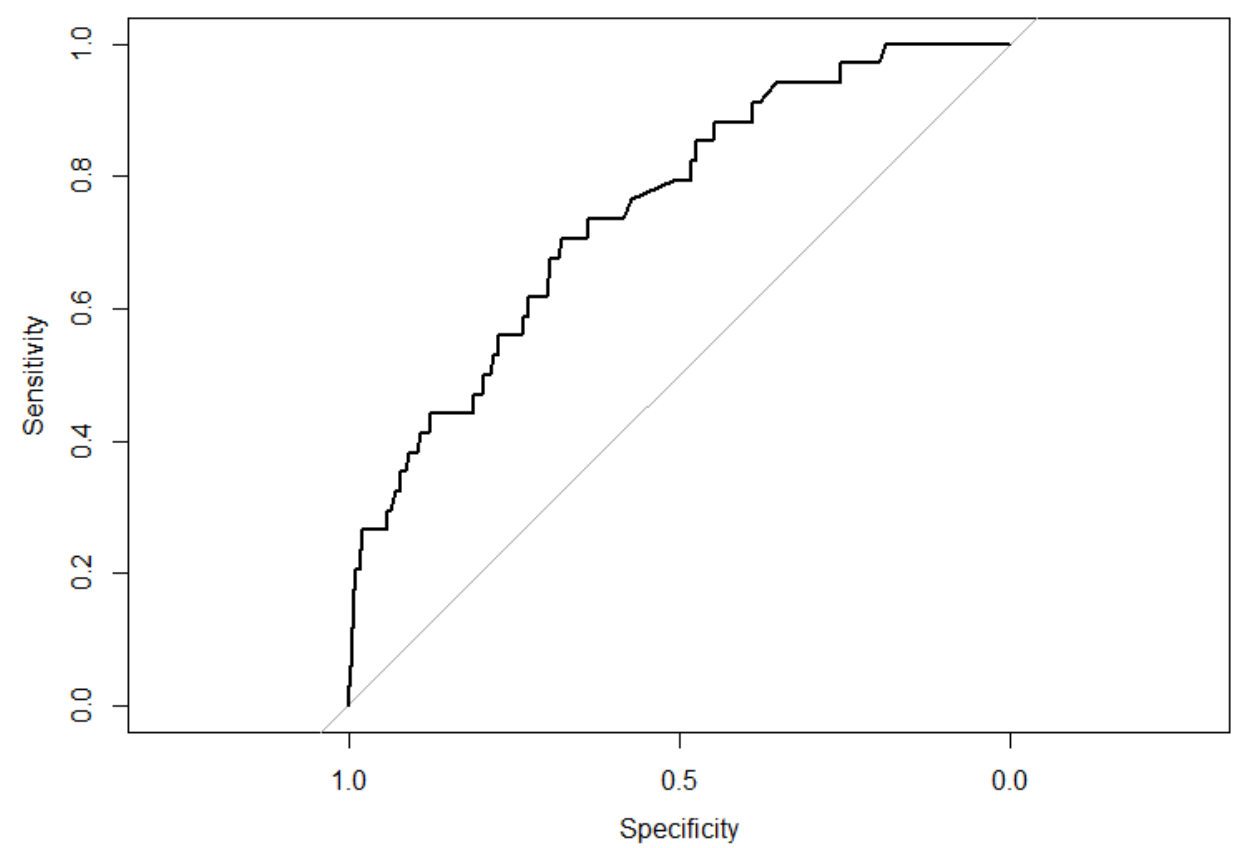

Abbildung 7: ROC-Kurve nach sechs Monaten

Die Kalibrierung des multivariablen Modells wurde mittels des Hosmer-Lemeshowgoodness-of-fit-Test evaluiert und zeigte sich ebenfalls adäquat $(\mathrm{p}=0,9205)$.

Unabhängig von der Randomisierungsgruppe und mRS-Score haben Patienten mit einem höheren BNP-Spiegel eine statistisch signifikant höhere Wahrscheinlichkeit für die Detektion von Vorhofflimmern.

\section{Analyse der Gesamtkohorte nach zwölf Monaten:}

Tab. 10 zeigt die univariate Analyse nach zwölf Monaten:

Tabelle 10: Univariate Analyse der Gesamtkohorte nach zwölf Monaten

$\begin{array}{lllll} & \begin{array}{l}\text { Total } \\ \mathbf{n = 3 9 8}\end{array} & \begin{array}{l}\text { keinVHF } \\ \mathbf{n = 3 5 9}\end{array} & \begin{array}{l}\text { VHF } \\ \mathbf{n}=\mathbf{3 9}\end{array} & \begin{array}{c}\text { p-Wert } \\ \text { Gruppenzuteilung }\end{array} \\ \begin{array}{llll}\text { EKG } \\ \text { Langzeit-EKG }\end{array} & \begin{array}{l}198(50 \%) \\ \begin{array}{l}\text { Geschlecht } \\ \text { männlich }\end{array}\end{array} & 173(50 \%) & 12(31 \%) & \\ \text { weiblich } & 238(60 \%) & 219(61 \%) & 19(49 \%) & 0,17 \\ \begin{array}{l}\text { Alter } \\ \text { RR systolisch }\end{array} & 160(40 \%) & 140(39 \%) & 20(51 \%) & \\ \text { MW (SD) } & 73( \pm 7) & 72( \pm 7) & 75( \pm 9) & 0,12 \\ \text { fehlend } & 160( \pm 25) & 159( \pm 25) & 166( \pm 27) & 0,16 \\ & 6(2 \%) & 6(2 \%) & 0(0 \%) & \end{array}$




\begin{tabular}{|c|c|c|c|c|}
\hline & $\begin{array}{l}\text { Total } \\
n=398\end{array}$ & $\begin{array}{l}\text { keinVHF } \\
\mathrm{n}=359\end{array}$ & $\begin{array}{l}\text { VHF } \\
n=39\end{array}$ & p-Wert \\
\hline RR diastolisch & & & & 0,77 \\
\hline MW (SD) & $83( \pm 16)$ & $82( \pm 15)$ & $83( \pm 19)$ & \\
\hline fehlend & $7(2 \%)$ & $7(2 \%)$ & $0(0 \%)$ & \\
\hline Puls & & & & 0,34 \\
\hline $\mathrm{MW}(\mathrm{SD})$ & $74( \pm 14)$ & $74( \pm 14)$ & $71( \pm 11)$ & \\
\hline fehlend & $10(3 \%)$ & $10(3 \%)$ & $0(0 \%)$ & \\
\hline Hypertension & & & & 0,27 \\
\hline nein & $72(18 \%)$ & 68 (19\%) & $4(10 \%)$ & \\
\hline ja & 316 (79\%) & 282 (79\%) & 34 (87\%) & \\
\hline fehlend & $10(3 \%)$ & $9(3 \%)$ & $1(3 \%)$ & \\
\hline BMI & & & & 0,33 \\
\hline MW (SD) & $27( \pm 4)$ & $27( \pm 4)$ & $28( \pm 4)$ & \\
\hline fehlend & $20(5 \%)$ & $18(5 \%)$ & $2(5 \%)$ & \\
\hline Herzinsuffizienz & & & & 0,43 \\
\hline nein & 372 (93\%) & 337 (94\%) & 35 (90\%) & \\
\hline ja & $20(5 \%)$ & $17(5 \%)$ & $3(8 \%)$ & \\
\hline fehlend & $6(2 \%)$ & $5(1 \%)$ & $1(3 \%)$ & \\
\hline Diabetes mellitus Typ 2 & & & & 0,70 \\
\hline nein & 284 (71\%) & 255 (71\%) & $29(74 \%)$ & \\
\hline ja & $108(27 \%)$ & $99(28 \%)$ & $9(23 \%)$ & \\
\hline fehlend & $6(2 \%)$ & $5(1 \%)$ & $1(3 \%)$ & \\
\hline Hyperlipidämie & & & & 0,15 \\
\hline nein & 210 (53\%) & 186 (52\%) & $24(62 \%)$ & \\
\hline ja & $164(41 \%)$ & 153 (43\%) & $11(28 \%)$ & \\
\hline fehlend & $24(6 \%)$ & $20(6 \%)$ & $4(10 \%)$ & \\
\hline Koronare Herzkrankheit & & & & 0,48 \\
\hline nein & 325 (82\%) & 292 (81\%) & 33 (85\%) & \\
\hline ja & $61(15 \%)$ & 57 (16\%) & $4(10 \%)$ & \\
\hline fehlend & $12(3 \%)$ & $10(3 \%)$ & $2(5 \%)$ & \\
\hline mRS-Score & & & & 0,024 \\
\hline hoch $(>2)$ & 147 (37\%) & 126 (35\%) & 21 (54\%) & \\
\hline niedrig ( $\leq 2)$ & 251 (63\%) & 233 (65\%) & 18 (46\%) & \\
\hline NIHSS-Score & & & & 0,054 \\
\hline hoch $(>3)$ & 145 (36\%) & 125 (35\%) & 20 (51\%) & \\
\hline niedrig $(\leq 3)$ & 252 (63\%) & 233 (65\%) & 19 (49\%) & \\
\hline fehlend & $1(0 \%)$ & $1(0 \%)$ & $0(0 \%)$ & \\
\hline CHADS-Score & & & & 0,50 \\
\hline hoch & 199 (50\%) & 177 (49\%) & 22 (56\%) & \\
\hline niedrig & 199 (50\%) & 182 (51\%) & 17 (44\%) & \\
\hline 12cECG PQ & & & & 0,42 \\
\hline MW (SD) & $171( \pm 35)$ & $170( \pm 33)$ & $177( \pm 46)$ & \\
\hline fehlend & $5(1 \%)$ & $4(1 \%)$ & $1(3 \%)$ & \\
\hline BNP & & & & $<0,0001$ \\
\hline
\end{tabular}




\begin{tabular}{|c|c|c|c|c|}
\hline & $\begin{array}{l}\text { Total } \\
\mathbf{n}=398\end{array}$ & $\begin{array}{l}\text { keinVHF } \\
\mathrm{n}=359\end{array}$ & $\begin{array}{l}\text { VHF } \\
n=39\end{array}$ & p-Wert \\
\hline MW (SD) & $68( \pm 151)$ & $57( \pm 94)$ & $170( \pm 377)$ & \\
\hline fehlend & $25(6 \%)$ & $23(6 \%)$ & $2(5 \%)$ & \\
\hline Cholesterin & & & & 0,56 \\
\hline MW (SD) & $199( \pm 46)$ & $200( \pm 47)$ & $194( \pm 37)$ & \\
\hline fehlend & $7(2 \%)$ & $6(2 \%)$ & $1(3 \%)$ & \\
\hline LDL & & & & 0,84 \\
\hline MW (SD) & $124( \pm 40)$ & $124( \pm 41)$ & $122( \pm 32)$ & \\
\hline fehlend & $9(2 \%)$ & $8(2 \%)$ & $1(3 \%)$ & \\
\hline HDL & & & & 0,93 \\
\hline MW (SD) & $49( \pm 16)$ & $49( \pm 16)$ & $48( \pm 11)$ & \\
\hline fehlend & $9(2 \%)$ & $8(2 \%)$ & $1(3 \%)$ & \\
\hline Triglyzeride & & & & 0,69 \\
\hline MW (SD) & $142( \pm 73)$ & $142( \pm 74)$ & $137( \pm 66)$ & \\
\hline fehlend & $10(3 \%)$ & $9(3 \%)$ & $1(3 \%)$ & \\
\hline HbA1c & & & & 0,84 \\
\hline MW (SD) & $7( \pm 7)$ & $7( \pm 8)$ & $6( \pm 1)$ & \\
\hline fehlend & $20(5 \%)$ & $19(5 \%)$ & $1(3 \%)$ & \\
\hline CRP & & & & 0,30 \\
\hline MW (SD) & $6( \pm 16)$ & $5( \pm 14)$ & $12( \pm 30)$ & \\
\hline fehlend & $3(1 \%)$ & $3(1 \%)$ & $0(0 \%)$ & \\
\hline Kreatinin & & & & 0,82 \\
\hline MW (SD) & $1( \pm 1)$ & $1( \pm 1)$ & $1( \pm 0)$ & \\
\hline fehlend & $4(1 \%)$ & $4(1 \%)$ & $0(0 \%)$ & \\
\hline GFR & & & & 0,30 \\
\hline MW (SD) & $71( \pm 21)$ & $71( \pm 22)$ & $67( \pm 18)$ & \\
\hline fehlend & $5(1 \%)$ & $5(1 \%)$ & $0(0 \%)$ & \\
\hline Zerebrale Ischämie & & & & 0,64 \\
\hline nie & 299 (75\%) & 267 (74\%) & 32 (82\%) & \\
\hline Insult & 77 (19\%) & $71(20 \%)$ & $6(15 \%)$ & \\
\hline TIA & $22(6 \%)$ & $21(6 \%)$ & $1(3 \%)$ & \\
\hline Rauchen & & & & 0,40 \\
\hline nein & 206 (52\%) & 188 (52\%) & 18 (46\%) & \\
\hline ja & 186 (47\%) & 165 (46\%) & $21(54 \%)$ & \\
\hline fehlend & $6(2 \%)$ & $6(2 \%)$ & $0(0 \%)$ & \\
\hline
\end{tabular}

Alter in Jahren, RR in mmHg, Puls in 1/Min, 12cECG PQ in Sekunden, BNP in pg/ml, Cholesterin in mg/dl, LDL in mg/dl, HDL in mg/dl, Triglyzeride in mg/dl, HbA1c in \%, CRP in mg/dl, Kreatinin in mg/dl, GFR in $\mathrm{ml} / \mathrm{min}$

Analog dazu ergab die univariate Analyse nach zwölf Monaten einen statistisch signifikanten Unterschied zwischen beiden Interventionsgruppen für den BNP-Wert $(p<0,0001)$ und den mRS-Score $(p=0,024)$. Der NIHSS war hier mit einem $p$-Wert von 0,054 knapp nicht mehr signifikant. 
Patienten mit einem erhöhten BNP-Spiegel oder einem höheren mRS-Score haben in der univariaten Analyse eine höhere Wahrscheinlichkeit für die Detektion von Vorhofflimmern verglichen mit Patienten mit niedrigem BNP-Spiegel oder mRS-Score.

Tab. 11 zeigt die Odds Ratios, Konfidenzintervalle und p-Werte der multivariablen Analyse nach zwölf Monaten.

Tabelle 11: Odds Ratio, Konfidenzintervall und p-Wert der multivariablen Analyse nach zwölf Monaten

\begin{tabular}{|c|c|c|c|c|}
\hline & & Odds Ratio & $\begin{array}{l}\text { 95\% Konfidenzinter- } \\
\text { vall }\end{array}$ & p-Wert \\
\hline \multirow[t]{2}{*}{ Gruppenzuteilung } & Kontrolle & 1 (Referenz) & & \\
\hline & Intervention & 2,515 & 1,208 bis 5,578 & 0,017 \\
\hline BNP (niedrig) & & 1 (Referenz) & & \\
\hline \multirow[t]{2}{*}{ BNP (hoch) } & & $1,003 \quad$ (pro & 1,001 bis 1,006 & 0,016 \\
\hline & & Einheit) & & \\
\hline mRS (niedrig) & & 1 (Referenz) & & \\
\hline mRS (hoch) & & 1,701 & 0,820 bis 3,523 & 0,150 \\
\hline
\end{tabular}

Mit einem Anstieg des BNP-Werts um eine Einheit erhöht sich die Wahrscheinlichkeit $(p=0,016)$ einer Vorhofflimmerdetektion um das 1,003fache.

Für die Auswertung des mRS-Scores ergibt sich ein $p$-Wert von $p=0,150$. Hier kann nicht mehr von einem Trend gesprochen werden.

Es wurde keine statistische Interaktion zwischen mRS und BNP festgestellt $(p=0,7676)$.

Die Diskriminierung des multivariablen Modells nach zwölf Monaten wurde mittels Receiver-Operating-Characteristic-Kurve (ROC) evaluiert und ist als adäquat einzustufen: Es ergab sich eine ROC-Kurve mit einer AUC (Area Under Curve) von 0,7056 (Abb. 8). 


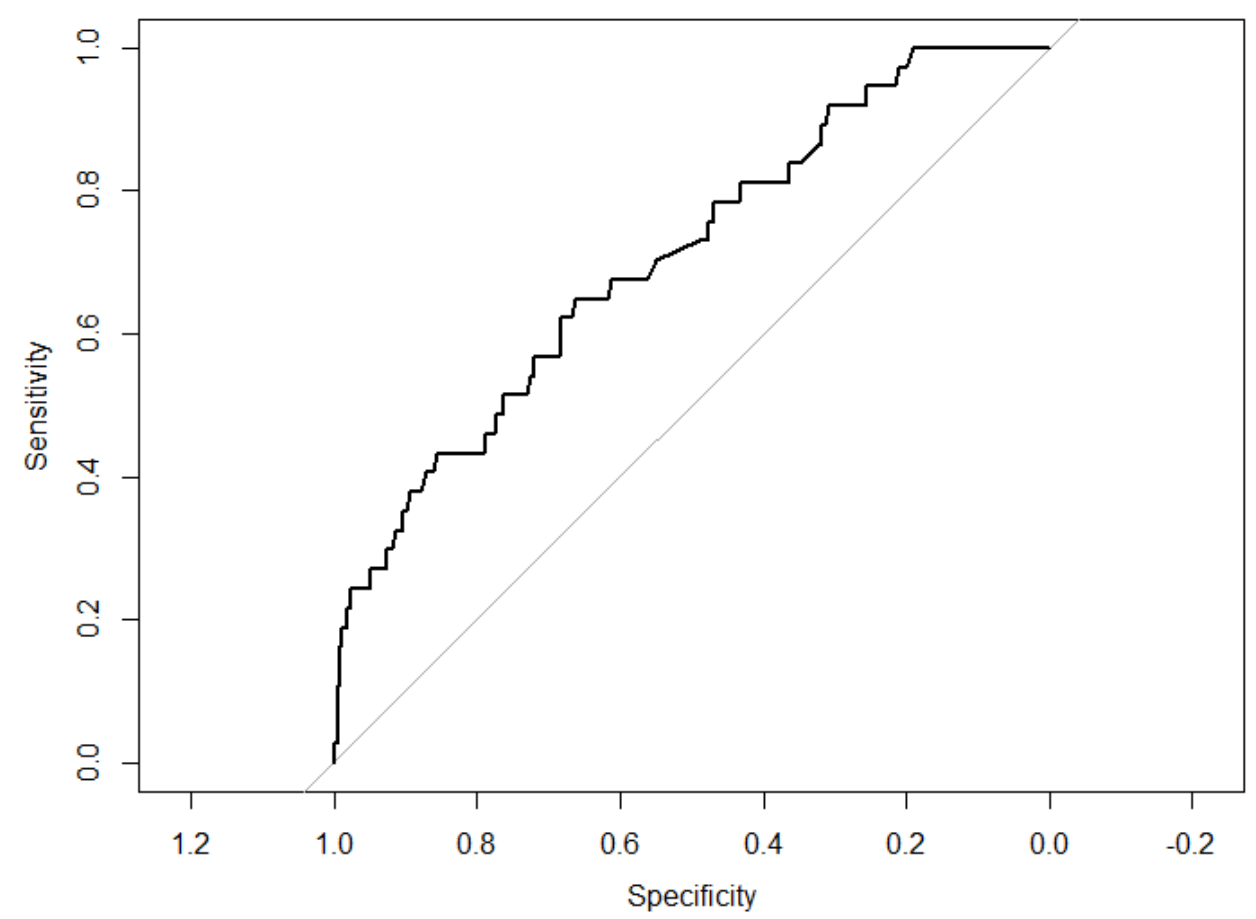

Abbildung 8: ROC-Kurve nach zwölf Monaten

Die Kalibrierung des multivariablen Modells wurde mittels des Hosmer-Lemeshowgoodness-of-fit-Test evaluiert und zeigte sich nach zwölf Monaten ebenfalls adäquat $(\mathrm{p}=0,8626)$.

\subsubsection{Separate Subgruppenanalyse - Interventionsgruppe}

In einem nächsten Schritt wurden Interventions- und Kontrollgruppe separat auf Prädiktionsfaktoren für VHF untersucht:

Tabelle 12 zeigt die univariate Subgruppenanalyse der Interventionsgruppe nach Ablauf von sechs Monaten. Nach zwölf Monaten ergeben sich hier keine neuen Werte, da die Intervention nach sechs Monaten beendet wurde.

Tabelle 12: Univariate Subgruppenanalyse der Interventionsgruppe nach sechs Monaten

$\begin{array}{clllc} & \begin{array}{l}\text { Total } \\ \mathbf{n = 2 0 0}\end{array} & \begin{array}{l}\text { keinVHF } \\ \mathbf{n = 1 7 3}\end{array} & \begin{array}{l}\text { VHF } \\ \mathbf{n = 2 7}\end{array} & \begin{array}{c}\text { p-Wert } \\ \text { Geschlecht }\end{array} \\ \text { männlich } & 115(57 \%) & 103(60 \%) & 12(44 \%) & 0,15 \\ \text { weiblich } & 85(42 \%) & 70(40 \%) & 15(56 \%) & \\ \text { Alter } & 72( \pm 7) & 72( \pm 7) & 74( \pm 10) & 0,45\end{array}$




\begin{tabular}{|c|c|c|c|c|}
\hline & $\begin{array}{l}\text { Total } \\
\mathbf{n}=\mathbf{2 0 0}\end{array}$ & $\begin{array}{l}\text { keinVHF } \\
\mathbf{n}=173\end{array}$ & $\begin{array}{l}\text { VHF } \\
\mathbf{n}=27\end{array}$ & p-Wert \\
\hline RR systolisch & & & & 0,28 \\
\hline MW (SD) & $161( \pm 27)$ & $160( \pm 26)$ & $167( \pm 30)$ & \\
\hline fehlend & $3(2 \%)$ & $3(2 \%)$ & $0(0 \%)$ & \\
\hline RR diastolisch & & & & 0,66 \\
\hline MW (SD) & $83( \pm 16)$ & $82( \pm 15)$ & $84( \pm 22)$ & \\
\hline fehlend & $3(2 \%)$ & $3(2 \%)$ & $0(0 \%)$ & \\
\hline Puls & & & & 0,67 \\
\hline MW (SD) & $75( \pm 13)$ & $75( \pm 14)$ & $73( \pm 11)$ & \\
\hline fehlend & $6(3 \%)$ & $6(3 \%)$ & $0(0 \%)$ & \\
\hline Hypertension & & & & 0,42 \\
\hline nein & $36(18 \%)$ & 33 (19\%) & $3(11 \%)$ & \\
\hline ja & 157 (78\%) & $134(77 \%)$ & $23(85 \%)$ & \\
\hline fehlend & $7(4 \%)$ & $6(3 \%)$ & $1(4 \%)$ & \\
\hline BMI & & & & 0,12 \\
\hline MW (SD) & $28( \pm 4)$ & $27( \pm 4)$ & $29( \pm 4)$ & \\
\hline fehlend & $12(6 \%)$ & $11(6 \%)$ & $1(4 \%)$ & \\
\hline Herzinsuffizienz & & & & 0,16 \\
\hline nein & 186 (93\%) & 163 (94\%) & $23(85 \%)$ & \\
\hline ja & $11(6 \%)$ & $8(5 \%)$ & $3(11 \%)$ & \\
\hline fehlend & $3(2 \%)$ & $2(1 \%)$ & $1(4 \%)$ & \\
\hline Diabetes mellitus Typ 2 & & & & 0,82 \\
\hline nein & $141(70 \%)$ & $123(71 \%)$ & $18(67 \%)$ & \\
\hline ja & $56(28 \%)$ & 48 (28\%) & 8 (30\%) & \\
\hline fehlend & $3(2 \%)$ & $2(1 \%)$ & $1(4 \%)$ & \\
\hline Hyperlipidämie & & & & 0,83 \\
\hline nein & 115 (57\%) & $100(58 \%)$ & 15 (56\%) & \\
\hline ja & 77 (38\%) & 68 (39\%) & $9(33 \%)$ & \\
\hline fehlend & $8(4 \%)$ & $5(3 \%)$ & $3(11 \%)$ & \\
\hline Koronare Herzkrankheit & & & & 0,54 \\
\hline nein & 170 (85\%) & 147 (85\%) & 23 (85\%) & \\
\hline ja & 27 (14\%) & 25 (14\%) & $2(7 \%)$ & \\
\hline fehlend & $3(2 \%)$ & $1(1 \%)$ & $2(7 \%)$ & \\
\hline mRS-Score & & & & 0,090 \\
\hline hoch & $79(40 \%)$ & 64 (37\%) & 15 (56\%) & \\
\hline niedrig & $121(60 \%)$ & 109 (63\%) & $12(44 \%)$ & \\
\hline NIHSS-Score & & & & 0,30 \\
\hline hoch (>3) & 84 (42\%) & 70 (40\%) & $14(52 \%)$ & \\
\hline niedrig $(\leq 3)$ & 116 (58\%) & 103 (60\%) & 13 (48\%) & \\
\hline CHADS-Score & & & & 0,68 \\
\hline hoch & 103 (52\%) & 88 (51\%) & 15 (56\%) & \\
\hline niedrig & 97 (48\%) & 85 (49\%) & $12(44 \%)$ & \\
\hline 12cECG PQ & & & & 0,30 \\
\hline MW (SD) & $171( \pm 32)$ & $170( \pm 30)$ & $177( \pm 45)$ & \\
\hline
\end{tabular}




\begin{tabular}{|c|c|c|c|c|}
\hline & $\begin{array}{l}\text { Total } \\
\mathbf{n}=\mathbf{2 0 0}\end{array}$ & $\begin{array}{l}\text { keinVHF } \\
\text { n=173 }\end{array}$ & $\begin{array}{l}\text { VHF } \\
n=27\end{array}$ & p-Wert \\
\hline fehlend & $3(2 \%)$ & $2(1 \%)$ & $1(4 \%)$ & \\
\hline BNP & & & & 0,0003 \\
\hline MW (SD) & $74( \pm 188)$ & $55( \pm 95)$ & $193( \pm 432)$ & \\
\hline fehlend & $14(7 \%)$ & $13(8 \%)$ & $1(4 \%)$ & \\
\hline Cholesterin & & & & 0,37 \\
\hline MW (SD) & $201( \pm 41)$ & $203( \pm 42)$ & $194( \pm 37)$ & \\
\hline fehlend & $6(3 \%)$ & $5(3 \%)$ & $1(4 \%)$ & \\
\hline LDL & & & & 0,61 \\
\hline MW (SD) & $125( \pm 35)$ & $126( \pm 36)$ & $121( \pm 30)$ & \\
\hline fehlend & $7(4 \%)$ & $6(3 \%)$ & $1(4 \%)$ & \\
\hline HDL & & & & 0,93 \\
\hline MW (SD) & $49( \pm 15)$ & $49( \pm 16)$ & $48( \pm 13)$ & \\
\hline fehlend & 7 (4\%) & $6(3 \%)$ & $1(4 \%)$ & \\
\hline Triglyzeride & & & & 0,73 \\
\hline MW (SD) & $149( \pm 77)$ & $150( \pm 78)$ & $145( \pm 72)$ & \\
\hline fehlend & 7 (4\%) & $6(3 \%)$ & $1(4 \%)$ & \\
\hline HbA1c & & & & 0,82 \\
\hline MW (SD) & $7( \pm 7)$ & $8( \pm 8)$ & $6( \pm 1)$ & \\
\hline fehlend & $12(6 \%)$ & $11(6 \%)$ & $1(4 \%)$ & \\
\hline CRP & & & & 0,060 \\
\hline MW (SD) & $6( \pm 20)$ & $5( \pm 16)$ & $16( \pm 36)$ & \\
\hline fehlend & $3(2 \%)$ & $3(2 \%)$ & $0(0 \%)$ & \\
\hline Kreatinin & & & & 0,71 \\
\hline MW (SD) & $1( \pm 0)$ & $1( \pm 0)$ & $1( \pm 0)$ & \\
\hline fehlend & $3(2 \%)$ & $3(2 \%)$ & $0(0 \%)$ & \\
\hline GFR & & & & 0,28 \\
\hline MW (SD) & $70( \pm 22)$ & $71( \pm 23)$ & $66( \pm 17)$ & \\
\hline fehlend & $4(2 \%)$ & $4(2 \%)$ & $0(0 \%)$ & \\
\hline Zerebrale Ischämie & & & & 0,70 \\
\hline nie & 152 (76\%) & 132 (76\%) & 20 (74\%) & \\
\hline Insult & 34 (17\%) & 28 (16\%) & $6(22 \%)$ & \\
\hline TIA & $14(7 \%)$ & $13(8 \%)$ & $1(4 \%)$ & \\
\hline Rauchen & & & & 0,31 \\
\hline nein & 106 (53\%) & 94 (54\%) & $12(44 \%)$ & \\
\hline ja & 91 (46\%) & 76 (44\%) & $15(56 \%)$ & \\
\hline fehlend & 3 (2\%) & $3(2 \%)$ & $0(0 \%)$ & \\
\hline
\end{tabular}

Alter in Jahren, RR in mmHg, Puls in 1/Min, 12cECG PQ in Sekunden, BNP in pg/ml, Cholesterin in mg/dl, LDL in mg/dl, HDL in mg/dl, Triglyzeride in mg/dl, HbA1c in \%, CRP in mg/dl, Kreatinin in mg/dl, GFR in $\mathrm{ml} / \mathrm{min}$

Für die Interventionsgruppe zeigte sich in der nachfolgenden multivariablen Analyse nur der BNP-Wert signifikant ( $\mathrm{p}=0,0489$; OR=1,003998, 95\% CI: 1,0009875 bis 1,0085944) 
Pro Einheit des BNP-Werts erhöht sich die Wahrscheinlichkeit einer Detektion von Vorhofflimmern um das 1,003998-fache.

\subsubsection{Separate Subgruppenanalyse - Kontrollgruppe}

Tabelle 13 zeigt die univariate Subgruppenanalyse der Kontrollgruppe nach Ablauf von sechs Monaten.

Tabelle 13: Univariate Subgruppenanalyse der Kontrollgruppe nach sechs Monaten

\begin{tabular}{|c|c|c|c|c|}
\hline & $\begin{array}{l}\text { Total } \\
\mathbf{n}=198\end{array}$ & $\begin{array}{l}\text { keinVHF } \\
n=189\end{array}$ & $\begin{array}{l}\text { VHF } \\
\mathrm{n}=9\end{array}$ & p-Wer \\
\hline Geschlecht & & & & 0,73 \\
\hline männlich & $123(62 \%)$ & $118(62 \%)$ & $5(56 \%)$ & \\
\hline weiblich & 75 (38\%) & 71 (38\%) & $4(44 \%)$ & \\
\hline Alter & $73( \pm 8)$ & $73( \pm 8)$ & $77( \pm 6)$ & 0,075 \\
\hline RR systolisch & & & & 0,80 \\
\hline MW (SD) & $158( \pm 23)$ & $158( \pm 23)$ & $161( \pm 23)$ & \\
\hline fehlend & $3(2 \%)$ & $3(2 \%)$ & $0(0 \%)$ & \\
\hline RR diastolisch & & & & 0,85 \\
\hline MW (SD) & $83( \pm 15)$ & $83( \pm 15)$ & $81( \pm 10)$ & \\
\hline fehlend & $4(2 \%)$ & $4(2 \%)$ & $0(0 \%)$ & \\
\hline Puls & & & & 0,51 \\
\hline MW (SD) & $73( \pm 14)$ & $73( \pm 14)$ & $69( \pm 7)$ & \\
\hline fehlend & $4(2 \%)$ & $4(2 \%)$ & $0(0 \%)$ & \\
\hline Hypertension & & & & 1,0 \\
\hline nein & 36 (18\%) & 35 (19\%) & $1(11 \%)$ & \\
\hline ja & 159 (80\%) & $151(80 \%)$ & $8(89 \%)$ & \\
\hline fehlend & $3(2 \%)$ & $3(2 \%)$ & $0(0 \%)$ & \\
\hline BMI & & & & 0,25 \\
\hline MW(SD) & $27( \pm 4)$ & $27( \pm 4)$ & $25( \pm 3)$ & \\
\hline fehlend & $8(4 \%)$ & $7(4 \%)$ & $1(11 \%)$ & \\
\hline Herzinsuffienz & & & & 1,0 \\
\hline nein & 186 (94\%) & 177 (94\%) & $9(100 \%)$ & \\
\hline ja & $9(5 \%)$ & $9(5 \%)$ & $0(0 \%)$ & \\
\hline fehlend & $3(2 \%)$ & $3(2 \%)$ & $0(0 \%)$ & \\
\hline Diabetes mellitus Typ 2 & & & & 0,45 \\
\hline nein & $143(72 \%)$ & $135(71 \%)$ & $8(89 \%)$ & \\
\hline ja & $52(26 \%)$ & $51(27 \%)$ & $1(11 \%)$ & \\
\hline fehlend & $3(2 \%)$ & $3(2 \%)$ & $0(0 \%)$ & \\
\hline Hyperlipidämie & & & & 0,036 \\
\hline nein & 95 (48\%) & 87 (46\%) & 8 (89\%) & \\
\hline
\end{tabular}




\begin{tabular}{|c|c|c|c|c|}
\hline & $\begin{array}{l}\text { Total } \\
\mathrm{n}=198\end{array}$ & $\begin{array}{l}\text { keinVHF } \\
\text { n=189 }\end{array}$ & $\begin{array}{l}\text { VHF } \\
\text { n=9 }\end{array}$ & p-Wert \\
\hline ja & 87 (44\%) & $86(46 \%)$ & $1(11 \%)$ & \\
\hline fehlend & $16(8 \%)$ & $16(8 \%)$ & $0(0 \%)$ & \\
\hline Koronare Herzkrankheit & & & & 0,37 \\
\hline nein & 155 (78\%) & $146(77 \%)$ & $9(100 \%)$ & \\
\hline ja & 34 (17\%) & 34 (18\%) & $0(0 \%)$ & \\
\hline fehlend & $9(5 \%)$ & $9(5 \%)$ & $0(0 \%)$ & \\
\hline mRS-Score & & & & 0,066 \\
\hline $\operatorname{hoch}(>2)$ & $68(34 \%)$ & $62(33 \%)$ & $6(67 \%)$ & \\
\hline niedrig $(\leq 2)$ & 130 (66\%) & 127 (67\%) & $3(33 \%)$ & \\
\hline NIHSS-Score & & & & 0,027 \\
\hline hoch (>3) & $61(31 \%)$ & 55 (29\%) & $6(67 \%)$ & \\
\hline niedrig $(\leq 3)$ & $136(69 \%)$ & $133(70 \%)$ & $3(33 \%)$ & \\
\hline fehlend & $1(1 \%)$ & $1(1 \%)$ & $0(0 \%)$ & \\
\hline CHADS-Score & & & & 0,74 \\
\hline hoch & $96(48 \%)$ & $91(48 \%)$ & $5(56 \%)$ & \\
\hline niedrig & $102(52 \%)$ & 98 (52\%) & $4(44 \%)$ & \\
\hline 12cECG PQ & & & & 0,63 \\
\hline MW (SD) & $171( \pm 37)$ & $171( \pm 38)$ & $164( \pm 22)$ & \\
\hline fehlend & $2(1 \%)$ & $2(1 \%)$ & $0(0 \%)$ & \\
\hline $\mathrm{BNP}$ & & & & 0,28 \\
\hline MW (SD) & $62( \pm 102)$ & $59( \pm 92)$ & $129( \pm 237)$ & \\
\hline fehlend & $11(6 \%)$ & $10(5 \%)$ & $1(11 \%)$ & \\
\hline Cholesterin & & & & 0,48 \\
\hline MW (SD) & $197( \pm 51)$ & $197( \pm 52)$ & $203( \pm 29)$ & \\
\hline fehlend & $1(1 \%)$ & $1(1 \%)$ & $0(0 \%)$ & \\
\hline LDL & & & & 0,44 \\
\hline MW (SD) & $123( \pm 44)$ & $122( \pm 44)$ & $131( \pm 32)$ & \\
\hline fehlend & $2(1 \%)$ & $2(1 \%)$ & $0(0 \%)$ & \\
\hline HDL & & & & 0,44 \\
\hline MW (SD) & $50( \pm 16)$ & $50( \pm 16)$ & $50( \pm 8)$ & \\
\hline fehlend & $2(1 \%)$ & $2(1 \%)$ & $0(0 \%)$ & \\
\hline Triglyzeride & & & & 0,54 \\
\hline MW (SD) & $135( \pm 69)$ & $136( \pm 70)$ & $117( \pm 41)$ & \\
\hline fehlend & $3(2 \%)$ & $3(2 \%)$ & $0(0 \%)$ & \\
\hline HbA1c & & & & 0,90 \\
\hline MW (SD) & $7( \pm 7)$ & $7( \pm 7)$ & $6( \pm 1)$ & \\
\hline fehlend & $8(4 \%)$ & $8(4 \%)$ & $0(0 \%)$ & \\
\hline CRP & $5( \pm 11)$ & $5( \pm 11)$ & $4( \pm 8)$ & 0,65 \\
\hline Kreatinin & & & & 0,50 \\
\hline MW (SD) & $1( \pm 1)$ & $1( \pm 1)$ & $1( \pm 0)$ & \\
\hline fehlend & $1(1 \%)$ & $1(1 \%)$ & $0(0 \%)$ & \\
\hline GFR & & & & 0,54 \\
\hline MW (SD) & $71( \pm 21)$ & $71( \pm 21)$ & $75( \pm 19)$ & \\
\hline
\end{tabular}




\begin{tabular}{|c|c|c|c|c|}
\hline & $\begin{array}{l}\text { Total } \\
n=198\end{array}$ & $\begin{array}{l}\text { keinVHF } \\
n=189\end{array}$ & $\begin{array}{l}\text { VHF } \\
n=9\end{array}$ & p-Wert \\
\hline fehlend & $1(1 \%)$ & $1(1 \%)$ & $0(0 \%)$ & \\
\hline Zerebrale Ischämie & & & & 0,29 \\
\hline nie & $147(74 \%)$ & $138(73 \%)$ & $9(100 \%)$ & \\
\hline Insult & $43(22 \%)$ & 43 (23\%) & $0(0 \%)$ & \\
\hline TIA & $8(4 \%)$ & $8(4 \%)$ & $0(0 \%)$ & \\
\hline Rauchen & & & & 0,74 \\
\hline nein & $100(51 \%)$ & 96 (51\%) & $4(44 \%)$ & \\
\hline ja & 95 (48\%) & $90(48 \%)$ & $5(56 \%)$ & \\
\hline fehlend & $3(2 \%)$ & $3(2 \%)$ & $0(0 \%)$ & \\
\hline
\end{tabular}

Alter in Jahren, RR in mmHg, Puls in 1/Min, 12cECG PQ in Sekunden, BNP in pg/ml, Cholesterin in mg/dl, LDL in mg/dl, HDL in mg/dl, Triglyzeride in mg/dl, HbA1c in \%, CRP in mg/dl, Kreatinin in mg/dl, GFR in $\mathrm{ml} / \mathrm{min}$

Für die Kontrollgruppe nach sechs Monaten zeigte sich in der nachfolgenden multivariablen Analyse nur der dichotomisierte NIHSS signifikant ( $\mathrm{p}=0,03031$; OR=4,950557, 95\% CI: 1,226646 bis 24,6464). Ein höherer NIHSS (>3) hat eine 4,9fache Wahrscheinlichkeit zu einer Detektion von VHF zu führen, wobei hier das große Konfidenzintervalls beachtet werden sollte. Die halbierte Patientenzahl und die geringe Menge an Outcomes (Detektion von VHF) führt zu instabilen Punktschätzern und daraus resultierend zu großen Konfidenzintervallen.

Eine Tendenz zur Signifikanz zeigte sich des Weiteren bei einer Hyperlipidämie ( $p=0,05238 ; O R=0,1232673,95 \%$ CI: 0,006521939 bis 0,7063714). Dies würde bei Signifikanznachweis bedeuten, dass Patienten mit Hyperlipidämie eine geringere Wahrscheinlichkeit für VHF haben.

Tabelle 14 zeigt die univariate Subgruppenanalyse der Kontrollgruppe nach zwölf Monaten:

Tabelle 14: Univariate Subgruppenanalyse der Kontrollgruppe nach zwölf Monaten

\begin{tabular}{|c|c|c|c|c|}
\hline & $\begin{array}{l}\text { Total } \\
\mathbf{n}=198\end{array}$ & $\begin{array}{l}\text { keinVHF } \\
n=186\end{array}$ & $\begin{array}{l}\text { VHF } \\
n=12\end{array}$ & p-Wert \\
\hline Geschlecht & & & & 0,77 \\
\hline männlich & 123 (62\%) & $116(62 \%)$ & 7 (58\%) & \\
\hline weiblich & 75 (38\%) & 70 (38\%) & $5(42 \%)$ & \\
\hline Alter & $73( \pm 8)$ & $73( \pm 7)$ & $77( \pm 8)$ & 0,071 \\
\hline RR systolisch & & & & 0,47 \\
\hline MW (SD) & $158( \pm 23)$ & $158( \pm 23)$ & $163( \pm 21)$ & \\
\hline fehlend & $3(2 \%)$ & $3(2 \%)$ & $0(0 \%)$ & \\
\hline
\end{tabular}


Total

$\mathrm{n}=198$

RR diastolisch

MW (SD)

Puls

MW (SD)

fehlend

Hypertension

nein

ja

fehlend

BMI

MW (SD)

fehlend

Herzinsuffizienz

nein

ja

fehlend

Diabetes mellitus Typ 2

nein

ja

fehlend

Hyperlipidämie

nein

ja

fehlend

Koronare Herzkrankheit

nein

ja

fehlend

mRS-Score

hoch $(>2)$

niedrig $(\leq 2)$

NIHSS-Score

hoch $(>3)$

niedrig ( $\leq 3)$

fehlend

CHADS-Score

hoch

niedrig

12cECG PQ

MW (SD)

fehlend

BNP

$4(2 \%)$

$3(2 \%)$

8 (4\%)

9 (5\%)

3 (2\%)

$3(2 \%)$

9 (5\%)

$1(1 \%)$

2 (1\%)

\section{keinVHF}

$n=186$

$83( \pm 15)$

$4(2 \%)$

0,17

$73( \pm 14)$

$73( \pm 14)$

$4(2 \%)$

36 (18\%)

159 (80\%)

$27( \pm 4)$

186 (94\%)

143 (72\%)

52 (26\%)

95 (48\%)

87 (44\%)

16 (8\%)

155 (78\%)

34 (17\%)

68 (34\%)

130 (66\%)

61 (31\%)

136 (69\%)

96 (48\%)

102 (52\%)

$171( \pm 37)$

VHF

$\mathrm{n}=12$

p-Wert

0,81

$83( \pm 9)$

0 (0\%)

$67( \pm 9)$

0 (0\%)

0,70

35 (19\%)

1 (8\%)

148 (80\%)

$11(92 \%)$

0 (0\%)

0,39

$26( \pm 3)$

1 (8\%)

7 (4\%)

1,00

174 (94\%)

9 (5\%)

3 (2\%)

12 (100\%)

0 (0\%)

0 (0\%)

132 (71\%)

0,19

11 (92\%)

51 (27\%)

1 (8\%)

$0(0 \%)$

0,060

9 (75\%)

2 (17\%)

1 (8\%)

1,0

10 (83\%)

2 (17\%)

0 (0\%)

9 (5\%)

0,35

62 (33\%)

$6(50 \%)$

124 (67\%)

$6(50 \%)$

0,20

55 (30\%)

6 (50\%)

130 (70\%)

$6(50 \%)$

0 (0\%)

0,56

7 (58\%)

5 (42\%)

97 (52\%)

0,91

$170( \pm 36)$

$176( \pm 50)$

2 (1\%)

0 (0\%) 


\begin{tabular}{|c|c|c|c|c|}
\hline & $\begin{array}{l}\text { Total } \\
n=198\end{array}$ & $\begin{array}{l}\text { keinVHF } \\
n=186\end{array}$ & $\begin{array}{l}\text { VHF } \\
n=12\end{array}$ & p-Wert \\
\hline MW (SD) & $62( \pm 102)$ & $59( \pm 92)$ & $116( \pm 201)$ & \\
\hline fehlend & $11(6 \%)$ & 10 (5\%) & $1(8 \%)$ & \\
\hline Cholesterin & & & & 0,99 \\
\hline MW (SD) & $197( \pm 51)$ & $198( \pm 52)$ & $194( \pm 38)$ & \\
\hline fehlend & $1(1 \%)$ & $1(1 \%)$ & $0(0 \%)$ & \\
\hline LDL & & & & 0,95 \\
\hline MW (SD) & $123( \pm 44)$ & $123( \pm 44)$ & $122( \pm 36)$ & \\
\hline fehlend & $2(1 \%)$ & $2(1 \%)$ & $0(0 \%)$ & \\
\hline HDL & & & & 0,79 \\
\hline MW (SD) & $50( \pm 16)$ & $50( \pm 16)$ & $49( \pm 7)$ & \\
\hline fehlend & $2(1 \%)$ & $2(1 \%)$ & $0(0 \%)$ & \\
\hline Triglyzeride & & & & 0,53 \\
\hline MW (SD) & $135( \pm 69)$ & $136( \pm 70)$ & $120( \pm 48)$ & \\
\hline fehlend & $3(2 \%)$ & $3(2 \%)$ & $0(0 \%)$ & \\
\hline HbA1c & & & & 0,64 \\
\hline MW (SD) & $7( \pm 7)$ & $7( \pm 8)$ & $6( \pm 1)$ & \\
\hline fehlend & $8(4 \%)$ & $8(4 \%)$ & $0(0 \%)$ & \\
\hline CRP & $5( \pm 11)$ & $5( \pm 11)$ & $3( \pm 7)$ & 0,41 \\
\hline Kreatinin & & & & 0,98 \\
\hline MW (SD) & $1( \pm 1)$ & $1( \pm 1)$ & $1( \pm 0)$ & \\
\hline fehlend & $1(1 \%)$ & $1(1 \%)$ & $0(0 \%)$ & \\
\hline GFR & & & & 0,94 \\
\hline MW (SD) & $71( \pm 21)$ & $71( \pm 21)$ & $70( \pm 21)$ & \\
\hline fehlend & $1(1 \%)$ & $1(1 \%)$ & $0(0 \%)$ & \\
\hline Zerebrale Ischämie & & & & 0,16 \\
\hline nie & 147 (74\%) & 135 (73\%) & $12(100 \%)$ & \\
\hline Insult & $43(22 \%)$ & 43 (23\%) & $0(0 \%)$ & \\
\hline TIA & $8(4 \%)$ & $8(4 \%)$ & $0(0 \%)$ & \\
\hline Rauchen & & & & 1,0 \\
\hline nein & 100 (51\%) & 94 (51\%) & $6(50 \%)$ & \\
\hline ja & 95 (48\%) & 89 (48\%) & $6(50 \%)$ & \\
\hline fehlend & $3(2 \%)$ & $3(2 \%)$ & $0(0 \%)$ & \\
\hline
\end{tabular}

Alter in Jahren, RR in mmHg, Puls in 1/Min, 12cECG PQ in Sekunden, BNP in pg/ml, Cholesterin in mg/dl, LDL in mg/dl, HDL in mg/dl, Triglyzeride in mg/dl, HbA1c in \%, CRP in mg/dl, Kreatinin in mg/dl, GFR in $\mathrm{ml} / \mathrm{min}$

Für die Kontrollgruppe nach zwölf Monaten zeigten sich in der multivariablen Analyse keine signifikanten Variablen.

Tendenziell signifikant ist hier das Alter ( $\mathrm{p}=0,0923$; $\mathrm{OR}=1$ 1,069616, 95\% CI: 0,9899123 bis 1,1601194). Bei Signifikanznachweis würde dieses Ergebnis bedeuten, dass ältere Pati- 
enten pro Lebensjahr eine knapp 7\% höhere Wahrscheinlichkeit für die Detektion von VHF haben.

Die Diskriminierung mittels Receiver-Operating-Characteristic-Kurve (ROC) testet die Genauigkeit, wie gut die Intervention mittels Langzeit-EKGs Patienten mit und Patienten ohne Vorhofflimmern unterscheidet.

Für die 6-Monats-Analyse ergibt sich für die Area Under Curve (AUC) ein Wert von 0,749 und für die Analyse nach zwölf Monaten ein Wert von 0,706.

\subsection{BNP-Bestimmung}

Bei Baseline (drei Tage nach Schlaganfall) und bei der 3-Monats-Visite wurde der BNPWert bestimmt. Tab. 15 zeigt - aufgeteilt nach Interventions- und Kontrollgruppe - die Anzahl der Patienten, bei denen der BNP-Wert bestimmt wurde:

Tab. 15: BNP-Bestimmung aufgeteilt nach Randomisierungsgruppe:

\begin{tabular}{|l|l|l|l|l|}
\hline Zeitpunkt & \multicolumn{3}{|l|}{ Interventionsgruppe (n=200) } & \multicolumn{2}{l|}{ Kontrollgruppe (n=198) } \\
\hline & $\begin{array}{l}\text { BNP } \\
\text { bestimmt }\end{array}$ & $\begin{array}{l}\text { BNP nicht } \\
\text { bestimmt }\end{array}$ & $\begin{array}{l}\text { BNP } \\
\text { bestimmt }\end{array}$ & $\begin{array}{l}\text { BNP nicht } \\
\text { bestimmt }\end{array}$ \\
\hline Baseline & $186(93 \%)$ & $14(7 \%)$ & $187(94 \%)$ & $11(6 \%)$ \\
\hline 3-Monats-Visite & $140(70 \%)$ & $60(30 \%)$ & $143(72 \%)$ & $55(28 \%)$ \\
\hline
\end{tabular}


Abb. 9 zeigt die Verteilung von BNP-Werten bei der Baseline-Untersuchung sowie nach der 3-Monats-Visite mittels einer Boxplot-Darstellung.

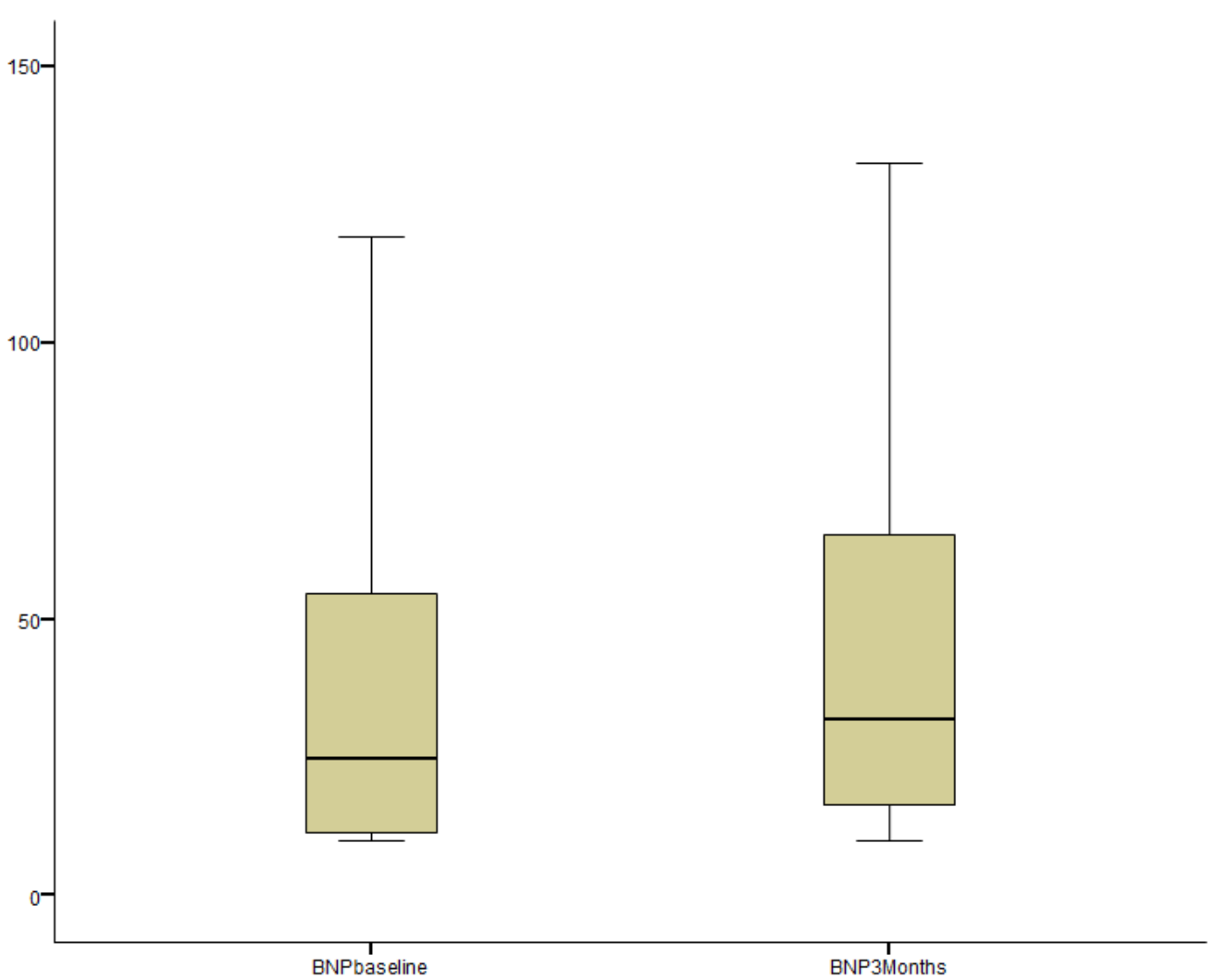

Abb. 9: Verteilung von BNP-Werten bei Baseline und 3-Monats-Visite

Der Median des BNP-Werts bei der Baseline-Untersuchung lag bei 25 ng/ml (11;56). Der Median des BNP-Werts bei der 3-Monats-Visite betrug 32 (16;66). Für diese Analyse wurden die BNP-Werte derjenigen Patienten berücksichtigt, von denen Messwerte zu beiden Zeitpunkten vorlagen $(n=275, p=0,006)$.

Die Werte lagen nach drei Monaten höher als zum Zeitpunkt der Baseline. 


\section{DISKUSSION}

Die vorliegende Arbeit erbrachte die folgenden Haupterkenntnisse:

1. BNP ist ein unabhängiger Prädiktor von VHF in der Interventionsgruppe, jedoch nicht in der Kontrollgruppe.

2. BNP ist ein unabhängiger Prädiktor von VHF in der Gesamtkohorte.

3. Ein erhöhter mRS-Score $(>2)$ und NIHSS-Score $(>3)$ sowie fortgeschrittenes Alter weisen tendenziell auf eine höhere Detektionsrate für VHF hin.

Es erfolgte zunächst ein Vergleich zwischen beiden Randomisierungsgruppen und eine Adjustierung auf eventuelle Unterschiede in klinischen Charakteristika zwischen den Gruppen.

Es zeigte sich daraufhin eine zeitliche Abhängigkeit der unterschiedlichen Detektionsverfahren. Nach der multivariablen Analyse nach sechs Monaten beträgt die Odds Ratio 3,5. Das kann derart interpretiert werden, dass die Wahrscheinlichkeit in den ersten sechs Monaten Vorhofflimmern zu detektieren in der Interventionsgruppe 3,5fach höher war als in der Kontrollgruppe. Diese Wahrscheinlichkeit sinkt jedoch bei der Betrachtung der Analyse nach zwölf Monaten. Hier beträgt die Odds Ratio 2,5.

Hierfür gibt es zwei Gründe: Zum einen erhielten beide Gruppen in den Monaten 7-12 die gleiche Behandlung, d. h. ein nach sechs Monaten bestehender Unterschied wurde verringert, und zum anderen waren im Kontrollarm mehr Patienten mit unentdecktem VHF, so dass dort eine höhere Chance bestand, VHF zu detektieren.

Im zweiten Teil der statistischen Datenauswertung erfolgte eine Analyse von Prädiktoren für das Auftreten von Vorhofflimmern unabhängig sowie zusätzlich abhängig von der Gruppenzuteilung. Es wurde eine Analyse für sechs und zwölf Monate durchgeführt.

\subsection{BNP als Prädiktor von Vorhofflimmern}

Nach der multivariablen Analyse der Gesamtkohorte nach sechs Monaten zeigte sich eine Signifikanz für den BNP-Wert ( $\mathrm{p}=0,024)$. Die Odds Ratio des BNP-Werts nach der multivariablen Analyse beträgt 1,003. Dies bedeutet, dass mit jedem Anstieg des BNP-Werts pro Einheit die Wahrscheinlichkeit um 0,3\% steigt, Vorhofflimmern zu detektieren. 
Dieser Faktor erscheint zunächst gering, jedoch gewinnt der Effekt an Bedeutung aufgrund der großen Spannbreite des BNP-Werts.

Der diskriminatorische Wert von BNP war jedoch lediglich moderat (AUC 0,749), was den Effekt einschränkt.

Nach der multivariablen Analyse der Gesamtkohorte nach zwölf Monaten zeigte sich ebenfalls eine Signifikanz für den BNP-Wert $(\mathrm{p}=0,016)$. Die Odds Ratio des BNP-Werts beträgt - wie bei der 6-Monats-Analyse - 1,003.

Ähnliche Ergebnisse fanden Wachter et al. 2012 in der Vorgängerstudie zu FindAF RANDOMISED. Sie konnten zeigen, dass BNP ein unabhängiger Prädiktor bei Patienten mit zerebraler Ischämie mit durch Holter-EKG entdecktem paroxysmalem Vorhofflimmern ist. Okada et al. 2010 und Shibazaki et al. 2012 zeigten ebenfalls, dass eine Erhöhung von BNP die Wahrscheinlichkeit einer Vorhofflimmern-Diagnose bei Patienten mit einem akuten ischämischen Schlaganfall deutlich erhöht.

Im Gegensatz dazu konnten Rossi et al. 2000 die Rolle von BNP als unabhängigem Marker für VHF nicht bestätigen. Mögliche Erklärungen hierfür sind die relativ geringe Patientenzahl $(n=100)$ sowie die Tatsache, dass sich die Studie nicht auf Diagnostik nach zerebraler Ischämie fokussierte.

Auch bei der separaten Subgruppenanalyse ließ sich im Interventionsarm nach der multivariablen Analyse eine Signifikanz für den BNP-Wert in der Prädiktion von VHF feststellen ( $\mathrm{p}=0,0489)$, nicht jedoch im Kontrollarm. Dies könnte ein Hinweis darauf sein, dass das Holter-EKG spezifisch Vorhofflimmern bei Patienten mit erhöhten BNP-Werten diagnostizierte, welches im Falle der Durchführung eines 24-Stunden-Standard-EKGs übersehen worden wäre.

Des Weiteren können verschiedenste Komorbiditäten zu hoher Variabilität der BNP-Werte führen. Ebenfalls beitragen zu einer hohen Variabilität der BNP-Werte kann der Zeitpunkt der Blutabnahme: Durch die hämodynamischen Veränderungen eines Insultes kann es an sich bereits zur einer BNP-Wert-Erhöhung kommen. Wachter et al. 2012 zeigten, dass es in den ersten Stunden nach einer zerebralen Ischämie zu einem Anstieg von BNP kommt. Tomita et al. 2008 konnten zeigen, dass es einen Monat nach einem Schlaganfall wieder zu einem signifikanten Abfall von BNP kommt. 
Wie in Abb. 9 gezeigt, liegt bei Find-AF RANDomised der BNP-Wert nach drei Monaten jedoch sogar höher als in der Baseline-Untersuchung. Dies weist darauf hin, dass bereits drei Tage nach Schlaganfall keine relevante BNP-Ausschüttung aus dem Hirn mehr vorliegt, denn in diesem Falle wären die Werte nach drei Tagen höher als nach drei Monaten gewesen.

Unsere Ergebnisse sind in Konkordanz mit der Mehrzahl der Literaturergebnisse (Okada et al. 2010; Shibazaki et al. 2012; Wachter et al. 2012).

Daraus leitet sich die Schlussfolgerung ab, dass eine routinemäßige Bestimmung des BNPWerts bei zerebralen Ischämien unklarer Genese in Erwägung gezogen werden sollte. Patienten mit einem erhöhten BNP-Wert sind dementsprechend vorrangig EKGUntersuchungen zuzuführen, da die frühe und präzise Detektion von VHF und die damit verbundene Therapieeinleitung maßgeblich für die sekundäre Prävention von weiteren Insulten sind.

\subsection{Weitere Prädiktoren von Vorhofflimmern}

\subsubsection{Analyse der Gesamtkohorte}

In der multivariablen Analyse nach sechs und nach zwölf Monaten zeigte sich lediglich der BNP-Wert signifikant. Nach sechs Monaten zeigte sich zudem ein Trend bei erhöhtem mRS- und erhöhtem NIHSS-Score.

Ähnliche Ergebnisse konnten Kimura et al. 2005, Figueiredo et al. 2014, Li et al. 2015 und Yiin et al. 2017 zeigen: Der NIHSS-Score bei Krankenhauseinweisung war bei Patienten mit akuter zerebraler Ischämie in der Vorhofflimmern-Gruppe größer als in der Gruppe ohne VHF - der Schlaganfall ging also mit einer schwereren funktionellen Einschränkung einher. Li et al. 2015 zeigten zusätzlich noch mittels eines höheren mRS-Scores in der VHF-Gruppe ein schlechteres Outcome gegenüber Patienten ohne Vorhofflimmern.

Lin et al. 1996 nutzten zur Bestimmung der Schwere des Schlaganfalls den Barthel-Index und nicht den NIHSS- oder mRS-Score und konnten zeigen, dass Patienten mit Vorhofflimmern höhere funktionelle Einschränkungen besaßen als Patienten ohne Vorhofflimmern. Der Barthel-Index wurde durch unsere Studie zwar nicht erhoben, aber NIHSS- und mRS-Score bilden ebenfalls funktionelle Einschränkungen nach zerebraler Ischämie ab. 
Ein schlechteres (Short-Term-)Outcome nicht bestätigen konnten Sant'Angelo et al. 2012. Sie nutzten die Functional Independence Measure-Skala (FIM), um die funktionelle Einschränkung bei Schlaganfallpatienten zu messen. Ein signifikanter Unterschied zwischen Patienten mit und ohne Vorhofflimmern konnte weder bei Aufnahme noch Entlassung gezeigt werden. Eine mögliche Erklärung hierfür könnte eine Vorauswahl der Patienten gewesen sein: In die Studie wurden lediglich Patienten aus Intensivrehabilitationszentren eingeschlossen.

\subsubsection{Interventionsgruppe}

In der Interventionsgruppe wurde lediglich eine Analyse nach sechs Monaten durchgeführt, da die Intervention nach sechs Monaten endete und kein weiterer Patient mit Vorhofflimmern diagnostiziert wurde.

Nach sechs Monaten zeigte sich lediglich BNP als unabhängiger Prädiktor in der Interventionsgruppe (s. Kap. 4.1).

\subsubsection{Kontrollgruppe}

In der Kontrollgruppe wurde in der multivariablen Analyse nach sechs Monaten ein erhöhter NIHSS-Score $(>3)$ als unabhängiger Prädiktor für Vorhofflimmern identifiziert ( $p=0,03031)$, was sich jedoch nicht in der Gesamtkohorte widerspiegelte. Eine mögliche Erklärung hierfür könnte sein, dass von dem Holter-EKG auch weniger gravierende Fälle von Vorhofflimmern diagnostiziert wurden, die von der Routine-Diagnostik nicht entdeckt worden wären und mit einem niedrigeren NIHSS-Score einhergehen. Eine andere Erklärung hierfür könnte sein, dass die Erhebung der Scores von einem wechselnden Studienpersonal und nicht von einem unabhängigen Komitee durchgeführt wurde. Darüber hinaus könnte es sich auch um einen zufälligen Effekt handeln, da die Richtung des Effekts in der Gesamtkohorte gleich war und der p-Wert in der univariaten Analyse an der Signifikanzgrenze $(p=0,054)$ lag.

Es ist durchaus möglich, dass unsere Studie ein zu kleines Patientenkollektiv besaß und bei einem größeren Patientenkollektiv für diese Werte eine Signifikanz hätte nachgewiesen werden können. Find-AFrandomised konnte demzufolge nicht sicher zeigen, dass unab- 
hängig von der gewählten EKG-Untersuchung bei Patienten mit erhöhtem mRS-Score oder NIHSS-Wert eine höhere Wahrscheinlichkeit für die Detektion von Vorhofflimmern besteht, obwohl dies in der Literatur bereits zahlreich belegt wurde. Wie bereits oben erwähnt, ist auch hier möglich, dass die Bestimmung der Scores durch ein unabhängiges Komitee zu anderen Ergebnissen hätte führen können.

In unseren Ergebnissen gab es in der Kontrollgruppe zudem eine Tendenz zu höherer VHF-Detektion bei Fehlen einer Hyperlipidämie $(\mathrm{p}=0,05238)$ nach sechs Monaten sowie bei fortgeschrittenem Alter ( $p=0,0923$ ) nach zwölf Monaten. Für die Variable Alter ist ein Zusammenhang biologisch plausibel und gut belegt (Campbell et al. 1974; Jorgensen et al. 1996; Benjamin et al. 1998; Go et al. 2001; Dang et al. 2002). Ein protektiver Effekt einer Hyperlipidämie als Schutz vor VHF ist bisher nicht bekannt. Hier ist das Vorliegen eines Fehlers 1. Art bei einer Auftrittsrate von 5\% wahrscheinlich, da es auch in der Literatur hierzu keinen Anhalt gibt.

Neben BNP, NIHSS- und mRS-Score kommen weitere Variablen als potentielle Prädiktoren für VHF in Frage:

Die Vorgängerstudie zu Find-AFRANDOMISED, welche ebenfalls an der Uniklinik Göttingen durchgeführt wurde, konnte ein fortgeschrittenes Alter, anhaltende Symptome >24 Stunden und eine koronare Herzkrankheit als signifikante voneinander unabhängige Prädiktionsfaktoren für paroxysmales Vorhofflimmern identifizieren (Wohlfahrt et al. 2014). Bei FindAFRANDOMISED konnte von diesen Faktoren keiner als signifikant bestätigt werden, wobei die Variable anhaltende Symptome $>24$ Stunden bereits eines der Einschlusskriterien für Find-AF RANDOMISED war und daher ein direkter Vergleich erschwert ist.

NT-proBNP ist ein weiteres natriuretisches Peptid, das mit BNP verwandt ist und mit Vorhofflimmern assoziiert wird. NT-proBNP ist das terminale Segment des BNP (Maries und Manitiu 2013). Hier liegt eine enge Korrelation zwischen beiden Peptiden nahe und der diagnostische Wert wurde durch einige Studien erfasst (Patton et al. 2009; Wachter et al. 2012; Rodríguez-Yáñez et al. 2013; Seegers et al. 2015).

Longstreth et al. 2013 nutzten die Bestimmung von NT-proBNP bei Patienten mit ischämischen Schlaganfällen und angenommener nicht-kardialer Ursache, um eine Subgruppe an Patienten zu identifizieren, die von einer oralen Antikoagulation mehr profitieren als von 
einer Plättchenhemmung. In den Studien, auf denen die Ergebnisse basieren, fand jedoch keine Rhythmusüberwachung statt, welche ein potentiell zugrunde liegendes paroxysmales VHF hätte identifizieren können. Angenommen bei Patienten mit erhöhten NT-proBNPSpiegeln lag ein paroxysmales VHF vor, würde dies die Schlaganfall-Reduktion durch Warfarin im Vergleich zur Plättchenhemmung erklären.

Wachter et al. 2012 bestimmten bei Patienten mit akuter zerebraler Ischämie BNP, NTproBNP und NT-proANP im Hinblick auf Prädiktion von paroxysmalem VHF. In der multivariablen Analyse zeigte sich allerdings nur BNP als unabhängiger Prädiktor (Wachter et al. 2012).

In unserer Studie wurde nur BNP bestimmt, weshalb über NT-proBNP keine Aussage getroffen werden kann.

Bisher hat keine randomisierte Studie differentiell VHF-Prädiktion in Abhängigkeit vom Detektionsverfahren analysiert. Diese Analyse ist jedoch für den Alltag hochrelevant, denn es sollen ja Parameter definiert werden, um Patienten zu identifizieren, die besonders von den jeweiligen Detektionsverfahren profitieren.

\subsection{Stärken und Limitationen der Studie}

Die Stärken von Find-AFrandomised sind die mit 402 eingeschlossenen Patienten verhältnismäßig hohe Patientenzahl (vgl.: in der Vorgängerstudie Find-AF wurden 281 Patienten eingeschlossen; Wohlfahrt et al. 2014) und das multizentrische randomisierte Studiendesign.

Dennoch sollten die Ergebnisse von Find-AF RANDOMISED vor dem Hintergrund der Limitationen der Studie betrachtet werden: Sie fand an vier Zentren in Deutschland statt mit einem überwiegenden Anteil ethnisch kaukasischer Patienten. Die Ergebnisse könnten in anderen Ländern, anderen Gesundheitssystemen und einer anderen ethnischen Zusammensetzung der Patienten abweichen.

Das Langzeit-EKG ist eine vergleichsweise einfache Maßnahme zur Früherkennung von Vorhofflimmern. Ein jedoch gravierender Nachteil sind die Umstände, welche das Tragen des Gerätes mit sich bringt. Über die Laufzeit der Studie hinweg nahm die Bereitschaft, 
das EKG über zehn Tage zu tragen, deutlich ab (68,2\% bei der zweiten Follow-Up-Visite und 65,4\% bei der dritten, vgl. Kap. 3.2). Eine Visite in unserer Studienambulanz ließ sich gelegentlich nur erreichen, wenn den Patienten versichert wurde, dass kein Langzeit-EKG mehr abgeleitet wird bzw. nur für eine geringere Zeitdauer.

Möglicherweise würden eine höhere Compliance oder angenehmere Umstände (z. B. aufklebbare Pflaster, T-Shirts, andere Wearables) eine erhöhte Detektionsrate von Vorhofflimmern bewirken.

Die Anamnesedaten (insbesondere von Scores wie dem NIHSS oder mRS) sind während der Laufzeit der Studie durch wechselndes Studienpersonal erhoben worden. Möglicherweise würden höhere Konstanz des Personals und eine spezielle Schulung zu abweichenden Ergebnissen führen.

Des Weiteren wurde als Einschlusskriterium für die Studie ein Alter 60+ gewählt. Da die Prävalenz von Vorhofflimmern mit dem Alter ansteigt, würde eine andere Altersstruktur der Patienten die Ergebnisse verändern. Darüber hinaus können keine Aussagen über jüngere Patienten getroffen werden.

\subsection{Klinische Relevanz und Ausblick}

Die Ergebnisse zeigen eine gute Prädiktion von Vorhofflimmern für die nach einer zerebralen Ischämie gemessenen BNP-Werte. Die routinemäßige Bestimmung von BNP und die anschließend gezielte Überwachung des Herzrhythmus mittels intensivierten EKGs bei diesen Patienten könnten helfen, frühzeitig ein eventuelles paroxysmales Vorhofflimmern zu diagnostizieren und eine Therapie einzuleiten. Ob es noch weitere klinische Prädiktoren gibt, die eventuell in Kombination mit der Bestimmung von BNP die Prädiktion von Vorhofflimmern verbessern und ab welchem BNP-Wert eine Diagnostik sinnvoll ist, müssen weitere Studien zeigen.

Da fortgeschrittenes Alter und Schwere des Schlaganfalls nach zerebralem Insult, wie oben gezeigt, mit einer höheren Wahrscheinlichkeit eines Vorliegens von VHF einhergehen, sollte explizit in Konstellationen, in denen diese Risikofaktoren vermehrt kombiniert auftreten, wie bspw. Rehabilitationszentren, ein intensiviertes Monitoring im Sinne eines Langzeit-EKGs in Erwägung gezogen werden. Weiterhin könnten Vorselektionen von Pa- 
tienten durch die Bestimmung von zusätzlichen Variablen, wie beispielsweise echokardiographischen Risikofaktoren und/oder BNP-Wert, durchgeführt werden. 


\section{ZUSAMMENFASSUNG}

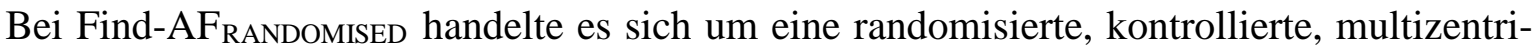
sche Studie. Patienten, die sich mit einem zerebralen Insult vorstellten und die Einschlusskriterien erfüllten, wurden in eine von zwei Gruppen randomisiert: Eine Interventionsgruppe, in der die Patienten bei Studienaufnahme und nach drei und sechs Monaten ein Langzeit-EKG über jeweils zehn Tage trugen, und eine Kontrollgruppe, in welcher die Patienten lediglich den aktuellen Standard of Care - ein 24-Stunden-EKG - erhielten.

In der Interventionsgruppe konnte nach Adjustierung auf Unterschiede in den klinischen Charakteristika eine 3,3fach höhere Wahrscheinlichkeit, Vorhofflimmern zu diagnostizieren, nachgewiesen werden als in der Kontrollgruppe. Hier ist ein deutlicher Unterschied in der Detektionsrate zu verzeichnen.

Die Hauptfragestellungen dieser Arbeit bestanden darin, ob es einen Unterschied in der Prädiktion von Vorhofflimmern gibt - diagnostiziert durch Holter-EKG vs. 24-StundenStandard-EKG - sowie in der Frage nach spezifischen Prädiktionsfaktoren von Vorhofflimmern mittels eines verlängerten Monitorings.

Diese Arbeit zeigt, dass ein Unterschied in der Prädiktion von Vorhofflimmern nach zerebraler Ischämie - diagnostiziert durch Holter-EKG vs. Usual Care - besteht:

- BNP ist ein Prädiktor von VHF in der Interventionsgruppe, jedoch nicht in der Kontrollgruppe, wobei BNP auch ein unabhängiger Prädiktor von Vorhofflimmern in der Gesamtkohorte ist.

- Es konnte für die Interventionsgruppe kein spezifischer Prädiktionsfaktor festgestellt werden, der sich nicht auch in der Gesamtkohorte prädiktiv für Vorhofflimmern zeigte.

- $\quad$ Ein erhöhter NIHSS-Score (>3) war in der Kontrollgruppe nach sechs Monaten ein unabhängiger Prädiktor für VHF.

Vor Schwierigkeiten stellte uns die Compliance der Patienten, das Langzeit-EKG zu tragen. Gegebenenfalls kann ein verbessertes Tragesystem mit angenehmeren EKGElektrodenaufklebern in Kombination mit einer ausführlichen Aufklärung der Patienten diese Bereitschaft erhöhen. 
Diese Arbeit zeigt zum einen den hohen Nutzen des Langzeit-EKGs, welches als verhältnismäßig einfache und wenig aufwendige diagnostische Detektionsmöglichkeit von Vorhofflimmern den Anteil kryptogener Insulte bei nur geringen Nachteilen reduzieren kann, und zum anderen, dass die routinemäßige Bestimmung von BNP bei Patienten mit zerebraler Ischämie in Erwägung gezogen werden sollte.

Im Falle des BNP sind weitere, tiefergehende Studien zu empfehlen, die sich eingehend mit Abnahmezeitpunkt, Anzahl von Abnahmen und Höhe der Werte beschäftigen.

Ein erhöhter mRS-Score und NIHSS-Score erreichten nicht in allen Analysen statistische Signifikanz. Hier sind weitere Studien mit höheren Patientenzahlen zu empfehlen, um einen Signifikanznachweis zu erbringen. 


\section{ANHANG}

\section{modified Rankin Scale (mRS-Score)}

Der Score misst physische Einschränkungen nach zerebralem Insult (Saver et al. 2010).

\section{6 tot}

5 starke Beeinträchtigung: ans Bett gebunden, inkontinent und ständige Aufmerksamkeit erforderlich

4 moderat starke Beeinträchtigung: unfähig ohne Unterstützung zu gehen und körperlichen Bedürfnissen nachzukommen

3 moderate Beeinträchtigung: Unterstützung erforderlich, jedoch fähig alleine zu gehen

2 geringe Beeinträchtigung: unfähig alle Gewohnheiten durchzuführen, jedoch nicht auf fremde Unterstützung angewiesen

1 keine signifikante Beeinträchtigung: trotz Symptomen fähig zur Durchführung aller Pflichten und Gewohnheiten

\section{$0 \quad$ keine Beeinträchtigung}

Abb. 10: modified Rankin Scale (mRS-Score), nach Saver et al. 2010 


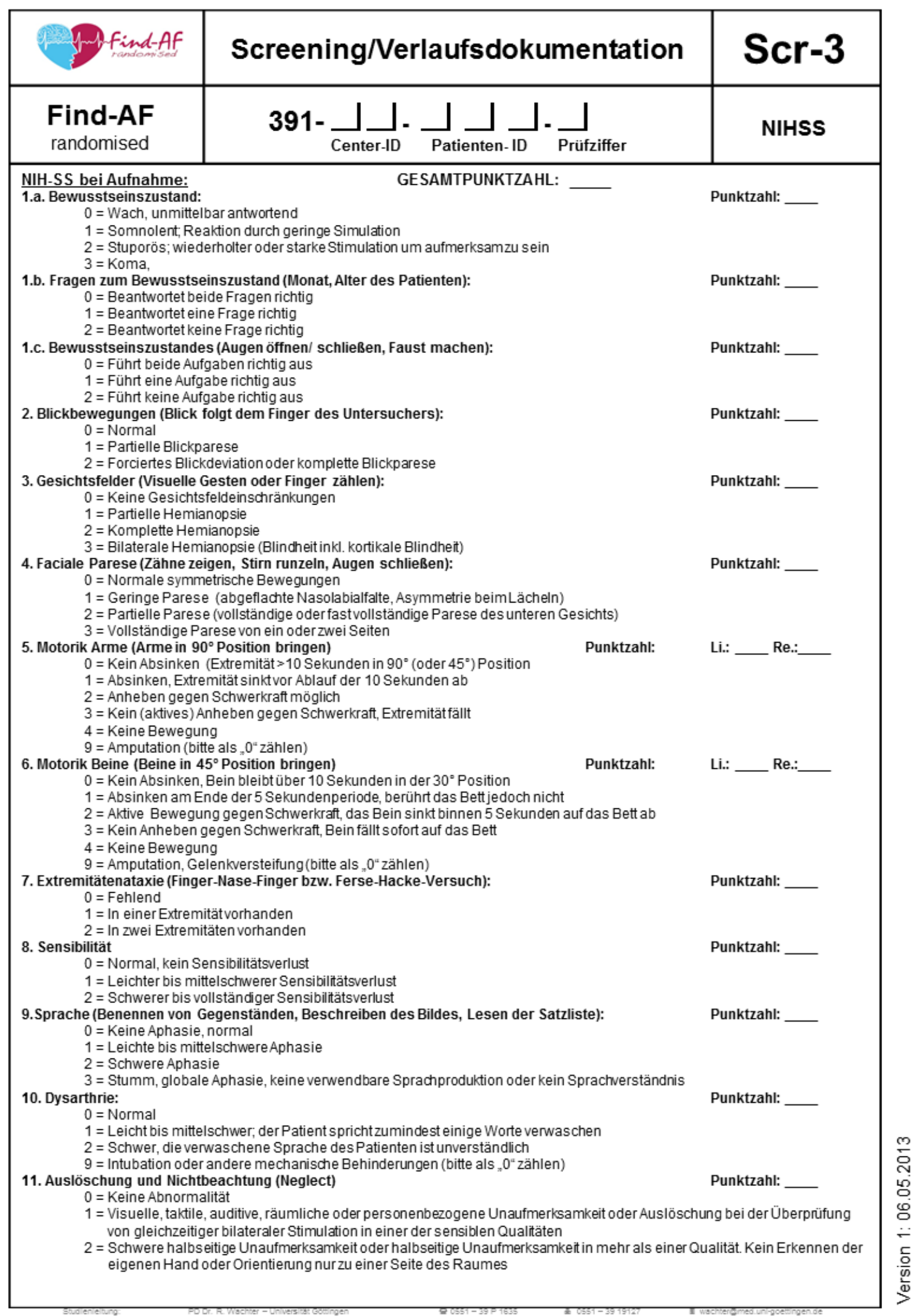

Abb. 11: National Institutes of Health Stroke Scale 
Fragebogen Gesundheitsökonomie:

\begin{tabular}{|c|c|c|}
\hline Inf find-Af & 180-Tage-Visite (V2) & V2-6 \\
\hline $\begin{array}{l}\text { Find-AF } \\
\text { randomised }\end{array}$ & 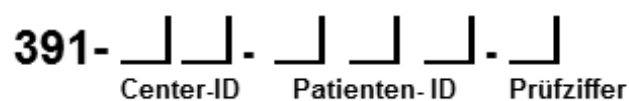 & $\begin{array}{l}\text { GESUNDHEITS } \\
\text { OKKONOMIE }\end{array}$ \\
\hline
\end{tabular}

Bitte für alle Patienten ausfüllen:

Pflegebedürftigkeit:

Liegteine Pflegebedürttigkeitvor?

Besteht/änderte sich die Pflegebedürtigkeitdurch den Schlaganfall?
Aktuelle Pflegestufe? $\quad \square 1 \quad \square 2 \quad \square 3 \quad \square 3+$ (Härtefall)

Liegteine erheblich eingeschränkte Alltagskompetenz vor $\left({ }_{x}\right.$ Stufe $\left.0^{\circ}\right)$ ?

$\square$ ja $\quad$ nein

$\square$ Pflegegeld: seit__ Monaten

$\square$ Pflegedienst seit__ Monaten

$\square$ Betreuungsgeld: seit___Monaten

Verminderte Erwerbsfähigkeit:

Liegteine verminderte Erwerbsfähigkeitvor? a ja $\quad$ nein

Bestehtländerte sich die Erwerbsunfähigkeit durch einen Schlaganfall? ? ja $\quad$ nein

Aktuelle Erwerbsminderung:
$\square$ teilweise
seit
(dd.mm.jijj); mögliche Arbeitszeit:
$\mathrm{h} / \mathrm{Tag}$
口 vollstāndig
seit (dd.mm.jijJ) 
Gründe Nicht-Teilnahme gescreenter Patienten

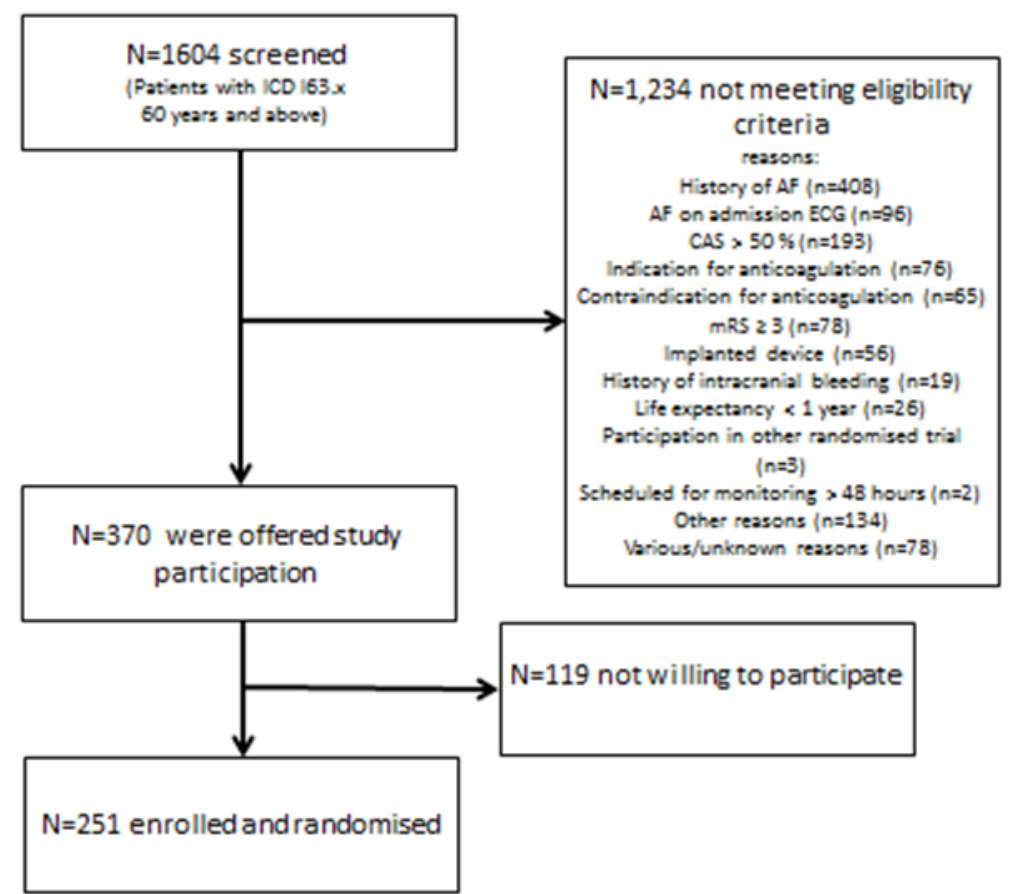

Abbildung 13: Gründe für eine Nicht-Teilnahme der gescreenten Patienten aus den beiden größten Studienzentren, welche 251 Patienten einschlossen (mit freundlicher Genehmigung von R. Wachter). 
Elektrodenpads-Anordnung

\subsubsection{Elektrodenanordnung bei 5 Leitungen für 2 Kanäle}

Fünf Elektroden werden angelegt und mit farblich markierten Leitungen angeschlossen, um ein Zwei-Kanal-EKG aufzuzeichnen.

Hinweis: Ein entscheidender Vorteil bei der Verwendung von sieben Leitungen für drei Kanäle besteht darin, dass bei einer gelösten Elektrode immer noch zwei EKG-Kanäle aufgezeichnet werden. Voraussetzung für die Abrechnung eines Langzeit-EKG ist die Aufzeichnung von zwei EKG-Kanälen über mindestens 18 Stunden.

weiß: $\quad K a n a l 1(-)$ Elektrode am oberen rechten Rand des Brustbeins rot: Kanal 1 (+) Elektrode auf der vorderen Axillarlinie, in Höhe der sechsten Rippe

schwarz: Kanal 2 (-) Elektrode am oberen linken Rand des Brustbeins braun: Kanal 2 (+) Elektrode auf der linken mittleren Clavicularlinie in Höhe der sechsten Rippe

grün: $\quad$ Erdung unterer rechter Brustkorbrand auf dem Knochen

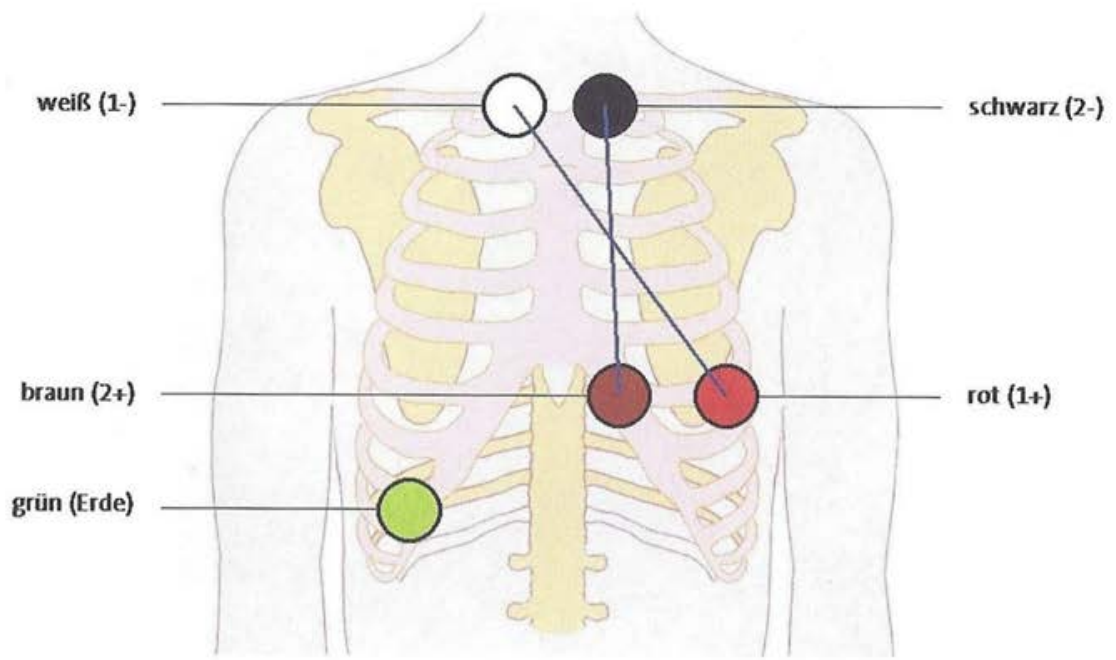

Abb. 14: Elektrodenpads-Anordnung 


\section{Literaturverzeichnis}

Achterberg P, Bergmann E, Bertz J, Böhm K, Brennecke R, Burger M, Eßer P, Forster T, Gibis B, Hölling G et al. (2006): Gesundheitsberichterstattung des Bundes: Gesundheit in Deutschland. Berlin 2006

Aho K, Harmsen P, Hatano S, Marquardsen J, Smirnov VE, Strasser T (1980): Cerebrovascular disease in the community: results of a WHO collaborative study. Bull World Health Organ $\underline{58}, 113-$ 130

Andersen KK, Olsen TS, Dehlendorff C, Kammersgaard LP (2009): Hemorrhagic and ischemic strokes compared: stroke severity, mortality, and risk factors. Stroke 40, 2068-2072

Arboix A (2015): Cardiovascular risk factors for acute stroke: Risk profiles in the different subtypes of ischemic stroke. World J Clin Cases $\underline{3}, 418-429$

Auer J, Scheibner P, Mische T, Langsteger W, Eber O, Eber B (2001): Subclinical hyperthyroidism as a risk factor for atrial fibrillation. Am Heart J $\underline{142}, 838-842$

Bang OY, Lee PH, Joo SY, Lee JS, Joo IS, Huh K (2003): Frequency and mechanisms of stroke recurrence after cryptogenic stroke. Ann Neurol $\underline{54}$, 227-234

Benjamin EJ, Levy D, Vaziri SM, D'Agostino RB, Belanger AJ, Wolf PA (1994): Independent Risk Factors for Atrial Fibrillation in a Population-Based Cohort. JAMA 271, 840

Benjamin EJ, Wolf PA, D'Agostino RB, Silbershatz H, Kannel WB, Levy D (1998): Impact of Atrial Fibrillation on the Risk of Death: The Framingham Heart Study. Circulation 98, 946-952

Berkhemer OA, Fransen PSS, Beumer D, van den Berg LA, Lingsma HF, Yoo AJ, Schonewille WJ, Vos JA, Nederkoorn PJ, Wermer MJH et al. (2015): A randomized trial of intraarterial treatment for acute ischemic stroke. $\mathrm{N}$ Engl J Med 372, 11-20

Brignole M, Vardas P, Hoffman E, Huikuri H, Moya A, Ricci R, Sulke N, Wieling W, Auricchio A, Lip GYH et al. (2009): Indications for the use of diagnostic implantable and external ECG loop recorders. Europace 11, 671-687

Britton M, Gustafsson C (1985): Non-rheumatic atrial fibrillation as a risk factor for stroke. Stroke $\underline{16}, 182-188$

Calkins H, Reynolds MR, Spector P, Sondhi M, Xu Y, Martin A, Williams CJ, Sledge I (2009): Treatment of atrial fibrillation with antiarrhythmic drugs or radiofrequency ablation: two systematic literature reviews and meta-analyses. Circ Arrhythm Electrophysiol 2, 349-361

Camm AJ, Kirchhof P, Lip, GYH, Schotten U, Savelieva I, Ernst S, Van Gelder, Isabelle C, Al-Attar N, Hindricks $G$, Prendergast $B$ et al.: Guidelines for the management of atrial fibrillation: the Task Force for the Management of Atrial Fibrillation of the European Society of Cardiology (ESC), 23692429

Camm AJ, Lip, GYH, Caterina R de, Savelieva I, Atar D, Hohnloser SH, Hindricks G, Kirchhof P (2012): 2012 focused update of the ESC Guidelines for the management of atrial fibrillation: an update of the 2010 ESC Guidelines for the management of atrial fibrillation. Developed with the special contribution of the European Heart Rhythm Association. European Heart Journal 33, 27192747

Campbell A, Caird FI, Jackson TF (1974): Prevalence of abnormalities of electrocardiogram in old people. Br Heart J $\underline{36}$, 1005-1011

Campbell BCV, Mitchell PJ, Kleinig TJ, Dewey HM, Churilov L, Yassi N, Yan B, Dowling RJ, Parsons MW, Oxley TJ et al. (2015): Endovascular therapy for ischemic stroke with perfusion-imaging selection. N Engl J Med 372, 1009-1018 
Carlsson J, Miketic S, Windeler J, Cuneo A, Haun S, Micus S, Walter S, Tebbe U (2003): Randomized trial of rate-control versus rhythm-control in persistent atrial fibrillation. J Am Coll Cardiol $\underline{41}$, 1690-1696

Chen J-Y, Zhang A-D, Lu H-Y, Guo J, Wang F-F, Li Z-C (2013): CHADS2 versus CHA2DS2-VASc score in assessing the stroke and thromboembolism risk stratification in patients with atrial fibrillation: a systematic review and meta-analysis. J Geriatr Cardiol JGC 10, 258-266

Clementy J, Dulhoste MN, Laiter C, Denjoy I, Dos Santos P (1992): Flecainide acetate in the prevention of paroxysmal atrial fibrillation: a nine-month follow-up of more than 500 patients. Am J Cardiol $\underline{70}$, 44A-49A

Connolly S, Pogue J, Hart R, Pfeffer M, Hohnloser S, Chrolavicius S, Yusuf S (2006): Clopidogrel plus aspirin versus oral anticoagulation for atrial fibrillation in the Atrial fibrillation Clopidogrel Trial with Irbesartan for prevention of Vascular Events (ACTIVE W): a randomised controlled trial. Lancet $\underline{367}, 1903-1912$

Connolly SJ, Ezekowitz MD, Yusuf S, Eikelboom J, Oldgren J, Parekh A, Pogue J, Reilly PA, Themeles $E$, Varrone $J$ et al. (2009): Dabigatran versus warfarin in patients with atrial fibrillation. The New England journal of medicine 361, 1139-1151

Connolly SJ, Eikelboom J, Joyner C, Diener H-C, Hart R, Golitsyn S, Flaker G, Avezum A, Hohnloser $\mathrm{SH}$, Diaz R et al. (2011): Apixaban in patients with atrial fibrillation. The New England journal of medicine $364,806-817$

Dang D, Arimie R, Haywood L (2002): A review of atrial fibrillation. Journal of the National Medical Association 94, 1036-1048

DEGAM: Schlaganfall. DEGAM-Leitlinie Nr. 8, Omikron Publishing, Düsseldorf 2012

Easton JD, Saver JL, Albers GW, Alberts MJ, Chaturvedi S, Feldmann E, Hatsukami TS, Higashida RT, Johnston SC, Kidwell CS et al. (2009): Definition and evaluation of transient ischemic attack: a scientific statement for healthcare professionals from the American Heart Association/American Stroke Association Stroke Council. Stroke 40, 2276-2293

Figueiredo MM, Rodrigues AC, Alves MB, Neto MC, Silva GS (2014): Score for atrial fibrillation detection in acute stroke and transient ischemic attack patients in a Brazilian population: The acute stroke atrial fibrillation scoring system. Clinics $\underline{69}, 241-246$

Francis J, Raghunathan S, Khanna P (2007): The role of genetics in stroke. Postgrad Med J 83, 590595

Friberg L, Hammar N, Rosenqvist M (2010): Stroke in paroxysmal atrial fibrillation: report from the Stockholm Cohort of Atrial Fibrillation. Eur Heart J 31, 967-975

Friberg L, Rosenqvist M, Lip GY (2012): Evaluation of risk stratification schemes for ischaemic stroke and bleeding in 182678 patients with atrial fibrillation: the Swedish Atrial Fibrillation cohort study. Eur Heart J 33, 1500-1510

Fuster V, Rydén LE, Cannom DS, Crijns HJ, Curtis AB, Ellenbogen KA, Halperin JL, Le Heuzey J-Y, Kay GN, Lowe JE et al. (2006): ACC/AHA/ESC 2006 guidelines for the management of patients with atrial fibrillation--executive summary: a report of the American College of Cardiology/American Heart Association Task Force on Practice Guidelines and the European Society of Cardiology Committee for Practice Guidelines. J Am Coll Cardiol 4ㅇ, 854-906

Gage BF, Waterman AD, Shannon W, Boechler M, Rich MW, Radford MJ (2001): Validation of clinical classification schemes for predicting stroke: results from the National Registry of Atrial Fibrillation. JAMA $\underline{285}$, 2864-2870 
Giansante C, Fiotti N, Miccio M, Altamura N, Salvi R, Guarnieri G (2000): Coagulation indicators in patients with paroxysmal atrial fibrillation: effects of electric and pharmacologic cardioversion. Am Heart J $\underline{140}$, 423-429

Go AS, Hylek EM, Phillips KA, Chang Y, Henault LE, Selby JV, Singer DE (2001): Prevalence of diagnosed atrial fibrillation in adults: national implications for rhythm management and stroke prevention: the AnTicoagulation and Risk Factors in Atrial Fibrillation (ATRIA) Study. JAMA 285, 23702375

Gould PA, Gula L, Bhayana V, Subbiah RN, Bentley C, Yee R, Klein GJ, Krahn AD, Skanes AC (2010): Characterization of cardiac brain natriuretic peptide release in patients with paroxysmal atrial fibrillation undergoing left atrial ablation. Circ Arrhythm Electrophysiol $\underline{3}, 18-23$

Goyal M, Demchuk AM, Menon BK, Eesa M, Rempel JL, Thornton J, Roy D, Jovin TG, Willinsky RA, Sapkota BL et al. (2015): Randomized assessment of rapid endovascular treatment of ischemic stroke. N Engl J Med 372, 1019-1030

Granger CB, Alexander JH, McMurray, John J V, Lopes RD, Hylek EM, Hanna M, Al-Khalidi HR, Ansell J, Atar D, Avezum A et al. (2011): Apixaban versus warfarin in patients with atrial fibrillation. N Engl J Med $\underline{365}$, 981-992

Grau AJ, Weimar C, Buggle F, Heinrich A, Goertler M, Neumaier S, Glahn J, Brandt T, Hacke W, Diener H-C (2001): Risk Factors, Outcome, and Treatment in Subtypes of Ischemic Stroke: The German Stroke Data Bank. Stroke 32, 2559-2566

Grecu N, Tiu C, Terecoasa E, Bajenaru O (2014): Endocarditis and Stroke. Mædica $\underline{9}$, 375-381

Hacke W, Donnan G, Fieschi C, Kaste M, Kummer R von, Broderick JP, Brott T, Frankel M, Grotta JC, Haley, E Clarke Jr et al. (2004): Association of outcome with early stroke treatment: pooled analysis of ATLANTIS, ECASS, and NINDS rt-PA stroke trials. Lancet $\underline{363}, 768-774$

Haïssaguerre M, Jaïs P, Shah DC, Takahashi A, Hocini M, Quiniou G, Garrigue S, Le Mouroux A, Le Métayer P, Clémenty J (1998): Spontaneous initiation of atrial fibrillation by ectopic beats originating in the pulmonary veins. N Engl J Med $\underline{339}, 659-666$

Hansson L, Hedner T, Dahlöf B (1992): Prospective randomized open blinded end-point (PROBE) study. A novel design for intervention trials. Prospective Randomized Open Blinded End-Point. Blood Press $\underline{1}, 113-119$

Hart RG, Pearce LA, Rothbart RM, McAnulty JH, Asinger RW, Halperin JL (2000): Stroke with intermittent atrial fibrillation: Incidence and predictors during aspirin therapy. J Am Coll Cardiol $\underline{35}$, 183-187

Hart RG, Pearce LA, Aguilar MI (2007): Meta-analysis: antithrombotic therapy to prevent stroke in patients who have nonvalvular atrial fibrillation. Ann Intern Med 146, 857-867

Heeringa J, Kors JA, Hofman A, van Rooij FJA, Witteman JCM (2008): Cigarette smoking and risk of atrial fibrillation: the Rotterdam Study. Am Heart J 156, 1163-1169

Henry WL, Morganroth J, PearIman AS, Clark CE, Redwood DR, Itscoitz SB, Epstein SE (1976): Relation between echocardiographically determined left atrial size and atrial fibrillation. Circulation 53, 273-279

Hohnloser SH, Kuck K-H, Lilienthal J (2000): Rhythm or rate control in atrial fibrillationPharmacological Intervention in Atrial Fibrillation (PIAF): A randomised trial. Lancet 356, 17891794

Hohnloser SH, Pajitnev D, Pogue J, Healey JS, Pfeffer MA, Yusuf S, Connolly SJ (2007): Incidence of stroke in paroxysmal versus sustained atrial fibrillation in patients taking oral anticoagulation or combined antiplatelet therapy: an ACTIVE W Substudy. J Am Coll Cardiol 50, 2156-2161 
Holmes DR, Reddy VY, Turi ZG, Doshi SK, Sievert H, Buchbinder M, Mullin CM, Sick P (2009): Percutaneous closure of the left atrial appendage versus warfarin therapy for prevention of stroke in patients with atrial fibrillation: a randomised non-inferiority trial. Lancet $374,534-542$

Jais P, Haissaguerre M, Shah DC, Chouairi S, Gencel L, Hocini M, Clementy J (1997): A Focal Source of Atrial Fibrillation Treated by Discrete Radiofrequency Ablation. Circulation 95, 572-576

Jorgensen HS, Nakayama H, Reith J, Raaschou HO, Olsen TS (1996): Acute Stroke With Atrial Fibrillation: The Copenhagen Stroke Study. Stroke 27, 1765-1769

Jovin TG, Chamorro A, Cobo E, Miquel MA de, Molina CA, Rovira A, San Román L, Serena J, Abilleira S, Ribó $\mathrm{M}$ et al. (2015): Thrombectomy within 8 hours after symptom onset in ischemic stroke. N Engl J Med 372, 2296-2306

Jug B, Sebestjen M, Sabovic M, Pohar M, Keber I (2009): Atrial fibrillation is an independent determinant of increased NT-proBNP levels in outpatients with signs and symptoms of heart failure. Wien Klin Wochenschr 121, 700-706

Kannel WB, Abbott RD, Savage DD, McNamara PM (1982): Epidemiologic features of chronic atrial fibrillation: the Framingham study. N Engl J Med $\underline{306}, 1018-1022$

Karthikeyan G, Eikelboom JW (2010): The CHADS2 score for stroke risk stratification in atrial fibrillation--friend or foe? Thromb Haemost 104, 45-48

Keren G, Etzion T, Sherez J, Zelcer AA, Megidish R, Miller HI, Laniado S (1987): Atrial fibrillation and atrial enlargement in patients with mitral stenosis. Am Heart J $\underline{114}, 1146-1155$

Kerr C, Boone J, Connolly S, Greene M, Klein G, Sheldon R, Talajic M (1996): Follow-up of atrial fibrillation: The initial experience of the Canadian Registry of Atrial Fibrillation. Eur Heart J 17 Suppl C, 48-51

Kimura K, Minematsu K, Yamaguchi T (2005): Atrial fibrillation as a predictive factor for severe stroke and early death in 15,831 patients with acute ischaemic stroke. J Neurol Neurosurg Psychiatry $76,679-683$

Kinlay S (2011): Changes in stroke epidemiology, prevention, and treatment. Circulation $\underline{124}$, e494-6

Kirchhof $\mathrm{P}$ (2009): Can we improve outcomes in AF patients by early therapy? BMC Med $\underline{7}, 72$

Kirchhof P, Benussi S, Kotecha D, Ahlsson A, Atar D, Casadei B, Castella M, Diener H-C, Heidbuchel $\mathrm{H}$, Hendriks J et al. (2016): 2016 ESC Guidelines for the management of atrial fibrillation developed in collaboration with EACTS. European Heart Journal 37, 2893-2962

Knudsen CW, Omland T, Clopton P, Westheim A, Wu AHB, Duc P, McCord J, Nowak RM, Hollander JE, Storrow AB et al. (2005): Impact of atrial fibrillation on the diagnostic performance of B-type natriuretic peptide concentration in dyspneic patients: an analysis from the breathing not properly multinational study. J Am Coll Cardiol 46, 838-844

Knuiman MW, Vu HT (1996): Risk factors for stroke mortality in men and women: The Busselton Study. J Cardiovasc Risk 3 , 447-452

Kolominsky-Rabas PL, Heuschmann PU (2002): Incidence, etiology and long-term prognosis of stroke. Fortschritte der Neurologie-Psychiatrie 70, 657-662

Kolominsky-Rabas PL, Weber M, Gefeller O, Neundoerfer B, Heuschmann PU (2001): Epidemiology of Ischemic Stroke Subtypes According to TOAST Criteria: Incidence, Recurrence, and Long-Term Survival in Ischemic Stroke Subtypes: A Population-Based Study. Stroke 32, 2735-2740

Lévy S, Camm AJ, Saksena S, Aliot E, Breithardt G, Crijns H, Davies W, Kay N, Prystowsky E, Sutton $R$ et al. (2003): International consensus on nomenclature and classification of atrial fibrillation. A collaborative project of the Working Group on Arrhythmias and the Working Group on Cardiac 
Pacing of the European Society of Cardiology and the North American Society of Pacing and Electrophysiology. Europace $\underline{5}, 119-122$

Lévy S, Breithardt G, Campbell RW, Camm AJ, Daubert JC, Allessie M, Aliot E, Capucci A, Cosio F, Crijns $\mathrm{H}$ et al. (1998): Atrial fibrillation: current knowledge and recommendations for management. Working Group on Arrhythmias of the European Society of Cardiology. European Heart Journal $\underline{19}$,1294-1320

Lévy S, Maarek M, Coumel P, Guize L, Lekieffre J, Medvedowsky J-L, Sebaoun A (1999): Characterization of Different Subsets of Atrial Fibrillation in General Practice in France: The ALFA Study. Circulation $\underline{99}$, 3028-3035

Li S, Wang S, Gu M, Cao B (2015): Characteristics and outcome of acute ischemic stroke patients with atrial fibrillation. Zhonghua yi xue za zhi 95, 3509-3513

Lin H-J, Wolf PA, Benjamin EJ, Belanger AJ, D'Agostino RB (1995): Newly Diagnosed Atrial Fibrillation and Acute Stroke: The Framingham Study. Stroke 26, 1527-1530

Lin H-J, Wolf PA, Kelly-Hayes M, Beiser AS, Kase CS, Benjamin EJ, D'Agostino RB (1996): Stroke Severity in Atrial Fibrillation: The Framingham Study. Stroke 27, 1760-1764

Lip GY (2011): The role of aspirin for stroke prevention in atrial fibrillation. Nat Rev Cardiol $\underline{8}, 602-$ 606

Lip G, Hee FL (2001): Paroxysmal atrial fibrillation. QJM 94, 665-678

Lip GY, Watson T (2008): Atrial fibrillation (acute onset). BMJ Clin Evid 2008, pii 0210

Lip GY, Nieuwlaat R, Pisters R, Lane DA, Crijns, Harry JGM (2010): Refining clinical risk stratification for predicting stroke and thromboembolism in atrial fibrillation using a novel risk factor-based approach: the euro heart survey on atrial fibrillation. Chest 137, 263-272

Li-Saw-Hee F, Blann A, Gurney D, Lip GY (2001): Plasma von Willebrand factor, fibrinogen and soluble P-selectin levels in paroxysmal, persistent and permanent atrial fibrillation. Effects of cardioversion and return of left atrial function. Eur Heart J 22, 1741-1747

Longstreth WT, Kronmal RA, Thompson JLP, Christenson RH, Levine SR, Gross R, Brey RL, Buchsbaum R, Elkind MSV, Tirschwell DL et al. (2013): Amino terminal pro-B-type natriuretic peptide, secondary stroke prevention, and choice of antithrombotic therapy. Stroke $\underline{44}, 714-719$

Maixent JM, Paganelli F, Scaglione J, Lévy S (1998): Antibodies against myosin in sera of patients with idiopathic paroxysmal atrial fibrillation. J Cardiovasc Electrophysiol $\underline{9}, 612-617$

Mant J, Hobbs, F D Richard, Fletcher K, Roalfe A, Fitzmaurice D, Lip GY, Murray E (2007): Warfarin versus aspirin for stroke prevention in an elderly community population with atrial fibrillation (the Birmingham Atrial Fibrillation Treatment of the Aged Study, BAFTA): a randomised controlled trial. Lancet 370, 493-503

Maries L, Manitiu I (2013): Diagnostic and prognostic values of B-type natriuretic peptides (BNP) and N-terminal fragment brain natriuretic peptides (NT-pro-BNP). Cardiovasc J Afr 24, 286-289

Meinertz T, Sydow K (2014): Diabetes mellitus--Risikofaktor für Vorhofflimmern. Potenzielle therapeutische Implikationen. Herz 39 , 320-324

Muir KW, Ford GA, Messow C-M, Ford I, Murray A, Clifton A, Brown MM, Madigan J, Lenthall R, Robertson F et al. (2017): Endovascular therapy for acute ischaemic stroke: the Pragmatic Ischaemic Stroke Thrombectomy Evaluation (PISTE) randomised, controlled trial. J Neurol Neurosurg Psychiatry 88, 38-44

Ogilvie IM, Welner SA, Cowell W, Lip GY (2011): Ischaemic stroke and bleeding rates in 'real-world' atrial fibrillation patients. Thromb Haemost 106, 34-44 
Okada Y, Shibazaki K, Kimura K, Iguchi Y, Miki T (2010): Brain natriuretic peptide as a predictor of delayed atrial fibrillation after ischaemic stroke and transient ischaemic attack. Eur J Neurol $\underline{17}$, 326-331

Olesen JB, Lip GY, Lindhardsen J, Lane DA, Ahlehoff O, Hansen ML, Raunso J, Tolstrup JS, Hansen PR, Gislason GH et al. (2011): Risks of thromboembolism and bleeding with thromboprophylaxis in patients with atrial fibrillation: A net clinical benefit analysis using a 'real world' nationwide cohort study. Thromb Haemost 106, 739-749

Park SH, Goo JM, Jo C-H (2004): Receiver operating characteristic (ROC) curve: practical review for radiologists. Korean J Radiol $\underline{5}, 11-18$

Patel MR, Mahaffey KW, Garg J, Pan G, Singer DE, Hacke W, Breithardt G, Halperin JL, Hankey GJ, Piccini JP et al. (2011): Rivaroxaban versus warfarin in nonvalvular atrial fibrillation. N Engl J Med $\underline{365}, 883-891$

Patton KK, Ellinor PT, Heckbert SR, Christenson RH, DeFilippi C, Gottdiener JS, Kronmal RA (2009): $\mathrm{N}$-terminal pro-B-type natriuretic peptide is a major predictor of the development of atrial fibrillation: the Cardiovascular Health Study. Circulation $\underline{120}$, 1768-1774

Pepi M, Evangelista A, Nihoyannopoulos P, Flachskampf FA, Athanassopoulos G, Colonna P, Habib G, Ringelstein EB, Sicari R, Zamorano JL et al. (2010): Recommendations for echocardiography use in the diagnosis and management of cardiac sources of embolism: European Association of Echocardiography (EAE) (a registered branch of the ESC). Eur J Echocardiogr 11, 461-476

Petersen P (1990): Thromboembolic complications in atrial fibrillation. Stroke $\underline{21}, 4-13$

Petersen P, Godtfredsen J (1984): Atrial fibrillation--a review of course and prognosis. Acta Med Scand 216, 5-9

Pisters R, Lane DA, Nieuwlaat R, de Vos, Cees B, Crijns, Harry J G M, Lip, GY (2010): A novel userfriendly score (HAS-BLED) to assess 1-year risk of major bleeding in patients with atrial fibrillation: the Euro Heart Survey. Chest 138, 1093-1100

Potpara TS, Lip GY (2014): Lone atrial fibrillation - an overview. Int J Clin Pract 68, 418-433

Reynolds K, Lewis B, Nolen JDL, Kinney GL, Sathya B, He J (2003): Alcohol Consumption and Risk of Stroke. JAMA 289, 579

Rodríguez-Yáñez M, Arias-Rivas S, Santamaría-Cadavid M, Sobrino T, Castillo J, Blanco M (2013): High pro-BNP levels predict the occurrence of atrial fibrillation after cryptogenic stroke. Neurology 81, 444-447

Rossi A, Enriquez-Sarano M, Burnett JC, Lerman A, Abel MD, Seward JB (2000): Natriuretic peptide levels in atrial fibrillation: a prospective hormonal and Doppler-echocardiographic study. J Am Coll Cardiol 35 , 1256-1262

Roy D, Talajic M, Nattel S, Wyse DG, Dorian P, Lee KL, Bourassa MG, Arnold, J Malcolm O, Buxton $A E$, Camm AJ et al. (2008): Rhythm control versus rate control for atrial fibrillation and heart failure. N Engl J Med 358, 2667-2677

Ruff CT, Giugliano RP, Braunwald E, Hoffman EB, Deenadayalu N, Ezekowitz MD, Camm AJ, Weitz $\mathrm{JI}$, Lewis BS, Parkhomenko A et al. (2014): Comparison of the efficacy and safety of new oral anticoagulants with warfarin in patients with atrial fibrillation: A meta-analysis of randomised trials. Lancet 383, 955-962

Sacco RL, Benjamin EJ, Broderick JP, Dyken M, Easton JD, Feinberg WM, Goldstein LB, Gorelick PB, Howard G, Kittner SJ et al. (1997): Risk Factors. Stroke 28, 1507-1517

Sacco RL, Kasner SE, Broderick JP, Caplan LR, Connors JJB, Culebras A, Elkind MSV, George MG, Hamdan AD, Higashida RT et al. (2013): An updated definition of stroke for the 21st century: a 
statement for healthcare professionals from the American Heart Association/American Stroke Association. Stroke 44, 2064-2089

Samokhvalov AV, Irving HM, Rehm J (2010): Alcohol consumption as a risk factor for atrial fibrillation: a systematic review and meta-analysis. Eur J Cardiovasc Prev Rehabil 17, 706-712

Sant'Angelo A, Bagnato S, Boccagni C, Guardabasso V, Galardi G (2012): Short-Term Outcome in Stroke Patients with or without Atrial Fibrillation: A Retrospective Case-Control Study. ISRN Rehabil 2012, 1-4

Sato $\mathrm{H}$, Ishikawa K, Kitabatake A, Ogawa S, Maruyama Y, Yokota Y, Fukuyama T, Doi Y, Mochizuki $S$, Izumi T et al. (2006): Low-dose aspirin for prevention of stroke in low-risk patients with atrial fibrillation: Japan Atrial Fibrillation Stroke Trial. Stroke 37, 447-451

Saver JL (2006): Time is brain--quantified. Stroke 37, 263-266

Saver JL, Filip B, Hamilton S, Yanes A, Craig S, Cho M, Conwit R, Starkman S (2010): Improving the reliability of stroke disability grading in clinical trials and clinical practice: the Rankin Focused Assessment (RFA). Stroke 41, 992-995

Saver JL, Goyal M, Bonafe A, Diener H-C, Levy El, Pereira VM, Albers GW, Cognard C, Cohen DJ, Hacke W et al. (2015): Stent-Retriever Thrombectomy after Intravenous t-PA vs. t-PA Alone in Stroke. N Engl J Med 372, 2285-2295

Schiffmann R (2015): Fabry disease. Handb Clin Neurol 132, 231-248

Seegers J, Zabel M, Grüter T, Ammermann A, Weber-Krüger M, Edelmann F, Gelbrich G, Binder L, Herrmann-Lingen C, Gröschel K et al. (2015): Natriuretic peptides for the detection of paroxysmal atrial fibrillation. Open Heart 2 , e000182

Shibazaki K, Kimura K, Fujii S, Sakai K, Iguchi Y (2012): Brain natriuretic peptide levels as a predictor for new atrial fibrillation during hospitalization in patients with acute ischemic stroke. Am J Cardiol 109, 1303-1307

Smajlović D (2015): Strokes in young adults: epidemiology and prevention. Vasc Health Risk Manag 11, 157-164

Sohara H, Amitani S, Kurose M, Miyahara K (1997): Atrial fibrillation activates platelets and coagulation in a time-dependent manner: a study in patients with paroxysmal atrial fibrillation. J Am Coll Cardiol 29, 106-112

Steinberg BA, Hellkamp AS, Lokhnygina Y, Patel MR, Breithardt G, Hankey GJ, Becker RC, Singer DE, Halperin JL, Hacke W et al. (2015): Higher risk of death and stroke in patients with persistent vs. paroxysmal atrial fibrillation: results from the ROCKET-AF Trial. Eur Heart J $\underline{36}$, 288-296

Sucu M, Davutoglu V, Ozer O (2009): Electrical cardioversion. Ann Saudi Med 29, 201-206

Suttorp MJ, Kingma JH, Koomen EM, van 't Hof, A, Tijssen JG, Lie KI (1993): Recurrence of paroxysmal atrial fibrillation or flutter after successful cardioversion in patients with normal left ventricular function. Am J Cardiol 71, 710-713

Takahashi N, Imataka K, Seki A, Fujii J (1982): Left atrial enlargement in patients with paroxysmal atrial fibrillation. Jpn Heart J $\underline{23}, 677-683$

Tamargo J, Caballero R, Delpon E (2012): Drug-induced atrial fibrillation. Expert Opin Drug Saf $\underline{11}$, 615-634

Therkelsen SK, Groenning BA, Kjaer A, Svendsen JH, Boje Jensen G (2008): ANP and BNP in atrial fibrillation before and after cardioversion--and their relationship to cardiac volume and function. Int J Cardiol 127, 396-399 
Tomita H, Metoki N, Saitoh G, Ashitate T, Echizen T, Katoh C, Fukuda M, Yasujima M, Osanai T, Okumura K (2008): Elevated plasma brain natriuretic peptide levels independent of heart disease in acute ischemic stroke: correlation with stroke severity. Hypertens Res 31, 1695-1702

Tsuchida K, Tanabe K (2004): Influence of paroxysmal atrial fibrillation attack on brain natriuretic peptide secretion. J Cardiol $\underline{44}, 1-11$

Tu HTH, Campbell BCV, Christensen S, Desmond PM, Silva DA de, Parsons MW, Churilov L, Lansberg MG, Mlynash M, Olivot J-M et al. (2015): Worse stroke outcome in atrial fibrillation is explained by more severe hypoperfusion, infarct growth, and hemorrhagic transformation. Int J Stroke $\underline{10}, 534-540$

Van Gelder, Isabelle C, Hagens VE, Bosker HA, Kingma JH, Kamp O, Kingma T, Said SA, Darmanata JI, Timmermans, Alphons J M, Tijssen, Jan G P et al. (2002): A comparison of rate control and rhythm control in patients with recurrent persistent atrial fibrillation. N Engl J Med 347, 18341840

Vaziri SM, Larson MG, Benjamin EJ, Levy D (1994): Echocardiographic predictors of nonrheumatic atrial fibrillation. The Framingham Heart Study. Circulation $\underline{89}$, 724-730

Veenhuyzen GD (2004): Atrial fibrillation. Can Med Assoc J 171, 755-760

Wachter R, Lahno R, Haase B, Weber-Krüger M, Seegers J, Edelmann F, Wohlfahrt J, Gelbrich G, Görlitz A, Kermer P et al. (2012): Natriuretic peptides for the detection of paroxysmal atrial fibrillation in patients with cerebral ischemia--the Find-AF study. PloS one $\underline{7}$, e34351

Wachter R, Gröschel K, Gelbrich G, Hamann GF, Kermer P, Liman J, Seegers J, Wasser K, Schulte A, Jürries $\mathrm{F}$ et al. (2017): Holter-electrocardiogram-monitoring in patients with acute ischaemic stroke (Find-AF RANDOMISED ): An open-label randomised controlled trial. Lancet Neurol $\underline{16}$, 282-290

Wardlaw JM, Murray V, Berge E, del Zoppo, Gregory J (2014): Thrombolysis for acute ischaemic stroke. Cochrane Database Syst Rev $\underline{7}, \mathrm{CD} 000213$

Weber-Kruger M, Gelbrich G, Stahrenberg R, Liman J, Kermer P, Hamann GF, Seegers J, Groschel $\mathrm{K}$, Wachter R (2014): Finding atrial fibrillation in stroke patients: Randomized evaluation of enhanced and prolonged Holter monitoring--Find-AF(RANDOMISED) --rationale and design. American heart journal $\underline{168}, 438-445 . e 1$

Wijffels MC, Kirchhof CJ, Dorland R, Allessie MA (1995): Atrial Fibrillation Begets Atrial Fibrillation: A Study in Awake Chronically Instrumented Goats. Circulation 92, 1954-1968

Wohlfahrt J, Stahrenberg R, Weber-Kruger M, Groschel S, Wasser K, Edelmann F, Seegers J, Wachter R, Groschel K (2014): Clinical predictors to identify paroxysmal atrial fibrillation after ischaemic stroke. Eur J Neurol 21, 21-27

Wolf PA, Dawber TR, Thomas, HE Jr, Kannel WB (1978): Epidemiologic assessment of chronic atrial fibrillation and risk of stroke: the Framingham study. Neurology 28, 973-977

Wozakowska-Kapłon B (2004): Effect of sinus rhythm restoration on plasma brain natriuretic peptide in patients with atrial fibrillation. Am J Cardiol 93, 1555-1558

Wozakowska-Kapłon B, Opolski G (2002): Atrial natriuretic peptide level after cardioversion of chronic atrial fibrillation. Int J Cardiol $\underline{83}, 159-165$

Wyse DG, Waldo AL, DiMarco JP, Domanski MJ, Rosenberg Y, Schron EB, Kellen JC, Greene HL, Mickel MC, Dalquist JE et al. (2002): A comparison of rate control and rhythm control in patients with atrial fibrillation. N Engl J Med 347, 1825-1833

Yamashita T, Murakawa Y, Sezaki K, Inoue M, Hayami N, Shuzui Y, Omata M (1997): Circadian variation of paroxysmal atrial fibrillation. Circulation $96,1537-1541$ 
Yiin GS, Howard DP, Paul NL, Li L, Mehta Z, Rothwell PM (2017): Recent time trends in incidence, outcome and premorbid treatment of atrial fibrillation-related stroke and other embolic vascular events: a population-based study. J Neurol Neurosurg Psychiatry 


\section{DANKSAGUNG}

An dieser Stelle möchte ich mich bei denjenigen Personen und Institutionen bedanken, die mich auf meinem Weg zur Promotion unterstützten und diese auf unterschiedlichste Weise erst ermöglichten.

An erster Stelle möchte ich Herrn Prof. Dr. Rolf Wachter danken, der mir von Anfang an als Doktorvater tatkräftig zur Seite stand, immer ansprechbar war und mit seiner freundlichen Unterstützung den Weg für diese Promotion ebnete.

Weiterhin danke ich dem DZHK, welches mir durch ein Stipendium die Finanzierung während des Projektes erheblich erleichterte.

Ebenfalls danken möchte ich Anna Schulte, Falko Jürries und Anna Messerschmid, die einen Großteil der Vorarbeit in der Studie und damit einen wichtigen Beitrag zum Erfolg der Studie leisteten.

Ein besonderer Dank gilt Dr. med. Annemarie Uhlig, die mir bei der Erstellung der statistischen Ergebnisse beratend zur Seite stand.

Des Weiteren möchte ich Doris von Grünhagen und Anna-Lena Meyer meinen Dank aussprechen, die im Rahmen der Studiendurchführung jederzeit hilfsbereit und ansprechbar waren.

Zu guter Letzt möchte ich den Patienten danken, die sich bereit erklärt haben, an der Studie teilzunehmen. Diese Partizipation erforderte wiederholte Krankenhausbesuche und einiges an Mehrarbeit auf Seiten der Patienten. Diesen Aufwand weiß ich zu würdigen. 